Federal Reserve Bank of Dallas

Globalization and Monetary Policy Institute

Working Paper No. 260

http://www.dallasfed.org/assets/documents/institute/wpapers/2016/0260.pdf

\title{
Optimal Monetary and Fiscal Policy at the Zero Lower Bound in a Small Open Economy ${ }^{*}$
}

\author{
Saroj Bhattarai \\ University of Texas-Austin \\ Konstantin Egorov \\ Pennsylvania State University
}

January 2016

\begin{abstract}
We investigate open economy dimensions of optimal monetary and fiscal policy at the zero lower bound (ZLB) in a small open economy model. At positive interest rates, the trade elasticity has negligible effects on optimal policy. In contrast, at the ZLB, the trade elasticity plays a key role in optimal policy prescriptions. The way in which the trade elasticity shapes policy depends on the government's ability to commit. Under discretion, the increase in government spending at the ZLB depends critically on the trade elasticity. Under commitment, the difference between future and current policies, both for domestic inflation and government spending, is smaller when the trade elasticity is higher.
\end{abstract}

JEL codes: E31, E52, E58, E61, E62, E63, F41

\footnotetext{
* Saroj Bhattarai, University of Texas at Austin, 2225 Speedway, Stop C3100, Austin, TX 78712. 512475-8539. saroj.bhattarai@austin.utexas.edu. Konstantin Egorov, Pennsylvania State University, 303 Kern Building University Park, PA 16802. 814-865-1457. kze112@psu.edu. We thank Guido Ascari, Hafedh Bouakez, Larry Christiano, Oli Coibion, Alessandro Dovis, Charles Engel, Michal Fabinger, Barry Ickes, Dmitry Mukhin, Andrea Tambalotti, Stephen Yeaple, seminar participants at the Dallas Fed, University of Tokyo, and Penn State, and conference participants at the ASSA Meetings, Norges Bank/HEC Montreal workshop on New Developments in Business Cycle Analysis, CESifo Global Economy Area conference, and XVII Annual Inflation Targeting Seminar of the Banco Central do Brasil for helpful comments and suggestions. First version: Dec 2013. This version: Dec 2015. The views in this paper are those of the authors and do not necessarily reflect the views of the Federal Reserve Bank of Dallas or the Federal Reserve System.
} 


\section{Introduction}

As a response to the recent global financial crisis and its adverse consequences on output and employment, central banks of several small open economies engaged in counter cyclical policy response and lowered their conventional policy instrument, the short-term nominal interest rate. Many of these central banks, as shown in Figure 1, in fact, found themselves at the zero lower bound (ZLB) on the short-term nominal interest rate and unable to provide further conventional policy accommodation. Such a development has raised the question of whether and how optimal policy prescriptions and equilibrium outcomes for a small open economy (SOE) at the ZLB differs from that for a closed economy, which is the usual benchmark in the literature. We study open economy dimensions of optimal monetary and fiscal policy at the ZLB, both with and without commitment, in a standard SOE model. ${ }^{1}$ We consider a general environment without restrictions on some model parameters which ensures that the optimal policy problem in the SOE is no longer isomorphic to the closed economy. We can then assess the differences in equilibrium outcomes and policy prescriptions as we vary the trade elasticity, a key open economy parameter.

At positive interest rates, optimal policy (either just monetary or joint monetary and fiscal) and equilibrium outcomes and welfare do not depend significantly on the trade elasticity. In particular, departures from the closed economy benchmark (at unit trade elasticity) arise due to a terms of trade externality that provides incentives to the government to manipulate the real exchange rate to make its own good more expensive. This externality however, is small for standard parameterizations. We find that at the ZLB, in sharp contrast to the case at positive interest rates, the trade elasticity plays a key role in creating differences in equilibrium outcomes, welfare, and optimal policy prescriptions. We now describe detailed results that support this main finding.

In a SOE, regardless of the shock that makes the ZLB bind, whether it is a positive technology or a negative demand (preference) shock, the natural dynamics of the real exchange rate constitutes a depreciation. With monetary policy constrained by the ZLB, this depreciation cannot happen sufficiently enough, and thus the real exchange rate is appreciated compared to the first-best level. In addition, under discretion, this effect is even stronger compared to commitment as monetary policy is constrained by its inability to make future promises of a depreciated real exchange rate. The size of this "appreciation bias" is governed by the trade elasticity. This is because for any given level of the real exchange rate, differences in the trade elasticity translate into differences in demand for home goods, which then also affect domestic prices. ${ }^{2}$ As a result, the trade elasticity has significant effects on equilibrium outcomes, duration of the liquidity trap, and welfare.

The precise way in which the trade elasticity drives equilibrium outcomes in a SOE can depend on the shock. For example, we find that with a higher trade elasticity, while equilibrium outcomes are better under the technology shock, they are worse under the preference shock. What is the

\footnotetext{
${ }^{1}$ The model features two-goods (a domestic good that is an imperfect substitute of the foreign good), sticky domestic prices, and a flexible exchange rate. The size of the SOE is negligible compared to the rest of the world, whose dynamics are exogenous.

${ }^{2}$ Note that in levels, the real exchange rate might either depreciate or appreciate as discuss next.
} 
intuition? Under the preference shock, the appreciation pressure caused by a binding ZLB is extremely strong and the equilibrium features a real exchange rate that appreciates in levels. Thus a higher trade elasticity leads to a weaker demand for home goods, which then translates into worse outcomes. The reverse is true for the technology shock as then the real exchange rate depreciates in levels. This means that a higher trade elasticity leads to a stronger demand for home goods and thus better outcomes. Regardless of these differences however, for both the shocks, the trade elasticity plays a significant role in creating differences in equilibrium outcomes and welfare at the ZLB. This is not the case at positive interest rates.

Similarly, the trade elasticity substantially affects optimal policy prescriptions at the ZLB. Importantly, the way in which it shapes policy depends on the ability of the SOE government to make credible promises. Under no commitment, optimal fiscal policy involves increasing government spending above the efficient level (that is, creating a positive government spending gap). This helps decrease the extent of adverse outcomes during the liquidity trap. ${ }^{3}$ We find that the extent of this increase in government spending depends critically on the trade elasticity. Why is this the case? Under optimal policy, the government implements a fiscal expansion to boost demand for home goods. Since the extent to which demand is weak at the ZLB depends on the trade elasticity, as we described above, the extent of optimal fiscal expansion is in turn a function of the trade elasticity. ${ }^{4}$

In addition, our results show that the open economy channel of optimal fiscal policy is qualitatively different depending on whether the economy is in a liquidity trap. As in the closed economy and as we discussed above, optimal fiscal policy in a SOE at the ZLB features a positive government spending gap. However, we find that our result holds even in situations where at positive interest rates, optimal policy features a negative government spending gap. ${ }^{5}$ So for instance, even for a big shock, as long as the ZLB does not bind, optimal government spending gap can be negative. As soon as the ZLB binds however, even in this case, optimal government spending gap switches to positive. This qualitative difference illustrates that the incentives at the ZLB to increase government spending in order to boost home inflation and depreciate the real exchange rate overpower the terms of trade manipulation incentives that determine optimal policy at positive interest rates.

Under credible commitment, the trade elasticity matters by governing the difference between (promised) future and current policies. For example, under optimal monetary policy, the SOE experiences home deflation at the ZLB and the government promises future home inflation. ${ }^{6} \mathrm{We}$ label the difference between the initial and the peak of home inflation as a "policy slope." Our result is that this "policy slope" in an open economy depends negatively on the trade elasticity. The mechanism behind this is as follows. Any promise of future home inflation is associated with

\footnotetext{
${ }^{3}$ Throughout the paper, we refer to a "gap" as the difference between a variable and its efficient counterpart.

${ }^{4}$ As before, the precise comparative statics depend on the shock. When the real exchange rate depreciates in levels (under the technology shock), a higher trade elasticity leads to a stronger demand for home goods. Thus, it implies a smaller increase in optimal government spending as the policymaker has less of an incentive to boost home demand. The opposite is true for the case when the real exchange rate appreciates in levels (under the preference shock).

${ }^{5}$ Note that this result cannot be appreciated in the closed economy or the isomorphic open economy contexts (at unit trade elasticity) as then, the optimal government spending gap is zero at positive interest rates.

${ }^{6}$ This is similar to the insight from a closed economy model.
} 
future real exchange rate depreciation. With a higher trade elasticity, a given amount of future exchange rate depreciation has a bigger effect on demand and prices. Therefore, as such a promise becomes more powerful, it becomes necessary to use less of it. Similar result holds for fiscal policy. Optimal policy at the ZLB is associated with current government spending that is higher than the future one. ${ }^{7}$ The higher the trade elasticity is, the smaller is the "policy slope," the difference between current and future fiscal spending. The mechanism behind this result is the same as for optimal monetary policy.

Importantly, these results on the "policy slope" under commitment are robust to the shock that drives the SOE to the ZLB. That is, they hold even when a higher trade elasticity leads to worse outcomes. This is the case for a negative preference shock, as we described above. This finding is striking as one might expect the central bank to promise an even higher home inflation, compared to current levels, when current outcomes are worse. This result highlights a new dynamic open economy channel of optimal policy: not only does the trade elasticity affect current outcomes, but it also governs the way in which future (promised) outcomes translate into current ones.

Our work is related to that of Svensson (2003 and 2004) and Jeanne and Svensson (2007), who use an open economy model and provide insights related to exchange rate dynamics and how to mitigate adverse outcomes under discretion. The main difference is that we consider a fully dynamic SOE model and an explicitly welfare maximizing government in characterizing optimal policy under both discretion and commitment. A major insight of Svensson (2003 and 2004), described as a "foolproof way," is that in an open economy the policymaker under commitment promises a depreciated nominal exchange rate. Our results on the "appreciation bias" of discretionary monetary policy at the ZLB build on this seminal insight. We derive this result in a micro-founded dynamic optimal policy model, where we directly compare discretion and commitment in terms of the real exchange rate. $^{8}$ Here, we also additionally study the role of optimal government spending at the ZLB in a SOE and moreover, throughout the paper, study the key role played by the trade elasticity.

In terms of the basic model environment we use to study optimal monetary policy at the ZLB, our SOE set-up is similar to that introduced in important work by Gali and Monacelli (2005). Gali and Monacelli (2005) characterized optimal monetary policy in a case isomorphic to the closedeconomy. This analysis was extended by Faia and Monacelli (2008) and De Paoli (2009) who considered a wider range of values for the trade elasticity and studied monetary policy under commitment. At positive interest rates, substantively, we additionally study optimal monetary policy under discretion and augment this basic model with a role for government spending. Our methodological contribution when the ZLB does not bind is to provide analytical non-linear solutions and properties of commitment and discretion equilibria. Our main focus and relative contribution however, is to study the commitment and no commitment case for both optimal monetary and fiscal policy when the ZLB binds due to either a technology or a preference shock.

\footnotetext{
${ }^{7}$ This again is similar to the insight from a closed economy model.

${ }^{8}$ The nominal exchange rate in our model is not stationary under discretion. Moreover, as we make clear later and emphasized above, the real exchange rate in levels under discretion might either appreciate or depreciate. Thus, one has to compare it to the level under commitment or first-best.
} 
We are also clearly building on a recently burgeoning literature on optimal policy at the ZLB. In particular, our work is related to the set of papers that study optimal monetary and government spending policy in a liquidity trap. Important contributions on optimal monetary policy in a liquidity trap situation in a closed economy context include Eggertsson and Woodford (2003), Jung, Teranishi, and Watanabe (2005), Adam and Billi (2006 and 2007), and Werning (2013). In studying the role for government spending in a liquidity trap situation under optimal policy, our work is related to that of Eggertsson (2001) and Werning (2013), who point out the efficacy of counter cyclical government spending policy in closed economy models. ${ }^{9}$ In the open economy literature, using two-country models, Jeanne (2009), Fujiwara et al (2013), and Cook and Devereux (2013) study optimal policy, where countries coordinate on their actions, in a global liquidity trap scenario. Our environment of a SOE provides a different focus, as only the home country is in a liquidity trap situation and it decides on optimal policy taking the rest of the world as given (on which, it exerts a negligible effect). Moreover, relative to this important open economy work, we consider a general environment without restrictions on parameters and study both discretion and commitment equilibria non-linearly. ${ }^{10}$

\section{Model}

There are two countries, home $(H)$ and foreign $(F)$. The home and foreign goods are imperfect substitutes of each other. The home country is a SOE. The foreign country is effectively a closed economy as home country variables have negligible effects on foreign variables. The home consumer and government consume the same bundle of home and foreign goods. The home good is produced in differentiated varieties by firms who face price adjustment costs. Monetary and fiscal policy is determined optimally, either under commitment or no commitment. We now describe the model in detail. ${ }^{11}$

\subsection{Private sector}

We first describe the environment faced by households and firms, their optimization problem, and the associated equilibrium conditions.

\footnotetext{
${ }^{9}$ In the interest of space, we only discuss the literature that focuses on optimal policy in a liquidity trap, but there is by now a large literature on the the effects of government spending, while modeling monetary policy as being governed by a Taylor type rule. See for example, Christiano, Eichenbaum, and Rebelo (2011), Egegertsson (2011), Woodford (2011), and Erceg and Linde (2014).

${ }^{10}$ We study numerically the fully non-linear perfect foresight equilibrium dynamics at the ZLB. We focus on perfect foresight dynamics as it will be computationally costly to solve for the non-linear stochastic equilibrium with the ZLB under commitment as there are multiple endogenous state-variables in the model. A clear and direct comparison between commitment and discretion is crucial for our results. For this reason, we consider perfect foresight dynamics under discretion too.

${ }^{11}$ Our model is similar to the SOE set-up in Faia and Monacelli (2008), augmented with a role for government spending.
} 


\subsubsection{Households}

A household at home maximizes expected discounted utility over the infinite horizon

$$
E_{t} \sum_{s=0}^{\infty} \beta^{s} U_{t+s}=E_{t} \sum_{s=0}^{\infty} \beta^{s}\left[u\left(C_{t+s}, \xi_{t+s}\right)-\int_{0}^{1} v\left(h_{t+s}(i), \xi_{t+s}\right) d i+g\left(G_{t+s}, \xi_{t+s}\right)\right]
$$

where $\beta$ is the discount factor, $C_{t}$ is household consumption of the composite final good, $h_{t}(i)$ is quantity supplied of labor of type $i, G_{t}$ is government consumption of the composite final good, and $\xi_{t}$ is a vector of aggregate exogenous (domestic) shocks. $E_{t}$ is the mathematical expectation operator conditional on period- $t$ information, $u($.$) is concave and strictly increasing in C_{t}$ for any possible value of $\xi_{t}, g($.$) is concave and strictly increasing in G_{t}$ for any possible value of $\xi_{t}$, and $v($.$) is increasing and convex in h_{t}(i)$ for any possible value of $\xi_{t}$.

The composite household final good is an aggregate of the home, $C_{H, t}$, and foreign, $C_{F, t}$, goods

$$
C_{t}=\left[(1-\alpha)^{\frac{1}{\eta}} C_{H, t}^{\frac{\eta-1}{\eta}}+\alpha^{\frac{1}{\eta}} C_{F, t}^{\frac{\eta-1}{\eta}}\right]^{\frac{\eta}{\eta-1}}
$$

where the goods in turn are a standard aggregate of a continuum of varieties indexed by $i$, $C_{H, t}=\int_{0}^{1}\left[c_{H, t}(i)^{\frac{\varepsilon-1}{\varepsilon}} d i\right]^{\frac{\varepsilon}{\varepsilon-1}}$ and $C_{F, t}=\int_{0}^{1}\left[c_{F, t}(i)^{\frac{\varepsilon-1}{\varepsilon}} d i\right]^{\frac{\varepsilon}{\varepsilon-1}}$. Here, $\eta>0$ is the elasticity of substitution between the goods, which we often refer to as the trade elasticity, $\varepsilon>1$ is the elasticity of substitution among the varieties, and $\alpha<1$ denotes the weight of the foreign, imported good in the home basket and therefore, is the degree of home bias. ${ }^{12}$ For simplicity, we assume that the composite government final good is defined similarly as an aggregate of the home, $G_{H, t}$, and foreign, $G_{F, t}$, goods

$$
G_{t}=\left[(1-\alpha)^{\frac{1}{\eta}} G_{H, t}^{\frac{\eta-1}{\eta}}+\alpha^{\frac{1}{\eta}} G_{F, t}^{\frac{\eta-1}{\eta}}\right]^{\frac{\eta}{\eta-1}}
$$

where the goods in turn are an aggregate of a continuum of varieties indexed by $i, G_{H, t}=$ $\int_{0}^{1}\left[g_{H, t}(i)^{\frac{\varepsilon-1}{\varepsilon}} d i\right]^{\frac{\varepsilon}{\varepsilon-1}}$ and $G_{F, t}=\int_{0}^{1}\left[g_{F, t}(i)^{\frac{\varepsilon-1}{\varepsilon}} d i\right]^{\frac{\varepsilon}{\varepsilon-1}}$.

The optimal price index of the composite good $P_{t}$ is given by $P_{t}=\left[(1-\alpha) P_{H, t}^{1-\eta}+\alpha P_{F, t}^{1-\eta}\right]^{\frac{1}{1-\eta}}$ where $P_{H, t}$ is the price in home currency of the home good while $P_{F, t}$ is the price in home currency of the foreign good. The demand for the aggregate goods is then given by

$$
\frac{C_{H, t}}{C_{t}}=\frac{G_{H, t}}{G_{t}}=(1-\alpha)\left(\frac{P_{H, t}}{P_{t}}\right)^{-\eta}, \quad \frac{C_{F, t}}{C_{t}}=\frac{G_{F, t}}{G_{t}}=\alpha\left(\frac{P_{F, t}}{P_{t}}\right)^{-\eta} .
$$

The optimal price indices for the home and foreign good are given by $P_{H, t}=\left[\int_{0}^{1} p_{H, t}(i)^{1-\varepsilon} d i\right]^{\frac{1}{1-\varepsilon}}$

\footnotetext{
${ }^{12}$ Note here that for simplicity, we impose the "SOE limit" already in defining the consumption bundles. A more general notation, following Faia and Monacelli (2008), would be to write $C_{t}=\left[\left(1-\alpha^{\prime}\right)^{\frac{1}{\eta}} C_{H, t}^{\frac{\eta-1}{\eta}}+\alpha^{\prime \frac{1}{\eta}} C_{F, t}^{\frac{\eta-1}{\eta}}\right]^{\frac{\eta}{\eta-1}}$ with $\alpha^{\prime}=(1-n) \alpha$, where $n$ is the size and $\alpha$ the trade openness of the home country. Then, $n \rightarrow 0$ would constitute the "SOE limit."
} 
and $P_{F, t}=\left[\int_{0}^{1} p_{F, t}(i)^{1-\varepsilon} d j\right]^{\frac{1}{1-\varepsilon}}$ where $p_{H, t}(i)$ is the price in home currency of the home variety $i$ while $p_{F, t}(i)$ is the price in home currency of the foreign variety $i$. The demand for the individual varieties is then given by $\frac{c_{H, t}(i)}{C_{H, t}}=\left(\frac{p_{H, t}(i)}{P_{H, t}}\right)^{-\varepsilon}, \frac{c_{F, t}(i)}{C_{F, t}}=\left(\frac{p_{F, t}(i)}{P_{F, t}}\right)^{-\varepsilon}, \frac{g_{H, t}(i)}{G_{H, t}}=\left(\frac{p_{H, t}(i)}{P_{H, t}}\right)^{-\varepsilon}$, and $\frac{g_{F, t}(i)}{G_{F, t}}=\left(\frac{p_{F, t}(i)}{P_{F, t}}\right)^{-\varepsilon}$.

The home household is subject to a sequence of flow budget constraints

$$
P_{t} C_{t}+B_{t}+E_{t}\left\{\rho_{t, t+1} A_{t+1}\right\} \leq \int_{0}^{1} n_{t}(i) h_{t}(i) d i+\left(1+i_{t-1}\right) B_{t-1}+A_{t}-P_{t} T_{t}+\int_{0}^{1} Z_{t}(i) d i
$$

where $n_{t}(i)$ is nominal wage of labor of type $i, Z_{t}(i)$ is nominal profit of home firm $i, B_{t}$ is the household's holding of one-period risk-less nominal government bond at the beginning of period $t+1$, and $T_{t}$ is (real) government taxes. $A_{t+1}$ is the value of the complete set of state-contingent securities at the beginning of period $t+1$, denominated in home currency for simplicity. Finally, $i_{t-1}$ is the nominal interest rate on government bond holdings at the beginning of period $t$ (which is subject to the zero lower bound $\left.i_{t} \geq 0\right)$, and $\rho_{t, t+1}$ is the stochastic discount factor between periods $t$ and $t+1$ that is used to value random nominal income in period $t+1$ in monetary units at date $t{ }^{13}$ Note that financial markets are complete both domestically and internationally.

The problem of the home household is thus to choose $\left\{C_{t+s}, h_{t+s}(i), B_{t+s}, A_{t+s}\right\}$ to maximize (1) subject to a sequence of flow budget constraints given by (5), while taking as exogenously given initial wealth and $\left\{P_{t+s}, n_{t+s}(i), i_{t+s}, \rho_{t, t+s}, \xi_{t+s}, Z_{t+s}(i), T_{t+s}\right\}$.

For the foreign country, in terms of notation, all foreign variables are denoted by a $*$. Since the home country is a SOE, the home good will have a negligible weight on the foreign composite consumption good. Thus, we have $P_{t}^{*}=P_{F, t}^{*}$ where $P_{t}^{*}$ is the price in terms of foreign currency of the foreign composite good while $P_{F, t}^{*}$ is the price in terms of foreign currency of the foreign good. Moreover, from the perspective of the home country, foreign private and government consumption, $C_{t}^{*}$ and $G_{t}^{*}$, will evolve exogenously. Finally, the foreign demand for the goods and the varieties are given by analogous expressions as above.

\subsubsection{Firms}

There is a continuum of monopolistically competitive firms indexed by $i$ in the two countries. Each firm at home produces a variety $i$ according to the production function

$$
y_{t}(i)=f\left(h_{t}(i), \xi_{t}\right)
$$

where $f($.$) is an increasing concave function for any \xi_{t} \cdot{ }^{14}$

There is no international price discrimination and the law of one price for each of the traded varieties holds. Thus, $p_{H, t}(i)=S_{t} p_{H, t}^{*}(i)$ and $p_{F, t}(i)=S_{t} p_{F, t}^{*}(i)$, where $S_{t}$ is the nominal exchange

\footnotetext{
${ }^{13}$ The household is subject to a standard no-Ponzi game condition.

${ }^{14}$ Note that $\xi_{t}$ is again a vector of aggregate exogenous (domestic) shocks.
} 
rate. ${ }^{15}$ This implies $P_{H, t}=S_{t} P_{H, t}^{*}$ and $P_{F, t}=S_{t} P_{F, t}^{*}$. Next, define $Q_{t}$ the real exchange rate as $Q_{t}=\frac{S_{t} P_{t}^{*}}{P_{t}}, \varsigma_{t}$ the terms of trade as $\varsigma_{t}=\frac{P_{F, t}}{P_{H, t}}=\frac{P_{F, t}^{*}}{P_{H, t}^{*}}=\frac{P_{t}^{*}}{P_{H, t}^{*}}$, and $r\left(\varsigma_{t}\right)$, a relative price, as the ratio of consumer and domestic prices $r\left(\varsigma_{t}\right)=\frac{P_{t}}{P_{H, t}} \cdot{ }^{16}$ This implies the following relationships

$$
\begin{gathered}
r\left(\varsigma_{t}\right)=\frac{P_{t}}{P_{H, t}}=\left[(1-\alpha)+\alpha \varsigma_{t}^{1-\eta}\right]^{\frac{1}{1-\eta}} \\
Q_{t}=\frac{S_{t} P_{t}^{*}}{P_{t}}=\frac{\varsigma_{t}}{r\left(\varsigma_{t}\right)}=q\left(\varsigma_{t}\right) .
\end{gathered}
$$

As in Rotemberg (1983), firms face a cost of changing prices given by $d\left(\frac{p_{H, t}(i)}{p_{H, t-1}(i)}\right) .{ }^{17}$ We assume, as is standard, that $d(1)=d^{\prime}(1)=0$ and $d^{\prime}\left(\Pi_{H}\right)>0$ if $\Pi_{H}>1$ and $d^{\prime}\left(\Pi_{H}\right)<0$ if $\Pi_{H}<1$. This adjustment cost makes the firm's pricing problem dynamic. The demand function for variety $i$ is given by

$$
\frac{y_{t}(i)}{Y_{t}}=\left(\frac{p_{H, t}(i)}{P_{H, t}}\right)^{-\varepsilon}
$$

where $Y_{t}$ is aggregate world demand. The firm maximizes expected discounted profits

$$
E_{t} \sum_{s=0}^{\infty} \rho_{t, t+s} Z_{t+s}(i)
$$

where $\rho_{t, t+s}$ is the stochastic discount factor between periods $t$ and $t+s$. The period profits $Z_{t}(i)$ are given by

$$
Z_{t}(i)=\left[(1+s) p_{H, t}(i) y_{t}(i)-n_{t}(i) h_{t}(i)-d\left(\frac{p_{H, t}(i)}{p_{H, t-1}(i)}\right) P_{H, t}\right]
$$

where $s$ is the production subsidy in steady-state, whose technical role we clarify later. We can re-write $Z_{t}(i)$ using (6) and (9) as

$$
Z_{t}(i)=\left[(1+s) Y_{t} p_{H, t}(i)^{1-\varepsilon} P_{H, t}^{\varepsilon}-n_{t}(i) f^{-1}\left(Y_{t} p_{H, t}(i)^{-\varepsilon} P_{H, t}^{\varepsilon}\right)-d\left(\frac{p_{H, t}(i)}{p_{H, t-1}(i)}\right) P_{H, t}\right]
$$

The problem of the home firm is thus to choose $\left\{p_{H, t+s}(i)\right\}$ to maximize (10), while taking as exogenously given $\left\{P_{H, t+s}, Y_{t+s}, n_{t+s}(i), \rho_{t, t+s}, \xi_{t+s}\right\}$.

\subsubsection{Private sector equilibrium conditions}

We can now derive the necessary conditions for equilibrium that arise from the maximization problems of the private sector described above. Households optimality conditions over labor supply

\footnotetext{
${ }^{15} \mathrm{An}$ increase of $S_{t}$ thus implies a depreciation of the home currency in our model.

${ }^{16}$ Clearly, this relative price is unity in a closed economy.

${ }^{17}$ We consider the Rotemberg model rather than the familiar Calvo model as we will compute non-linear solutions for optimal policy under the zero lower bound, which is much easier with the Rotemberg model as it does not feature a state variable related to price dispersion.
} 
and asset holdings are standard and given by

$$
\begin{gathered}
\frac{v_{h}\left(h_{t}(i), \xi_{t}\right)}{u_{C}\left(C_{t}, \xi_{t}\right)}=\frac{n_{t}(i)}{P_{t}} \\
\rho_{t, t+s}=\beta \frac{u_{C}\left(C_{t+s}, \xi_{t+s}\right)}{u_{C}\left(C_{t}, \xi_{t}\right)} \Pi_{t+s}^{-1} \\
\frac{1}{1+i_{t}}=E_{t}\left[\beta \frac{u_{C}\left(C_{t+1}, \xi_{t+1}\right)}{u_{C}\left(C_{t}, \xi_{t}\right)} \Pi_{t+1}^{-1}\right] \text { with } i_{t} \geq 0 .
\end{gathered}
$$

where $\Pi_{t}=\frac{P_{t}}{P_{t-1}}$ and (12) holds for each state of nature. ${ }^{18}$ Here, (13) is a standard (non-linear) Euler equation, which additionally also reflects the zero lower bound (ZLB) constraint on nominal interest rates. ${ }^{19}$ Given the assumption of complete international financial markets, where the two countries can trade state-contingent consumption claims, there exists a unique stochastic discount factor. Then, the standard risk-sharing condition (after assuming the same ex-ante per capita wealth distribution), is given by

$$
Q_{t}=q\left(\varsigma_{t}\right)=\frac{u_{C}\left(C_{t}^{*}, \xi_{t}^{*}\right)}{u_{C}\left(C_{t}, \xi_{t}\right)}
$$

Finally, the accounting identity given our definition of $\left[(1-\alpha)+\alpha \varsigma_{t}^{1-\eta}\right]^{\frac{1}{1-\eta}}=\frac{P_{t}}{P_{H, t}}=r\left(\varsigma_{t}\right)$ gives

$$
\frac{\Pi_{t}}{\Pi_{H, t}}=\frac{r\left(\varsigma_{t}\right)}{r\left(\varsigma_{t-1}\right)}
$$

The firm's optimality condition from price-setting is given by

$$
\begin{aligned}
& -(1-\varepsilon)(1+s) Y_{t} p_{H, t}(i)^{-\varepsilon} P_{H, t}^{\varepsilon}+\varepsilon n_{t}(i) f_{y}^{-1}\left(y_{t}(i)\right) Y_{t} p_{H, t}(i)^{-\varepsilon-1} P_{H, t}^{\varepsilon}+d^{\prime}\left(\frac{p_{H, t}(i)}{p_{H, t-1}(i)}\right) \frac{P_{H, t}}{p_{H, t-1}(i)} \\
& =E_{t}\left[\rho_{t, t+1} d^{\prime}\left(\frac{p_{H, t+1}(i)}{p_{H, t}(i)}\right) \frac{p_{H, t+1}(i)}{p_{H, t}(i)^{2}} P_{H, t+1}\right] .
\end{aligned}
$$

Next, we will focus on a symmetric equilibrium where all firms charge the same price and produce the same amount of output: $p_{H, t}(i)=P_{H, t}, y_{t}(i)=Y_{t}, h_{t}(i)=h_{t}, n_{t}(i)=n_{t}$. Then the firm's optimality condition from price-setting can be written, after using (11), (12), $\frac{P_{t}}{P_{H, t}}=r\left(\varsigma_{t}\right)$, and $\frac{\Pi_{t+1}}{\Pi_{H, t+1}}=\frac{r\left(\varsigma_{t+1}\right)}{r\left(\varsigma_{t}\right)}$, as well as by replacing $v_{h}\left(h_{t}, \xi_{t}\right) f_{y}^{-1}\left(Y_{t}\right)$ with $\tilde{v}_{y}\left(Y_{t}, \xi_{t}\right)$ where $\tilde{v}\left(y_{t}(i), \xi_{t}\right)=$

\footnotetext{
${ }^{18} \mathrm{~A}$ standard transversality condition is also a part of these conditions.

${ }^{19}$ We directly impose the ZLB constraint as is the standard in the recent literature. This can be derived rigorously in a model with cash.
} 
$v\left(f^{-1}\left(y_{t}(i), \xi_{t}\right)\right.$, as

$$
\begin{aligned}
& \varepsilon Y_{t}\left[\frac{\varepsilon-1}{\varepsilon}(1+s) u_{C}\left(C_{t}, \xi_{t}\right)-\tilde{v}_{y}\left(Y_{t}, \xi_{t}\right) r\left(\varsigma_{t}\right)\right]+u_{C}\left(C_{t}, \xi_{t}\right) d^{\prime}\left(\Pi_{H, t}\right) \Pi_{H, t} \\
& =E_{t}\left[\beta u_{C}\left(C_{t+1}, \xi_{t+1}\right) \frac{r\left(\varsigma_{t}\right)}{r\left(\varsigma_{t+1}\right)} d^{\prime}\left(\Pi_{H, t+1}\right) \Pi_{H, t+1}\right] .
\end{aligned}
$$

Here, (16) is the (non-linear) Phillips curve of a small open economy that governs the dynamics of home inflation $\Pi_{H, t}$.

\subsection{Government}

The government flow budget constraint is given by

$$
B_{t}=\left(1+i_{t-1}\right) B_{t-1}+P_{t} G_{t}-P_{t} T_{t}
$$

where in terms of notation, for simplicity, we are assuming that all government debt is held domestically. We assume that lump-sum taxes are available and so government debt dynamics is irrelevant for the non-fiscal variables and the determination of the private sector equilibrium. We thus abstract from it for the rest of the paper. We describe the objectives and the problem faced by the SOE government in the next section.

\subsection{Market clearing and net exports}

Given that the law of one price holds, it is straightforward to derive an exact non-linear resource constraint

$$
Y_{t}=(1-\alpha) r\left(\varsigma_{t}\right)^{\eta}\left(C_{t}+G_{t}\right)+\alpha \varsigma_{t}^{\eta}\left(C_{t}^{*}+G_{t}^{*}\right)+d\left(\Pi_{H, t}\right) .
$$

For future reference, we now derive an expression for the equilibrium trade balance or net exports $\left(N X_{t}\right)$, which we define in real terms as deflated by the home price level as

$$
N X_{t}=\frac{\left(Y_{t} P_{H, t}-C_{t} P_{t}-G_{t} P_{t}\right)}{P_{H, t}}=Y_{t}-r\left(\varsigma_{t}\right)\left(C_{t}+G_{t}\right)
$$

\subsection{Private sector equilibrium}

We are now ready to define the private sector equilibrium, that is the set of possible equilibria that are consistent with the private sector equilibrium conditions and the technological constraints on government policy. A private sector equilibrium is a collection of stochastic processes $\left\{Y_{t+s}, C_{t+s}, \Pi_{t+s}, \Pi_{H, t+s}, G_{t+s}, \varsigma_{t+s}, i_{t+s}\right\}$ for $s \geq 0$ that satisfy (6)-(8), (11)-(15), and (17), for each $s \geq 0$, given $\varsigma_{t-1}$ and an exogenous stochastic process for $\left\{\xi_{t+1}, \xi_{t+1}^{*}, C_{t}^{*}, G_{t}^{*}\right\}$. 


\section{Equilibrium}

We now describe the complete equilibrium of our model along with a detailed description of the objectives and commitment ability of the government.

\subsection{Recursive representation of private sector equilibrium}

It is useful to first derive a recursive representation of the private sector equilibrium that we described above, which clarifies the state variables of the model, in order to set-up the optimal policy problem. Define the expectation variable $f_{t}^{e}=E_{t}\left[u_{C}\left(C_{t+1}, \xi_{t+1}\right) \Pi_{t+1}^{-1}\right]$ to write (13) as

$$
1+i_{t}=\frac{u_{C}\left(C_{t}, \xi_{t}\right)}{\beta f_{t}^{e}}
$$

Define another expectation variable $S_{t}^{e}=E_{t}\left[u_{C}\left(C_{t+1}, \xi_{t+1}\right) d^{\prime}\left(\Pi_{H, t+1}\right) \frac{\Pi_{H, t+1}}{r\left(\varsigma_{t+1}\right)}\right]$ to write (16) as

$$
\varepsilon Y_{t}\left[\frac{\varepsilon-1}{\varepsilon}(1+s) u_{C}\left(C_{t}, \xi_{t}\right)-\tilde{v}_{y}\left(Y_{t}, \xi_{t}\right) r\left(\varsigma_{t}\right)\right]+u_{C}\left(C_{t}, \xi_{t}\right) d^{\prime}\left(\Pi_{H, t}\right) \Pi_{H, t}=\beta r\left(\varsigma_{t}\right) S_{t}^{e}
$$

This means that the necessary and sufficient condition for a private sector equilibrium is that variables $\left\{Y_{t}, C_{t}, \Pi_{t}, \Pi_{H, t}, G_{t}, \varsigma_{t}, i_{t}\right\}$ satisfy: (a) the following conditions

$$
\begin{gathered}
1+i_{t}=\frac{u_{C}\left(C_{t}, \xi_{t}\right)}{\beta f_{t}^{e}} \\
i_{t} \geq 0 \\
\varepsilon Y_{t}\left[\frac{\varepsilon-1}{\varepsilon}(1+s) u_{C}\left(C_{t}, \xi_{t}\right)-\tilde{v}_{y}\left(Y_{t}, \xi_{t}\right) r\left(\varsigma_{t}\right)\right]+u_{C}\left(C_{t}, \xi_{t}\right) d^{\prime}\left(\Pi_{H, t}\right) \Pi_{H, t}=\beta r\left(\varsigma_{t}\right) S_{t}^{e} \\
Y_{t}=(1-\alpha) r\left(\varsigma_{t}\right)^{\eta}\left(C_{t}+G_{t}\right)+\alpha \varsigma_{t}^{\eta}\left(C_{t}^{*}+G_{t}^{*}\right)+d\left(\Pi_{H, t}\right) \\
\frac{\Pi_{t}}{\Pi_{H, t}}=\frac{r\left(\varsigma_{t}\right)}{r\left(\varsigma_{t-1}\right)} \\
q\left(\varsigma_{t}\right)=\frac{u_{C}\left(C_{t}^{*}, \xi_{t}^{*}\right)}{u_{C}\left(C_{t}, \xi_{t}\right)}
\end{gathered}
$$

given $\varsigma_{t-1}$ and the expectations $f_{t}^{e}$ and $S_{t}^{e}$; (b) expectations are rational so that

$$
f_{t}^{e}=E_{t}\left[u_{C}\left(C_{t+1}, \xi_{t+1}\right) \Pi_{t+1}^{-1}\right], S_{t}^{e}=E_{t}\left[u_{C}\left(C_{t+1}, \xi_{t+1}\right) d^{\prime}\left(\Pi_{H, t+1}\right) \frac{\Pi_{H, t+1}}{r\left(\varsigma_{t+1}\right)}\right]
$$

Note that the possible private sector equilibrium defined above depends only on the (possibly relevant) endogenous state variable $\varsigma_{t-1}$, domestic shocks $\xi_{t}$, and foreign shocks $\xi_{t}^{*}, C_{t}^{*}$, and $G_{t}^{*}$. 
Also, note the following definitions

$$
r\left(\varsigma_{t}\right)=\left[(1-\alpha)+\alpha \varsigma_{t}^{1-\eta}\right]^{\frac{1}{1-\eta}}, q\left(\varsigma_{t}\right)=\frac{\varsigma_{t}}{r\left(\varsigma_{t}\right)}=\frac{\varsigma_{t}}{\left[(1-\alpha)+\alpha \varsigma_{t}^{1-\eta}\right]^{\frac{1}{1-\eta}}} .
$$

\subsection{Efficient equilibrium}

We first characterize the efficient (first-best) allocation by considering the SOE's planner's problem, which is to maximize

$$
U\left(C_{t}, G_{t}, \xi_{t}\right)=u\left(C_{t}, \xi_{t}\right)-\tilde{v}\left(Y_{t}\right)+g\left(G_{t}, \xi_{t}\right)
$$

subject to the social resource constraint and the international risk-sharing condition

$$
\begin{gathered}
Y_{t}=(1-\alpha) r\left(\varsigma_{t}\right)^{\eta}\left(C_{t}+G_{t}\right)+\alpha \varsigma_{t}^{\eta}\left(C_{t}^{*}+G_{t}^{*}\right) \\
q\left(\varsigma_{t}\right)=\frac{u_{C}\left(C_{t}^{*}, \xi_{t}^{*}\right)}{u_{C}\left(C_{t}, \xi_{t}\right)} .
\end{gathered}
$$

Note here that the planner's problem is static and the details of the problem and the associated optimality conditions are in the appendix.

The efficient equilibrium is a collection of stochastic processes $\left\{Y_{t+s}, C_{t+s}, G_{t+s}, \varsigma_{t+s}\right\}$ for $s \geq 0$ that solve the SOE planner's problem above and satisfy (17) and (14), for each $s \geq 0$, given an exogenous stochastic process for $\left\{\xi_{t+1}, \xi_{t+1}^{*}, C_{t}^{*}, G_{t}^{*}\right\}$. The first-best allocation is an important benchmark and point of reference for the rest of the paper.

\subsection{Commitment equilibrium}

We now describe the government's problem when its objective is to maximize the representative household's utility and when it can commit at time $t$ to a fully state-contingent path for its policy instruments $i_{t+s}$ and $G_{t+s}$. This is also known as the Ramsey problem in the literature. The (Ramsey) policy problem under commitment then is to maximize

$$
E_{t} \sum_{s=0}^{\infty} \beta^{s}\left[U\left(C_{t+s}, G_{t+s}, \xi_{t+s}\right)=u\left(C_{t+s}, \xi_{t+s}\right)-\tilde{v}\left(Y_{t+s}\right)+g\left(G_{t+s}, \xi_{t+s}\right)\right]
$$

subject to the private sector equilibrium conditions (18)-(23), the rational expectations restrictions (24), and the definitions (25). The details of the problem and the associated optimality conditions are in the appendix. Note that under credible commitment, the government can directly influence the expectations given by $f_{t}^{e}$ and $S_{t}^{e}$.

The Ramsey (commitment) equilibrium is the best competitive equilibrium, the private sector equilibrium that maximizes the utility of the representative household. Generally, the commitment equilibrium will not coincide with the first-best equilibrium described above. Moreover, as is wellknown, generally, the commitment equilibrium is time-inconsistent. We describe a time-consistent 
equilibrium next.

\subsection{Discretion equilibrium}

We finally describe the government's problem when its objective is to maximize the representative household's utility and when it cannot commit to a fully state-contingent path for its policy instruments $i_{t}$ and $G_{t}$. In particular, it acts with full discretion and chooses the values of its instruments period by period. The solution concept we use for this discretionary equilibrium is that of a Markov-perfect (time-consistent) equilibrium where the government and the private sector take actions simultaneously.

Given that the government cannot commit to future policy, a Markov-perfect equilibrium requires that the expectations $f_{t}^{e}$ and $S_{t}^{e}$ are only a function of the state variables $\left(\varsigma_{t-1}, \xi_{t}, \xi_{t}^{*}, C_{t}^{*}, G_{t}^{*}\right)$. That is, we can then define the expectations functions

$$
f_{t}^{e}=\bar{f}^{E}\left(\varsigma_{t-1}, \xi_{t}, \xi_{t}^{*}, C_{t}^{*}, G_{t}^{*}\right), S_{t}^{e}=\bar{S}^{E}\left(\varsigma_{t-1}, \xi_{t}, \xi_{t}^{*}, C_{t}^{*}, G_{t}^{*}\right)
$$

and the policy functions

$$
\begin{aligned}
Y_{t} & =\bar{Y}\left(\varsigma_{t-1}, \xi_{t}, \xi_{t}^{*}, C_{t}^{*}, G_{t}^{*}\right), C_{t}=\bar{C}\left(\varsigma_{t-1}, \xi_{t}, \xi_{t}^{*}, C_{t}^{*}, G_{t}^{*}\right), \Pi_{t}=\bar{\Pi}\left(\varsigma_{t-1}, \xi_{t}, \xi_{t}^{*}, C_{t}^{*}, G_{t}^{*}\right), \\
\Pi_{H, t} & =\Pi_{H}\left(\varsigma_{t-1}, \xi_{t}, \xi_{t}^{*}, C_{t}^{*}, G_{t}^{*}\right), \varsigma_{t}=\bar{\varsigma}\left(\varsigma_{t-1}, \xi_{t}, \xi_{t}^{*}, C_{t}^{*}, G_{t}^{*}\right), \\
i & =\bar{i}\left(\varsigma_{t-1}, \xi_{t}, \xi_{t}^{*}, C_{t}^{*}, G_{t}^{*}\right), G_{t}=\bar{G}\left(\varsigma_{t-1}, \xi_{t}, \xi_{t}^{*}, C_{t}^{*}, G_{t}^{*}\right) .
\end{aligned}
$$

The (Markov-perfect) policy problem under discretion can be written recursively as

$$
J\left(\varsigma_{t-1}, \xi_{t}, \xi_{t}^{*}, C_{t}^{*}, G_{t}^{*}\right)=\max _{i_{t}, G_{t}}\left[U\left(C_{t}, G_{t}, \xi_{t}\right)+\beta E_{t} J\left(\varsigma_{t}, \xi_{t+1}, \xi_{t+1}^{*}, C_{t+1}^{*}, G_{t+1}^{*}\right)\right]
$$

subject to the private sector equilibrium conditions (18)-(23), the expectation functions (26), and the definitions (25). Here, $J\left(\varsigma_{t-1}, \xi_{t}, \xi_{t}^{*}, C_{t}^{*}, G_{t}^{*}\right)$ is the value function of the government. Note that in equilibrium, the expectation functions (26) satisfy the rational expectation restrictions (24). ${ }^{20}$ That is, as is well-known, we have to solve a fixed-point problem to characterize the solution to the Markov-perfect equilibrium. The details of the problem and the associated optimality conditions are in the appendix.

The Markov-perfect (discretion) equilibrium is a collection of expectation functions (26), policy functions (27), and the value function $J\left(\varsigma_{t-1}, \xi_{t}, \xi_{t}^{*}, C_{t}^{*}, G_{t}^{*}\right)$ such that they solve the government's optimization problem (28) and satisfy the rational expectation restrictions (24). We note that while here we set up the Markov-perfect problem generally as a dynamic problem for the government, we show in the appendix formally that it reduces to a period-by-period maximization problem since the endogenous state variable $\varsigma_{t-1}$ is not relevant for policy as the constraint $(22)$ never binds. ${ }^{21}$

\footnotetext{
${ }^{20}$ We will only concentrate on equillibria where the value functions and expectation functions are differentiable.

${ }^{21}$ The intuition for this result can be obtained by noticing that only $\Pi_{t+1}^{-1}$ appears in $f_{t}^{e}=E_{t}\left[u_{C}\left(C_{t+1}, \xi_{t+1}\right) \Pi_{t+1}^{-1}\right]$, which can be substituted out by using (22) moved one period forward. This then removes all lagged variables from
} 
This makes solving the fixed-point problem easier as the expectation functions (26) only depend on exogenous state variables.

\section{Results}

We now present our results, starting with the steady-state of the model and the efficient equilibrium, and then proceeding to (non-linear, perfect foresight) dynamics, both out of and in ZLB and both with and without commitment, under optimal monetary and fiscal policy. We focus on perfect foresight dynamics, where an unexpected shock hits in the initial period and then the economy evolves in a deterministic fashion as it will be computationally quite demanding to solve for the stochastic equilibrium with the ZLB under commitment as then there are multiple endogenous state-variables in the model. In addition, a fair comparison between commitment and discretion is crucial for many of our results. For this reason, we consider perfect foresight dynamics under discretion too. ${ }^{22}$ We use a non-linear solver to numerically compute the equilibrium. All the details of our derivations, the proofs, and the detailed equilibrium conditions are in the appendix.

We mostly rely on numerical results since analytical results are not available except for the efficient equilibrium and under optimal policy for a special case when the ZLB does not bind. From now on we assume the following functional forms for utility, production, and price-adjustment cost functions

$$
\begin{gathered}
u(C, \xi)=\xi^{C} \frac{C^{1-\sigma}}{1-\sigma}, \quad g(G, \xi)=\xi^{C} \lambda_{G} \frac{G^{1-\sigma^{\prime}}}{1-\sigma^{\prime}} \\
v(h(i), \xi)=\lambda \xi^{C} \frac{h(i)^{1+\phi}}{1+\phi}, \quad y(i)=\xi^{P} h(i)^{\kappa}, \quad d(\Pi)=d_{1}(\Pi-1)^{2}
\end{gathered}
$$

where $\xi^{P}$ is the technology/productivity shock and $\xi^{C}$ is the discount factor/preference shock.

Our (quarterly) calibration is very standard and we present the parameter values we use in Table 1. For most parts, for ease of comparison with the literature, we use the same parameter values as in Faia and Monacelli (2008), including the discount factor $(\beta=0.99)$, log-utility specification $(\sigma=1)$, constant returns to scale in production $(\kappa=1)$, inverse of the Frisch elasticity $(\phi=3)$, the price-adjustment parameter $\left(d_{1}=75 / 2\right)$, and home bias $(\alpha=0.4) .{ }^{23}$ We then focus on showing results for different values of $\eta$, the elasticity of substitution between between domestic and foreign goods, as this is the key parameter of interest in this paper. ${ }^{24}$ One of the scale parameters in

the constraints.

${ }^{22}$ In modeling the binding ZLB as arising in a perfect foresight environment due to an unexpected, one-time shock that drives the efficient real interest to a large negative value, we follow, among others, Jung, Teranishi, Watanabe (2005), Christiano, Eichenbaum, and Rebelo (2011), and Werning (2013). Our solution computes the fully non-linear equilibrium.

${ }^{23}$ With the first-order equivalence of the Rotemberg and Calvo price stickiness framework, this value corresponds to price duration of around four quarters.

${ }^{24}$ We note that there is disagreement in the literature regarding a reasonable estimate of this parameter. Estimated or calibrated quantitative two-country business cycle models, such as Heathcote and Perri (2002) and Lubik and Schorfheide (2005), typically use an elasticity less than one. On the other hand, the trade literature estimates a much higher elasticity, in the range of 8-10, as discussed in Obstfeld and Rogoff (2000). 
the utility function, $\lambda$, is chosen so that the steady-state is consistent with our normalization that steady-state output is 1 . When we analyze the model with government spending, we choose the steady-state government spending-to-output ratio, $\theta_{G}$, of $0.2 .{ }^{25}$ The other scale parameter in the utility function, $\lambda_{G}$, is then chosen so that the steady-state of the model is consistent with this choice.

\begin{tabular}{llll}
\hline Parameter & Value & Parameter & Value \\
\hline \hline$\beta$ & 0.99 & $\eta$ & $0.7,1,1.3$ \\
$\sigma=\sigma^{\prime}$ & 1 & $\kappa$ & 1 \\
$\alpha$ & 0.4 & $d_{1}$ & $75 / 2$ \\
$\phi$ & 3 & $\varepsilon$ & 7.5 \\
$\rho$ & 0.95 & $\theta_{G}$ & 0.2 \\
\hline
\end{tabular}

Table 1: Numerical values of model parameters

Finally, for brevity, we focus on two domestic shocks only: technology shocks, since that is often the baseline case analyzed in the SOE optimal monetary policy literature and discount factor shocks, since that is often the baseline case analyzed in the closed economy optimal monetary policy literature when the ZLB binds. We consider a persistent process with an $\operatorname{AR}(1)$ parameter $(\rho)$ of 0.95. The size of the shocks varies depending on whether the ZLB binds or not and we describe our numerical values for the shocks later in this section.

We start with the steady-state of the model and the dynamics under the efficient equilibrium. Then we consider monetary policy only, out of ZLB and in ZLB, both under commitment and discretion. For the ease of exposition, first, we discuss only the technology shock and later present results based on the preference shock to show robustness. We conclude this section with the analysis of joint monetary and fiscal policy, again out of ZLB and in ZLB, both under commitment and discretion.

\subsection{Steady state}

We first characterize the non-stochastic steady-state when no aggregate shocks are present. ${ }^{26}$ In the proposition below we derive the appropriate production subsidy that ensures that the efficient, commitment, and discretion steady-states coincide. ${ }^{27}$ Our goal is to obtain for both the commitment and discretion equilibria, a steady-state with zero net inflation. Moreover, we also aim to ensure a symmetric steady-state across countries. The appropriate subsidy is thus consistent with both a steady-state equilibrium that has zero net inflation as well as a symmetric (consumption across countries) equilibrium with $\varsigma=1 .^{28}$

\footnotetext{
${ }^{25}$ This is roughly the ratio of government consumption to output in some advanced economies.

${ }^{26}$ We represent variables at the non-stochastic steady-state without a $t$ subscript.

${ }^{27}$ Faia and Monacelli (2008) does not feature this subsidy as they focus on the commitment solution out of ZLB.

${ }^{28}$ As we discuss below again, we abstract from and leave for future research, the possibility of a deflationary, zero interest rate steady-state in the model due to the zero lower bound constraint. This can be an issue for the discretion equilibrium.
} 
Proposition 1 The efficient, commitment, and the discretion (non-stochastic) steady-states coincide when the production subsidy take the form

$$
1+s=\frac{\varepsilon}{\varepsilon-1} \times \frac{\frac{1-\alpha}{\sigma} \theta_{C}}{(2-\alpha) \eta \alpha+\frac{(1-\alpha)^{2}}{\sigma} \theta_{C}}
$$

where $\theta_{C} \equiv \frac{C}{Y}$ is the share of consumption in output in the steady state. ${ }^{29}$

Proof. In appendix.

Intuitively, the production subsidy has both monopolistic competition and terms of trade components. The first component is standard (it is equal to the markup) and has been emphasized in the closed-economy literature. The second component reflects the incentive to appreciate terms of trade in the steady state in order to make domestic goods more expensive, and thereby increase consumption without having to exert additional labor.

For intuition, recall the market clearing (21) and risk-sharing conditions (23)

$$
\begin{gathered}
C_{t}=C_{t}^{*} q\left(\varsigma_{t}\right)^{\frac{1}{\sigma}} \\
Y_{t}=(1-\alpha) r\left(\varsigma_{t}\right)^{\eta}\left(C_{t}^{*} q\left(\varsigma_{t}\right)^{\frac{1}{\sigma}}+G_{t}\right)+\alpha \varsigma_{t}^{\eta}\left(C_{t}^{*}+G_{t}^{*}\right)+d\left(\Pi_{H, t}\right) .
\end{gathered}
$$

Taking derivatives with respect to the terms of trade evaluated at the steady state yields

$$
\begin{gathered}
\frac{\partial C}{\partial \varsigma}=\frac{(1-\alpha)}{\sigma} \theta_{C} \\
\frac{\partial Y}{\partial \varsigma}=(2-\alpha) \eta \alpha+\frac{(1-\alpha)^{2}}{\sigma} \theta_{C}
\end{gathered}
$$

which are exactly the numerator and denominator of the second term in the subsidy expression. ${ }^{30}$ So, for example, if after a terms of trade appreciation, consumption decreases by less than output (numerator is smaller than denominator), then it's optimal to work less (and thus to raise the relative price of domestic good through lower supply). ${ }^{31}$

This result nests several cases in the literature. For example, it shows that in a closed-economy approximation of $\alpha=0$, we get $1+s=\frac{\epsilon}{\epsilon-1}$, as is standard. Without government spending $\left(\theta_{C}=1\right)$,

\footnotetext{
${ }^{29}$ This ratio is uniquely pinned down by parameters of the model.

${ }^{30}$ Note that partial derivatives here mean holding constant other variables such as $C^{*}, G, G^{*}$, and $\Pi_{H}$. We make use of properties on the derivatives of $q\left(\varsigma_{t}\right)$ in deriving these expressions. Also, an increase in $\varsigma_{t}$ is a depreciation. Moreover, note that while here we concentrate on optimal choice of terms of trade, the same outcome could be achieved with the choice of production subsidy. That is, instead of considering appreciation, we can consider a policymaker suppressing output by reducing production subsidy. Here, throughout we support a symmetric steady state with $\varsigma=1$ using a production subsidy, which corrects for the terms of trade externality.

${ }^{31}$ Risk-aversion parameter $\sigma$ affects this tradeoff since the country that enjoys additional income from terms of trade manipulation has to share some of it with the other country due to perfect risk sharing. Note that this terms of trade externality is different from what is sometimes called such an externality, that is, the incentive of a country to increase its real income by making its own good more expensive. In this model, because of complete markets, real income does not have a separate role since consumption is pinned down by perfect risk sharing agreement. Nevertheless, we call it the terms of trade externality as it involves terms of trade manipulation to increase welfare.
} 
and restricting to $\eta \sigma=1$, we get $1+s=(1-\alpha) \frac{\epsilon}{\epsilon-1}$, as in Gali and Monacelli (2005). Finally, our subsidy derivation for the case without government spending is similar to Farhi and Werning (2013), who make sure that the flexible price allocation coincides with the efficient one. There are differences even in that restricted case as they consider an incomplete markets model with balanced trade as a restriction on the planner's problem, where the planner chooses pareto weights.

This result on the subsidy is very useful for us since we will focus on non-linear dynamics where the transition in the long-run will be back to this efficient non-stochastic steady-state that is common under both commitment and discretion. ${ }^{32}$ Under discretion in these models, generally there will be a non-zero inflation steady-state without the subsidy and moreover, there is a possibility of multiple steady-states, with one where the zero lower bound might bind forever. ${ }^{33}$ We thus ensure that there is one common steady-state for both commitment and discretion so that the comparison is straightforward. Moreover, while for the efficient equilibrium and under discretion, there are no endogenous state variables, under commitment, there are, and for their initial values, we will assume that they are equal to the non-stochastic steady-state. This also ensures a straightforward comparison across various equilibria, of both dynamics and welfare.

\subsection{Efficient equilibrium}

We now present the dynamics of the variables in the efficient equilibrium. For brevity, we only show results here for the technology shock and not for the preference shock case. We start with the model without government spending. Figure 2 shows the dynamic response of several model variables in the first-best equilibrium when a positive $10 \%$ technology shock in the initial period hits the economy. This shock leads to an increase in output and consumption as higher productivity means that more output can be produced with less labor effort, part of which is translated into higher consumption. Moreover, as expected, the positive supply shock leads to a depreciation of the real exchange rate and a fall in the equilibrium real interest rate. ${ }^{34}$ The higher is $\eta$, the elasticity of substitution between domestic and foreign goods, the higher is the output response, and lower is the depreciation and the consumption response. This is because due to perfect risk sharing, higher $\eta$ means that the same amount of depreciation causes a higher output response (through higher demand, both foreign and domestic), but the same consumption response (it's not directly affected by $\eta$ in the risk sharing condition).

Moreover, note the behavior of net exports. At $\eta=1$, net exports are exactly zero, a condition that also often appears in the literature (note that we have already imposed in calibration $\sigma=$ 1 , which means we have $\sigma=\eta=1$ ). However, notice that while $\sigma=\eta=1$ leads to balanced

\footnotetext{
${ }^{32}$ Thus, in the analysis at the zero lower bound, a temporary large shock will put the economy in the liquidity trap and slowly the economy will transition out of it.

${ }^{33}$ We will not explore the issue of multiple steady-states induced by the ZLB in an open economy in this paper and leave it for future research.

${ }^{34}$ The response of the real interest rate, while not directly in the SOE planner's problem described above, is useful for comparison with later exercises. This is the real interest rate consistent with the Euler equation when consumption is at the efficient level. It is a counterfactual notion.
} 
trade in equilibrium, $\sigma \eta=1$ does not. ${ }^{35}$ This distinction will be important in some of our optimal policy results below. To illustrate it visually, in Figure 3 below, we show the dynamic responses of the model variables at $\sigma=\eta=1$ and at two combination of parameter values that lead to $\sigma \eta=1$. Clearly, net exports are not zero for $\sigma \eta=1$ and moreover, it can be either positive or negative, depending on the exact parameter values, with a higher value of $\eta$ leading to a positive trade surplus.

Figure 4 shows the dynamic response of several model variables in the first-best equilibrium when a technology shock hits the economy in the model with government spending. The responses are basically the same when compared to Figure 2, with government expenditure following the path of consumption, as they enter household utility similarly.

We next move on to characterizing optimal policy in our model. Throughout the next two subsections, we refer to a "gap" as the difference between a variable and its efficient counterpart.

\subsection{Optimal monetary policy}

Before presenting results under jointly optimal monetary and fiscal policy, we first study optimal monetary policy only, both out of and in the ZLB. Thus, for now, the only policy instrument of the government is the short-term nominal interest rate and there is no government spending that yields utility to the household in the model. Studying only optimal monetary policy at the ZLB first provides a comparison with the closed economy literature and also helps clarify the additional, complementary role of fiscal policy when we allow optimal choice of government spending. Moreover, we start with out of the ZLB case, not only because it provides a baseline to interpret the ZLB results, but also because to the best of our knowledge, a systematic comparison between commitment and discretion outcomes even at positive interest rates has not been done before for the general parameter values in a SOE environment. First, we consider only the technology shock and at the end of this subsection we discuss the preference shock.

We study the dynamics of the model when an unexpected shock hits the economy in period 0 . For the commitment case, as is well-known, generally, there exists a time-inconsistency feature of the equilibrium. In particular, the period 0 government optimality conditions are different from period 1 onwards. As in Khan, King, and Wolman (1999), the numerical results we present are based on setting the initial Lagrange multipliers that appear in the government optimality conditions to their steady-state values.

\subsubsection{Out of ZLB}

We start with the case where a positive $10 \%$ technology shock hits the economy and this shock is not big enough to drive the economy into a liquidity trap. First, we establish the following result.

\footnotetext{
${ }^{35} \mathrm{As}$ is well-known, with $\sigma=\eta=1$, there is balanced trade with technology shocks as the effects of the real exchange rate on net exports through relative price change exactly off-sets the quantity change. See Benigno and Benigno (2003) for more discussion in a two-country model.
} 
Proposition 2 Under $\sigma \eta=1$, at positive interest rates and with technology shocks, optimal monetary policy with and without commitment achieves the efficient outcome by setting home-inflation and output gap to zero.

Proof. In appendix.

This result builds on a similar analytical result in Gali and Monacelli (2005), but is derived here for the fully non-linear model. Note that the reason for achieving first best is not isomorphism to the closed economy (as would be the case with balanced trade at $\sigma=\eta=1$ ), but rather the absence of additional terms of trade externality arising out of the steady state. To highlight the intuition consider an example with a positive technology shock. As a result of the shock, domestic consumers are richer because domestic goods are cheaper now, but they are also poorer as they are producers of the good that is cheaper. Under $\sigma=\eta=1$, these two effects (substitution and income) are equal to each other, and thus there has to be no net transfer of goods between countries under the risk sharing agreement to compensate domestic consumers.

To help build intuition about optimal response to the terms of trade externality, consider an expression for the ratio of home and foreign demand for home goods (by combining equations (4) for both countries with (23))

$$
\frac{C_{H, t}}{C_{H, t}^{*}}=\frac{1-\alpha}{\alpha} q\left(\varsigma_{t}\right)^{\frac{1}{\sigma}-\eta}
$$

where $q\left(\varsigma_{t}\right)$ is the real exchange rate (which is an increasing function of terms of trade $\varsigma_{t}$ ). Under $\sigma \eta=1$, all additional output is divided between home and foreign countries in the same proportion regardless of the level of real exchange rate. Thus, the policymaker's incentives to distort the terms of trade do not depend on the level of the terms of trade. In the case of higher $\eta$, the bigger is depreciation, the more of output will go abroad. Thus the policymaker has incentives to allow less of a depreciation. Then, the policymaker will try to appreciate, but since it is too costly to do so because of the cost of inflation, real exchange rate ends up higher (more depreciated) than efficient. This implies that output is also higher than efficient. The case of lower $\eta$ is the opposite. Both of these features are illustrated at Figures 5 and 6 for discretion and commitment respectively.

Under $\eta=1$ (note that we have already imposed $\sigma=1$ ), we see in a numerical illustration of the Proposition above that the first-best is achieved under optimal monetary policy. Departing from it leads to deviations from the first-best. Note that even though the sizes of gaps under commitment and discretion are different (as to be expected, under commitment, gaps can be reduced more), the signs of gaps are the same because they are caused by the same terms of trade externality.

Perhaps the most striking feature of these Figures is the small size of all the gaps compared to the $10 \%$ shock. This just reflects the small size of the underlying terms of trade externality. In this sense there is a limited role for the trade elasticity outside of the ZLB in this model. To stress it even further, in Table 2, we present welfare calculations for different trade elasticities under both discretion and commitment. ${ }^{36}$ The welfare numbers are presented in terms of deviations from the

\footnotetext{
${ }^{36}$ These differences in gaps, and welfare, can be slightly bigger if we consider a wider range of values for the trade
} 
steady-state welfare. As is clear, the differences are very small across different values of the trade elasticity. We will revisit this comparison when we consider the ZLB case next.

\subsubsection{In ZLB}

We now move on to the case where a $34 \%$ positive technology shock hits the economy and drives it into a liquidity trap. ${ }^{37}$ In particular, a large positive productivity shock today, which signals a negative productivity growth looking forward, drives the SOE into the zero lower bound. ${ }^{38}$ The economy then slowly transitions out of the ZLB. We first consider when the government can not commit and then move on to the commitment case.

Discretion Under discretion, optimal policy does not feature history dependence, as no endogenous state variables are relevant for the policy problem. ${ }^{39}$ As we will see, this contributes to making outcomes at the ZLB significantly worse compared to commitment. Figure 7 shows the dynamic response of various model variables under optimal monetary policy without commitment at the ZLB. A sufficiently large positive technology shock leads to a binding ZLB and a positive real interest rate gap. That is, the shock is big enough to drive the efficient real interest rate very low, which in turn makes the ZLB bind. Unable to reduce the nominal interest rate further and decrease the real interest rate, the central bank now has to confront a quite positive real interest rate gap. Associated with this, like in a closed-economy, is a negative response of home inflation (that is, deflation). ${ }^{40}$

Both positive real interest rate gap and deflation translate into a negative real exchange rate gap. The fact that policymaker can not decrease interest rates or inflate any further implies no further depreciation as well. As a result, the real exchange rate is more appreciated compared to the efficient level. We elaborate on this further in the next subsection, when we also compare the discretionary real exchange rate equilibrium with the commitment one.

Most importantly perhaps, we see that the trade elasticity $\eta$ affects outcomes at the ZLB in a significant way. In particular, both the real exchange rate gap and deflation are smaller at the ZLB. That is, outcomes in general are better with a higher trade elasticity. To understand this, note that in levels the real exchange rate has depreciated. Then, for a real exchange rate that is depreciated by a given amount, a higher trade elasticity leads to a bigger positive effect on demand

elasticity. Here, we focus on a smaller range to highlight how these gaps will increase more significantly at the ZLB even in this limited range.

${ }^{37}$ This size of a shock ensures that the ZLB binds across all parameter values both under commitment and discretion. While we do not calibrate our model to be consistent with data from SOEs at the ZLB, as that is not the focus of our paper, in the Appendix we present data that shows that SOEs at the ZLB suffered from negative output gaps, deflation, and real exchange rate appreciation pressures.

${ }^{38}$ Svensson (2004) is a pioneering study showing how this shock, as well as a negative preference shock, in a SOE can make the ZLB bind. We consider the preference shock at the end of this subsection.

${ }^{39}$ Again, we show this formally in the appendix.

${ }^{40}$ Note that the output gap is also negative. This as we will show later however, depends on the shock. Moreover, we show consumption in levels to associate the dynamics with the real exchange rate. The consumption gap (not shown for brevity) is also negative. The negative response of the consumption gap does not depend on the shock and is robust. 
of home goods (through expenditure switching) and home inflation (through the Phillips curve). This means that the extent of deflation and real exchange rate gap is smaller.

Overall, elasticity of substitution $\eta$ starts to play a nontrivial role in ZLB. To highlight it, we refer to welfare comparison across $\eta$ 's in Table 2. ${ }^{41}$ The key result here is that the difference in outcomes and in welfare across $\eta$ 's is significantly higher at the ZLB than out of ZLB. This reflects the fact that at the ZLB, the trade elasticity governs not only the terms of trade externality, but also the severity of outcomes through the open economy channel that translates home deflation into real appreciation and back into home deflation through weaker demand for home goods.

Commitment Figure 8 shows the dynamic response of various model variables under optimal monetary policy with commitment at the ZLB for the same technology shock as in discretion case. As in the closed economy, it is clear that outcomes are better under commitment than under discretion, and that there is time-inconsistency problem of optimal commitment policy as the central bank promises future home inflation to mitigate the positive real interest rate gap.

In an open economy, under optimal monetary policy, the discretionary equilibrium features an appreciated real exchange rate compared to both the commitment and the efficient equilibrium, as is evident from a bigger real exchange rate gap under discretion. We call this feature an "appreciation bias" of the central bank under discretion in an open economy. This insight is also available from the Euler equation (18) and (24), which after using (22) and risk sharing condition (23) to substitute for consumption, gives for both shocks

$$
1=\beta E_{t}\left[\frac{1+i_{t}}{\Pi_{H, t+1}}\left(\frac{q\left(\varsigma_{t}\right)^{\eta-1}-\alpha}{q\left(\varsigma_{t+1}\right)^{\eta-1}-\alpha}\right)^{\frac{1}{\eta-1}}\right] .
$$

At the ZLB, the policymaker wants to promise a depreciated future real exchange rate (and an associated higher future home inflation). However, under discretion, such ability is limited, and under exogenous future private-sector expectations, policymaker has no other choice than to suffer from a (relatively) appreciated real exchange rate. Our result here thus formalizes the insight of Svensson (2004) that under commitment, the policymaker in an open economy promises a depreciated exchange rate. Our key point is to compare the real exchange rate paths under discretion and commitment formally in a fully micro-founded model of optimal policy. ${ }^{42}$ Finally, this appreciation

\footnotetext{
${ }^{41} \mathrm{As}$ is a feature of standard business cycle models, welfare variations due to aggregate shocks tend to be small and our case is not an exception. Note also that while we do not show for brevity, welfare under first-best is always higher than either commitment or discretion except for the special case of unit elasticity out of ZLB, where as we proved above, they coincide.

${ }^{42}$ Svensson (2004) discusses in terms of the nominal exchange rate, but the nominal exchange rate is non stationary under discretion in our model as discretionary policy is fully forward looking unlike commitment. Moreover, one cannot look at the real exchange rate in levels in isolation under discretion to infer an "appreciation bias". It might either appreciate or depreciate depending on the trade elasticity and the persistence of the shock, compared to the steady state value of 1 . For instance, consider an iid shock that leads to a binding ZLB for only one period under discretion and the economy then reverts back to the steady-state next period. From (30) we then have an analytical result for the level of the real exchange rate that $\left(\frac{q\left(\varsigma_{t}\right)^{\eta-1}-\alpha}{1-\alpha}\right)^{\frac{1}{\eta-1}}=\frac{1}{\beta}$. Under unit trade elasticity, this gives $q\left(\varsigma_{t}\right)=\beta^{\alpha-1}$, which means that the real exchange rate in levels depreciates at the ZLB.
} 


\begin{tabular}{ccccc}
\hline \multicolumn{5}{c}{ Welfare (deviation from the steady state, \% points) } \\
$\eta$ & $\begin{array}{c}\text { Out of ZLB } \\
\text { Commitment }\end{array}$ & Discretion & Commitment & Discretion \\
\hline \hline 0.7 & 6.51910 & 6.51893 & 20.73034 & 20.49780 \\
1 & 6.54397 & 6.54397 & 20.98324 & 20.95594 \\
1.3 & 6.56188 & 6.56171 & 21.16198 & 21.15034 \\
\hline
\end{tabular}

Table 2: Welfare under optimal monetary policy for the technology shock

bias could be viewed as also a reflection of the closed economy "deflation bias" through the Phillips curve as a real appreciation drives down demand for home goods and thus firms lower their prices. ${ }^{43}$

Next, like under discretion, it is also the case that the trade elasticity matters more for outcomes at the ZLB compared to out of ZLB. We formalize this explicitly in terms of welfare as before in Table 2. ${ }^{44}$ Note that differences in welfare across different values of eta at the ZLB compared to out of ZLB are of a bigger order of magnitude than the difference in size of the shock in these two cases.

Finally, the outcomes under commitment reveal another mechanism through which the trade elasticity affects equilibrium. The closed-economy literature has highlighted that a distinct way in which commitment and discretion outcomes are different is the manner in which inflation overshoots the long-run level under optimal commitment policy. We see here the same dynamics whereby the policymaker also promises higher future (producer price) inflation for several periods, compared to discretion, which then after a period of overshooting, goes back to the steady state. A distinct aspect of the open economy environment is that the extent of the increase in future home inflation compared to current, which we refer to as the future promised "policy slope," drastically depends on the trade elasticity. Higher $\eta$ means lower "policy slope", that is, a smaller difference between current equilibrium inflation and future promised inflation. We elaborate more on this in the next subsection when we also discuss the preference shock as this result is common to both shocks.

\subsubsection{Preference shock}

Now we consider negative preference shock under optimal monetary policy, with and without commitment, out of and in ZLB. This shock signals an increased desire to save and reduce current consumption. The main goal here is to see which of our insights are robust to the source of the shock. ${ }^{45}$ Out of ZLB, the results are largely the same as for the technology shock except that first

\footnotetext{
${ }^{43}$ It is thus related to the closed economy deflation bias of discretionary policy studied in Eggertsson (2006). Finally, comparing commitment with discretion, the duration of ZLB can be higher or lower depending on the trade elasticity. The main reason is that unlike in a simple closed economy model, the path of interest rate out of ZLB does not coincide under commitment and discretion as there are policy trade-offs.

${ }^{44}$ Note that while utility function depends on $\eta$ through our calibration of $\lambda$ (as we make the steady state level of output equal to one across all parameters by using different values of $\lambda$ ), this welfare is nonetheless comparable in consumption units across different values of $\eta$ as steady state consumption is equal to one for all $\eta$ 's. As utility from consumption only, $u(C, \xi)$, is the same across different parameter values, we can convert this number back to welfare units.

${ }^{45}$ Note here that a discount factor shock in an open economy operates in another margin that is not present in the closed economy by perturbing the risk-sharing condition that equates the ratio of marginal utilities of consumption
} 
best is not achieved even under $\sigma=\eta=1$ (as would be the case in a closed economy). The main insight is that difference in outcomes under different values of $\eta$ is small as it represents terms of trade externality. For this reason we omit the corresponding figures but welfare results are available in Table 4 at the end, which shows the robustness of our results across both shocks. ${ }^{46}$

Figures 9 and 10 show dynamic response of various model variables to a negative $40 \%$ preference shock under discretion and commitment respectively. When domestic consumers become more patient and demand less of home goods, it naturally leads to a decrease in the real interest rate, which cannot happen sufficiently enough with a binding ZLB. First, the appreciation bias under preference shock is even greater than under technology shock, as discretion leads to appreciation of the real exchange rate in levels while commitment leads to depreciation in levels. This happens despite the fact that when domestic consumers become more patient and demand less of home goods, the real exchange rate naturally tends to depreciate.

Because of the dominant effect of the appreciation bias, unlike for the technology shock case, outcomes are generally worse under higher $\eta \cdot{ }^{47}$ The reason is straightforward. Now, for any given amount of appreciation, higher $\eta$ means smaller demand for home goods and thereby, higher deflation and a bigger real exchange rate gap. Thus, note that even though with different values of trade elasticity outcomes could be generally better or worse depending on source of the shock, trade elasticity continues to play a significant role at the ZLB. Table 4 at the end illustrates this in terms of welfare again at the ZLB for the preference shock. This, as we have emphasized before, constitutes one of the main result of our paper.

Second, our "policy slope" result is also robust to the source of the shock. That is, even when higher $\eta$ means worse outcomes, the "policy slope" of promised home inflation is still lower. This is striking as one might expect the central bank to promise even more of future inflation when the fall in inflation is higher under discretion (when no credible promises can be made). What is the intuition for the dependence of the difference between future and current inflation on the trade elasticity, regardless of source of the shock (and thus the level of initial decline under discretion)? The main economic reason is that under commitment, the policymaker promises future higher home inflation, which implies future real depreciation (not necessarily in levels as we have emphasized but in gaps). The extent to which future depreciation translates into better future outcomes like higher future inflation depends crucially on $\eta$. Thus, with a higher trade elasticity, the policymaker under commitment needs to promise less, compared to today, of future home inflation. This is because any given change of future exchange rate implies a bigger change in future inflation under higher $\eta$. This is the reason why the future "policy slope" is lower under higher trade elasticity.

in the two countries with the real exchange rate.

${ }^{46}$ The figures are available on request.

${ }^{47}$ Note also that unlike for the technology shock, here the output gap is positive. At the same time, while we show the level of consumption to ascertain the effects of the shock, the consumption gap is negative even for the preference shock. Thus for both shocks, at the ZLB, the consumption gap is negative even when this is not necessarily the case for the output gap. The wedge between consumption and output in an open economy, as well as the preference shock perturbing the risk-sharing condition, creates differences between the two shocks compared to the closed economy. The preference shock, which leads to an increase in desired savings, gets reflected in an open economy in terms of increased saving abroad as can be seen visually by the rise in net exports in Figure 9 . 
This is the second main result of this paper.

\subsection{Optimal monetary and fiscal policy}

We now move on to considering joint conduct of optimal monetary and fiscal policy. The policy instruments of the government are now the short-term nominal interest rate and the level of public spending. ${ }^{48}$ As given in Table 1, we choose the steady-state government spending-to-output ratio, $\theta_{G}$, of 0.2 . The scale parameter in the utility function, $\lambda_{G}$, is then chosen so that the steady-state of the model is consistent with this choice. Once again, first we will consider the technology shock, and in the last subsection we will discuss robustness under the preference shock.

\subsubsection{Out of ZLB}

We start with the case where a positive $10 \%$ technology shock hits the economy and this shock is not big enough to drive the economy into a liquidity trap. Even out of ZLB, our independent contribution is to analyze how government spending responds optimally since this case has not been considered in the literature. Figures 11 and 12 show the dynamic response of various model variables under optimal monetary and fiscal policy with and without commitment at different values of $\eta{ }^{49}$

As was the case with monetary policy only, the behavior of all variables is still driven by the terms of trade externality and thus does not differ much from that in the previous subsection. However, it is useful to note that even though under $\sigma \eta=1$ the ratio of home and foreign demand

for home goods $\frac{C_{H, t}}{C_{H, t}^{*}}$ from (29) is constant, the same ratio for government demand $\frac{G_{H, t}}{G_{H, t}^{*}}$ is not. The reason is that not all of domestic consumption, but rather only the private consumption part, is subject to complete risk sharing. Therefore, the same changes in the real exchange rate lead to different income effects in private and public consumption. As a result, there is still some terms of trade externality left to exploit in the government spending bundle. Thus the first-best is achieved only when the economy is isomorphic to a closed one, that is, under $\sigma=\eta=1$. We formalize this claim in the following proposition.

Proposition 3 Under log-utility and unit elasticity of substitution between domestic and foreign goods $(\sigma=\eta=1)$, at positive interest rates and with technology shocks, optimal monetary and fiscal policy with or without commitment achieves the efficient outcome by setting home-inflation, output gap, and government spending gap to zero.

Proof. In appendix.

Outside of this isomorphic case, the government optimally chooses government spending to deviate from the first-best level in order to manipulate the terms of trade. With monetary policy

\footnotetext{
${ }^{48}$ As discussed before, we consider only the optimal level of utility-yielding government spending as a tool of policy with lump-sum taxation available. As we will see, this already improves outcomes significantly, but in future work, it will be of interest to consider an expanded set of tax instruments as in the non-linear closed economy model of Correia et al (2013).

${ }^{49}$ Note that we scale the fiscal variables as a ratio of output.
} 
unable to achieve the first-best, fiscal policy thus has an additional role to play even at positive interest rates. As before, however, we stress the small role played by trade elasticity out of ZLB with welfare calculations in Table 3 below.

\subsubsection{In ZLB}

We now move on to the case where a large $34 \%$ positive technology shock hits the economy and drives the economy into a liquidity trap. We again first consider discretion and then move on to commitment.

Discretion Figure 13 shows the dynamic response of various model variables under optimal monetary policy without commitment at the ZLB for the technology shock. As is the case in a closed economy, optimal fiscal policy entails counter cyclical government spending. Because of the expansionary fiscal policy, outcomes in general become better. The drop in home inflation is less severe and the real exchange rate gap is less negative.

Our main contribution here comes from the fact that since there is a current policy instrument available under discretion, we can evaluate how policy choices themselves depend on trade elasticity. Before, under only optimal monetary policy without commitment, we could only evaluate equilibrium outcomes but not policy choices. Since all outcomes get better with fiscal policy, differences in outcomes across different values of $\eta$ get smaller. However, crucially, the extent of fiscal expansion itself depends on trade elasticity significantly. This finding constitutes an important component of one of our main overall results that policy prescriptions at the ZLB depend crucially on the trade elasticity. The intuition is straightforward. Without government spending, smaller $\eta$ led to worse outcomes as for a given amount of depreciation, the demand for home goods was weaker. Now the government can boost this demand by increasing its spending. Essentially, optimal fiscal policy can alleviate bad consequences of a smaller trade elasticity and the weak demand associated with it by increasing demand directly. Thus fiscal policy actions themselves depend critically on trade elasticity, even as the equilibrium outcomes appear not to depend on $\eta$ much.

As a secondary related result, note that by comparing Figure 13 with Figure 11 it is clear that a positive government spending gap constitutes optimal policy even when without the ZLB, government spending would decrease relative to the efficient level (such as when the trade elasticity is bigger than one). This result cannot be appreciated in the standard closed economy model as in that case, out of the ZLB, government spending does not deviate from the efficient level at all. Thus in an open economy, at the ZLB compared to out of ZLB, the incentives for the policymaker to increase government spending beyond the first-best level is particularly high. ${ }^{50}$ This is also another illustration of the theme that while there is terms of trade externality at positive interest rate in the model, it remains small. That is, this effect at positive interest rates leads to a role for a government spending gap, which sometimes might involve decreasing government spending

\footnotetext{
${ }^{50}$ So for instance, even for a big shock, as long as the ZLB does not bind, for a trade elasticity bigger than 1 , government spending gap is negative. As soon as the ZLB binds however, the government spending gap switches to positive. This is a qualitative difference.
} 
from the efficient level. This effect is small though and thus, the incentives to the government at the ZLB to increase government spending in order to boost home inflation and depreciate the real exchange rate overpower the existing term of trade manipulation incentives.

Commitment Figure 14 shows the dynamic response of various model variables under optimal monetary and fiscal policy with commitment at the ZLB. Optimal fiscal policy entails a path such that the current government spending gap is higher than the future gap. This is qualitatively similar to the closed economy literature. ${ }^{51}$ This involves, in this parameterization and shock, a positive government spending gap today followed by a negative government spending gap in future. Moreover, as in the discretion case, fiscal policy has a much more pronounced role at lower $\eta$, that is, precisely in the situation with worse outcomes in the model with only monetary policy.

More importantly, the result that the "policy slope" is smaller with higher trade elasticity turns out to be robust not only to source of the shock as we showed above for the case of monetary policy only, but also to a particular policy. Whether it's home inflation or government spending gap, the amount of future inflation (fiscal contraction) relative to current deflation (fiscal expansion) is smaller with higher trade elasticity. Again, intuition is based on the idea that higher trade elasticity translates into higher responsiveness of the economy to changes in real exchange rate that will necessarily accompany any optimal policy. This implies then that the government can achieve desired outcomes with smaller changes in actual policy. This is a major channel through which optimal policy in a SOE differs from policy in a closed economy.

We end this section with a welfare analysis. In Table 3 we present welfare calculations for different trade elasticities under both discretion and commitment for the case of technology shock. ${ }^{52}$ First, even though the difference in welfare across various values of the trade elasticity is not much higher at the ZLB than out of ZLB, there is still substantial difference in outcomes as is evident from Figure 13 and 14. The main insight then is that trade elasticity doesn't matter for welfare much only when it significantly matters for policy outcomes. Second, comparing across commitment and discretion for a given trade elasticity, we see that the differences now are smaller than when we for optimal monetary policy only. This implies that when we give an additional policy instrument to the government under discretion, outcomes are better and the government is able to negotiate the differential effects of the trade elasticity much better using government spending.

\subsubsection{Preference shock}

We conclude again with a robustness analysis of optimal policy under a preference shock. Once again we will omit Figures for out of ZLB as there are no additional insights. ${ }^{53}$ For the ZLB case, Figures 15 and 16 show dynamic response of various variables to the negative $40 \%$ preference shock under

\footnotetext{
${ }^{51}$ This response is optimal because by having a (relatively) higher government spending initially, and then promising to decrease it in future once the economy has recovered, the government is able to reduce the real interest rate gap during the liquidity trap. This then improves outcomes at the ZLB with respect to negative output gap, deflation, and the real exchange rate gap.

${ }^{52}$ The same comment applies to this welfare computation as in footnote for Table 2 .

${ }^{53}$ They are available upon request.
} 


\begin{tabular}{|c|c|c|c|c|}
\hline \multicolumn{5}{|c|}{ Welfare (deviation from the steady state, $\%$ points) } \\
\hline \multirow[b]{2}{*}{$\eta$} & \multicolumn{2}{|c|}{ Out of ZLB } & \multicolumn{2}{|c|}{ At the ZLB } \\
\hline & Commitment & Discretion & Commitment & Discretion \\
\hline 0.7 & 2.27355 & 2.27350 & 070 & 7.22369 \\
\hline 1 & 2.06920 & 2.06920 & 6.63494 & 6.63333 \\
\hline 1.3 & 1.90829 & 1.90823 & 6.15433 & 6.15274 \\
\hline
\end{tabular}

Table 3: Welfare under optimal monetary and fiscal policy for the technology shock

discretion and commitment respectively. Optimal policy under discretion features strong increase in spending, with fiscal expansion again generally bigger when outcomes without fiscal policy are worse (higher trade elasticity for this shock). Under commitment, it is sometimes the case that the current government spending gap is negative. Still, the robust prediction of the model is that government spending gap is higher currently compared to the future. For completeness, Table 4 at the end shows the corresponding welfare results, both for out of and in ZLB.

Finally, we see that the promised "policy slope" result for government spending is also robust to the preference shock. Thus, combining the results from optimal monetary policy and optimal monetary and fiscal policy under commitment, we have a succinct result unique to a SOE: the extent of future promises of (increases in) home inflation and (decreases in) government spending compared to initial levels decreases with higher trade elasticity.

\section{Conclusion}

In this paper, we investigate the open economy dimensions of optimal monetary and fiscal policy at the ZLB, both with and without commitment on the part of the government. We use a general small open economy (SOE) model and derive new insights that are novel to an open economy environment. We obtain results by focusing on the equilibrium dynamics of the real exchange rate and the role of a key open economy parameter, the trade elasticity, in driving equilibrium outcomes, policy prescriptions, and welfare. A major feature of the SOE at the ZLB is that the discretionary equilibrium suffers from an appreciated real exchange rate compared to both the commitment and the efficient equilibrium. In addition, we find that both equilibrium outcomes and welfare depend on the trade elasticity at the zero lower bound, even when at positive interest rates, their dependence is quite small. In addition, the trade elasticity also critically governs the optimal use of the policy instrument at the ZLB, such as the extent of optimal discretionary increase in government spending.

In future work, we can extend our work in both theoretical and quantitative directions. For example, we have considered a model where there is perfect risk-sharing between the SOE and the rest of the world. Relaxing this assumption by considering incomplete markets would provide an additional role for the real exchange rate and trade imbalances in driving optimal policy decisions. Finally, to evaluate more thoroughly the quantitative predictions, we can consider a set-up that features pricing to market/local currency pricing as it is an important feature of the data. ${ }^{54}$

\footnotetext{
${ }^{54}$ We can build on the work of Benigno (2009) who considers a two-country monetary model with incomplete
} 


\section{References}

[1] Adam, Klaus, and Roberto Billi (2006), "Optimal Monetary Policy under Commitment with a Zero Bound on Nominal Interest Rates," Journal of Money, Credit, and Banking, 38, 18771905.

[2] Adam, Klaus, and Roberto Billi (2007), "Discretionary Monetary Policy and the Zero Lower Bound on Nominal Interest Rates," Journal of Monetary Economics, 54, 728-752.

[3] Benigno, Gianluca, and Pierpaolo Benigno (2003), "Price Stability in Open Economies," Review of Economic Studies, 70, 743-764.

[4] Benigno, Pierpaolo (2009), "Price Stability with Imperfect Financial Integration," Journal of Money, Credit, and Banking, 41, 121-149.

[5] Cook, David, and Michael B. Devereux (2013), "Sharing the Burden: Monetary and Fiscal Responses to a World Liquidity Trap," American Economic Journal: Macroeconomics, 5, 190228.

[6] Correia, Isabel, Emmanuel Farhi, Juan Pablo Nicolini, and Pedro Teles (2013), "Unconventional Fiscal Policy at the Zero Bound," American Economic Review, 103, 1172-1211.

[7] Christiano, Lawrence, Martin Eichenbaum, and Sergio Rebelo (2011), "When Is the Government Spending Multiplier Large?" Journal of Political Economy, 119, 78-121.

[8] De Paoli, Bianca (2009), "Monetary Policy and Welfare in a Small Open Economy," Journal of International Economics, 77, 11-22.

[9] Eggertsson, Gauti B. (2001), "Real Government Spending in a Liquidity Trap," working paper.

[10] Eggertsson, Gauti B. (2006), "The Deflation Bias and Committing to Being Irresponsible," Journal of Money, Credit, and Banking, 38, 283-321.

[11] Eggertsson, Gauti B. (2011), "What Fiscal Policy is Effective at Zero Interest Rates," NBER Macroeconomics Annual, 25, 59-112.

[12] Eggertsson, Gauti B., and Michael Woodford (2003), "The Zero Bound on Interest Rates and Optimal Monetary Policy," Brookings Papers on Economic Activity, 34, 139-235.

[13] Engel, Charles (2011), "Currency Misalignments and Optimal Monetary Policy: A Reexamination," American Economic Review, 101, 2796-2822.

financial integration and of Engel (2009) who considers a two-country model with local currency pricing. Both these extensions will require a significant computational innovation to solve the discretionary equilibrium as several policy relevant state variables such as net foreign asset positions and law of one price deviations are likely to be introduced to the model. 
[14] Erceg, Christopher, and Jesper Linde (2014), "Is There a Fiscal Free Lunch in a Liquidity Trap," Journal of European Economic Association, 12, 73-107.

[15] Faia, Ester, and Tommaso Monacelli (2008), "Optimal Monetary Policy in a Small Open Economy with Home Bias," Journal of Money, Credit, and Banking, 40, 721-750.

[16] Farhi, Emmanuel, and Ivan Werning (2013), "Dealing with the Trilemma: Optimal Capital Controls with Fixed Exchange Rates," working paper.

[17] Fujiwara, Ippei, Tomoyuki Nakajima, Nao Sudo, and Yuki Teranishi (2013), "Global Liquidity Trap," Journal of Monetary Economics, 60, 936-949.

[18] Gali, Jordi, and Tommaso Monacelli (2005), "Monetary Policy and Exchange Rate Volatility in a Small Open Economy," Review of Economic Studies, 72, 707-734.

[19] Heathcote, Jonathan, and Fabrizio Perri (2002), "Financial Autarky and International Business Cycles," Journal of Monetary Economics, 49, 601-627.

[20] Jeanne, Olivier (2009), "Global Liquidity Trap," working paper.

[21] Jeanne, Olivier, and Lars E. O. Svensson (2007), "Credible Commitment to Optimal Escape From a Liquidity Trap: The Role of the Balance Sheet of an Independent Central Bank," American Economic Review, 97, 474-490.

[22] Jung, Taehun, Yuki Teranishi, and Tsutomu Watanabe (2005), "Optimal Monetary Policy at the Zero-Interest-Rate Bound," Journal of Money, Credit, and Banking, 37, 813-835.

[23] Khan, Aubhik, Robert G. King, and Alexander L. Wolman (2003), "Optimal Monetary Policy," Review of Economic Studies, 70, 825-860.

[24] Lubik, Thomas, and Frank Schorfheide (2005), "A Bayesian Look at the New Open Economy Macroeconomics," NBER Macroeconomics Annual, 20, 313-382.

[25] Obstfeld, Maurice, and Kenneth Rogoff (2000), "The Six Major Puzzles in International Macroeconomics: Is There a Common Cause?" NBER Macroeconomics Annual, 15, 339-412.

[26] Svensson, Lars E. O. (2003), "Escaping from a Liquidity Trap and Deflation: The Foolproof Way and Others," Journal of Economic Perspectives, 17, 145-166.

[27] Svensson, Lars E. O. (2004), "The Magic of the Exchange Rate: Optimal Escape from a Liquidity Trap in Small and Large Open Economies," working paper.

[28] Werning, Ivan (2013), "Managing a Liquidity Trap: Monetary and Fiscal Policy," working paper.

[29] Woodford, Michael (2011), "Simple Analytics of the Government Expenditure Multiplier," American Economic Journal: Macroeconomics, 3, 1-35. 


\section{Tables and Figures}

\begin{tabular}{ccccccccc}
\hline & \multicolumn{4}{c}{ Welfare (deviation from the steady state, \% points) } \\
\multicolumn{4}{c}{ Monetary policy } & \multicolumn{4}{c}{ Monetary and fiscal policy } \\
$\eta$ & Out of ZLB & At the ZLB & Out of ZLB & At the ZLB \\
& C & D & C & D & C & D & C & D \\
\hline \hline 0.7 & -3.2415 & -3.2435 & -11.6324 & -21.9856 & -0.0351 & -0.0363 & 0.3394 & -1.2138 \\
1 & -5.4075 & -5.4141 & -19.5223 & -33.7149 & -0.5598 & -0.5631 & -1.5609 & -4.2184 \\
1.3 & -7.4320 & -7.4453 & -26.8926 & -47.4619 & -0.9686 & -0.9744 & -3.0379 & -7.2196 \\
\hline
\end{tabular}

Table 4: Welfare under optimal commitment (C) and discretionary (D) policy for preference shock

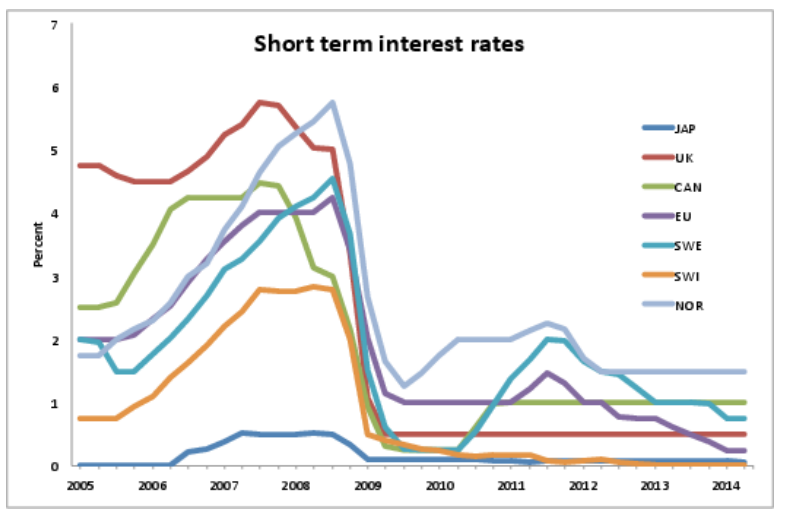

Figure 1: Interest rate of small open economies
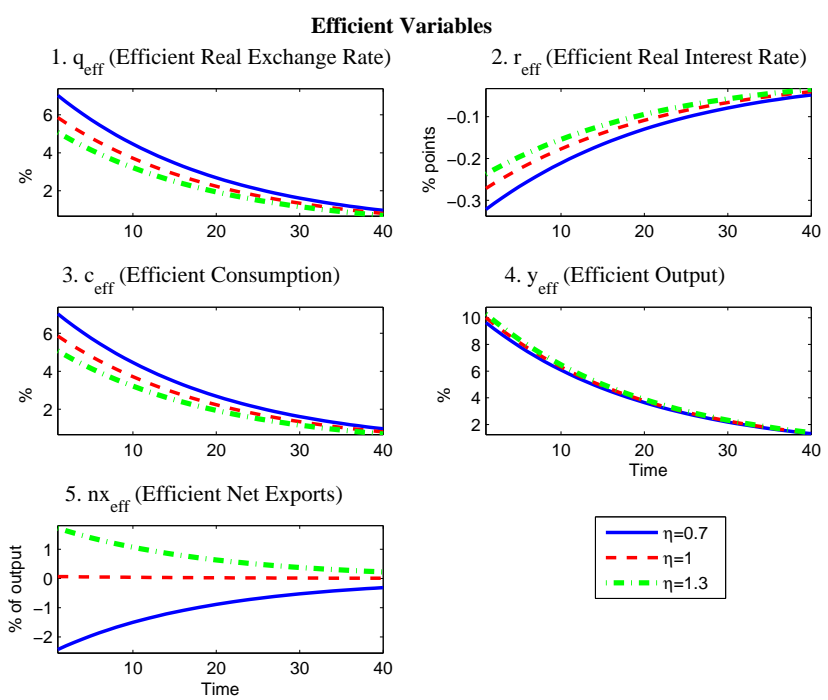

Figure 2: Response of model variables to the technology shock in the first-best equilibrium without fiscal policy 

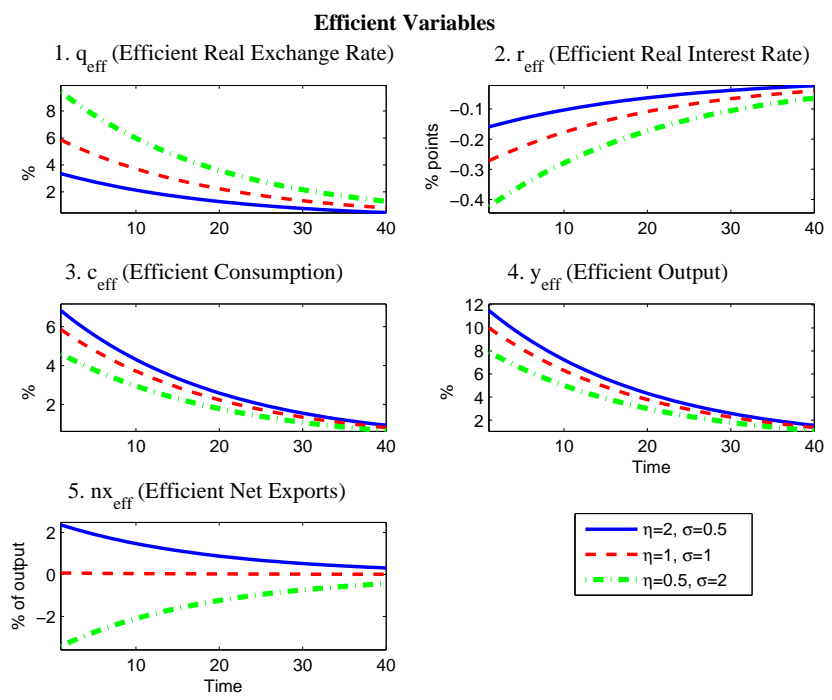

$$
\begin{aligned}
& \eta=2, \sigma=0.5 \\
& --\eta=1, \sigma=1 \\
& -\eta=0.5, \sigma=2
\end{aligned}
$$

Figure 3: Response of model variables to the technology shock in the first-best equilibrium without fiscal policy for various values of $\sigma$ and $\eta$
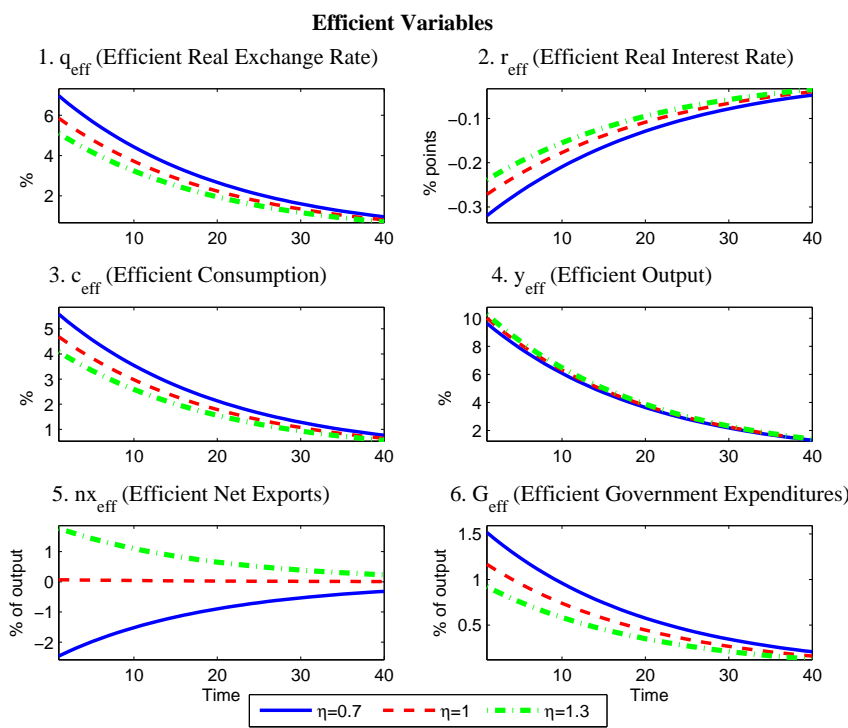

Figure 4: Response of model variables to the technology shock in the first-best equilibrium with fiscal policy 
Panel A: Conventional Variables

1. i (Nominal Interest Rate, in levels)

2. $\Pi_{\mathrm{H}}($ Home Inflation $)$
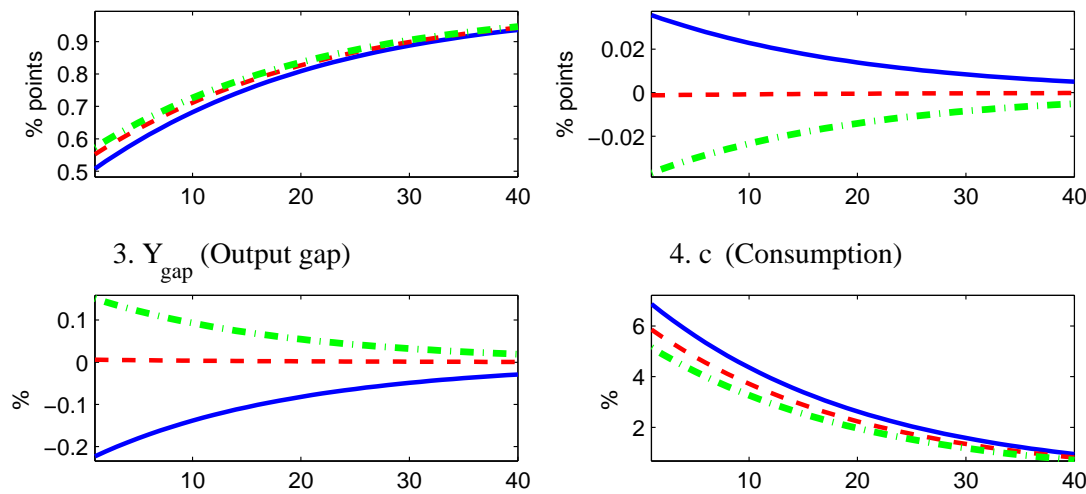

4. c (Consumption)

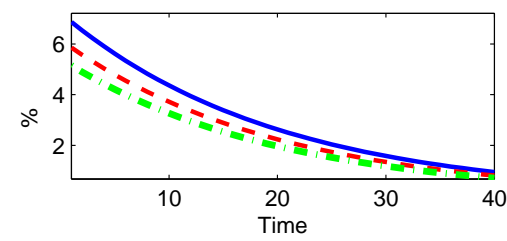

5. r råap $_{10}($ Real Interest Rate Gap)
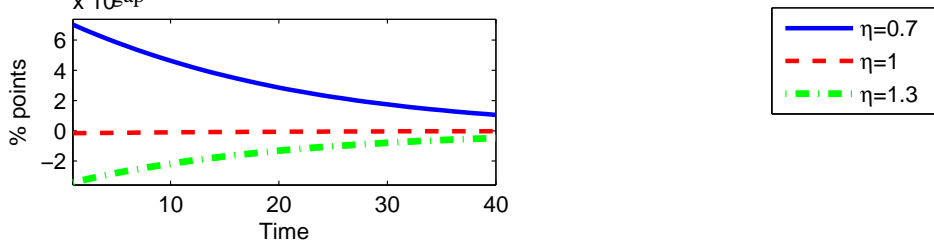

Panel B: Open Economy Variables

1. q (Real Exchange Rate)
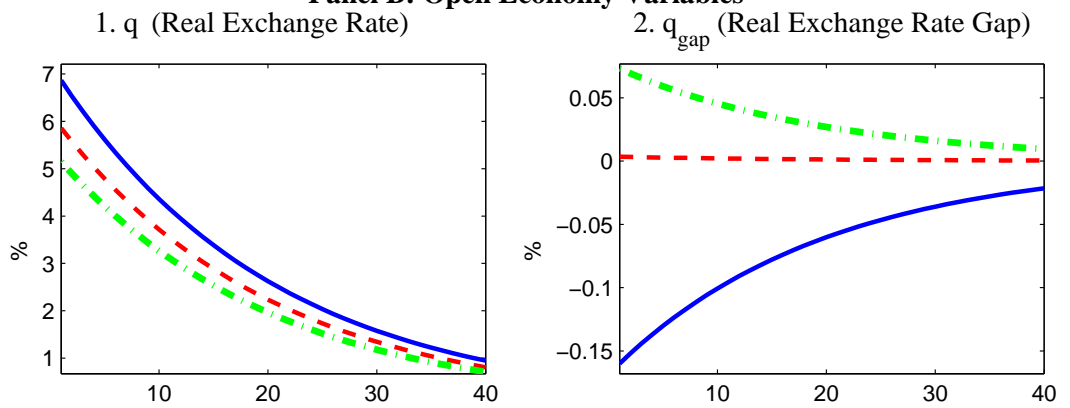

3. $\mathrm{nx}$ (Net Exports)

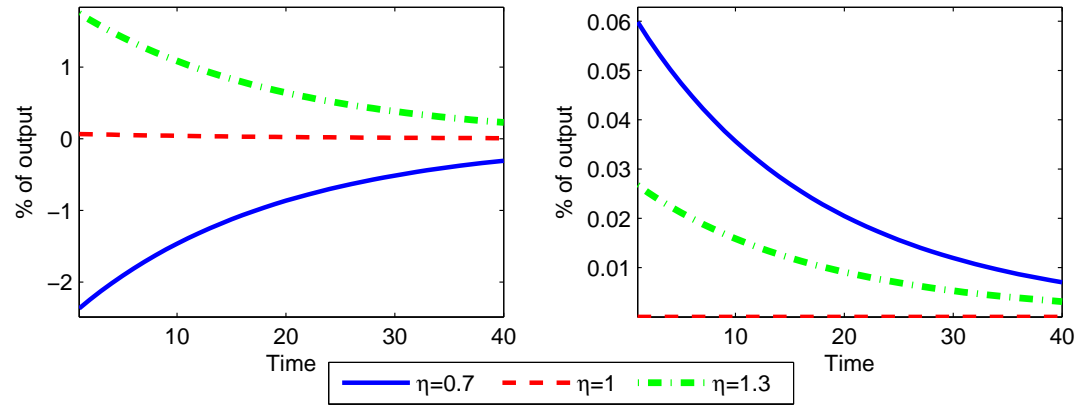

Figure 5: Response of model variables to the technology shock under optimal monetary policy without commitment out of ZLB 
Panel A: Conventional Variables

1. i (Nominal Interest Rate, in levels)

2. $\Pi_{H}$ (Home Inflation)
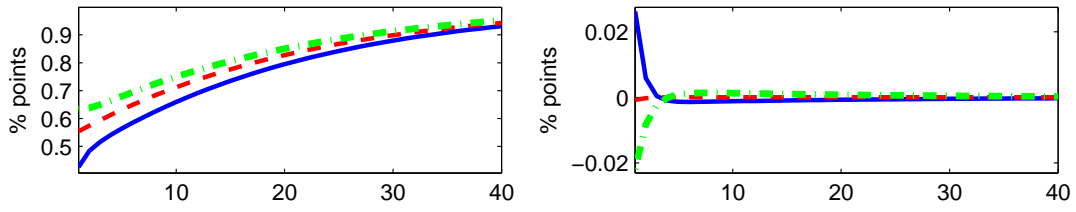

3. $\mathrm{Y}_{\text {gap }}$ (Output gap)

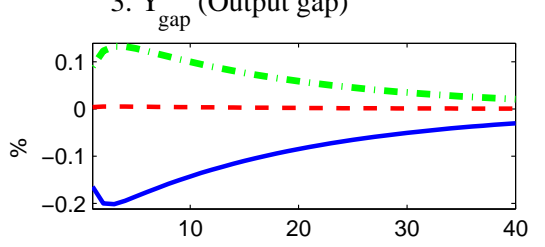

4. c (Consumption)

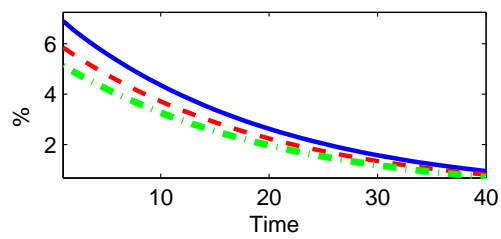

5. $r_{\text {gap }}$ (Real Interest Rate Gap)

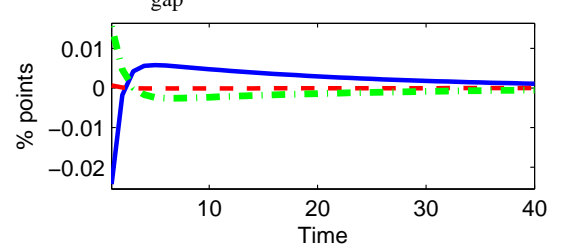

$\eta=0.7$

$\eta=\eta=1.3$

Panel B: Open Economy Variables

1. q (Real Exchange Rate)
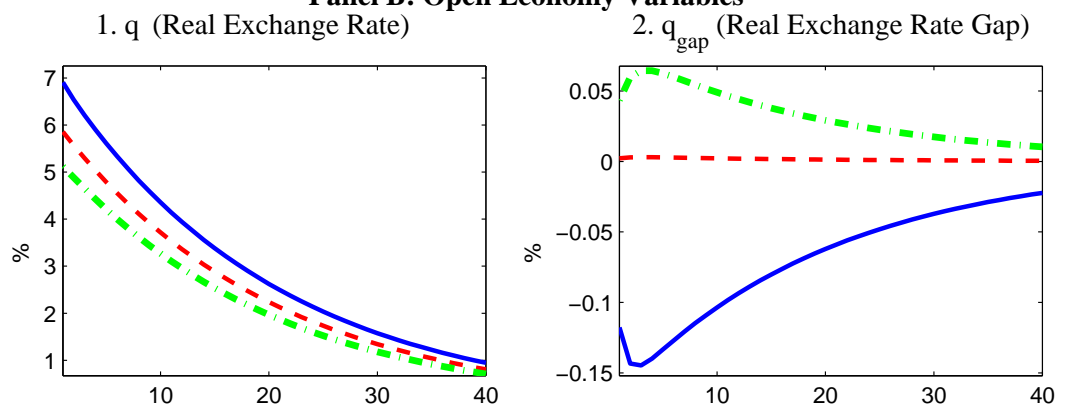

3. $\mathrm{nx}$ (Net Exports)

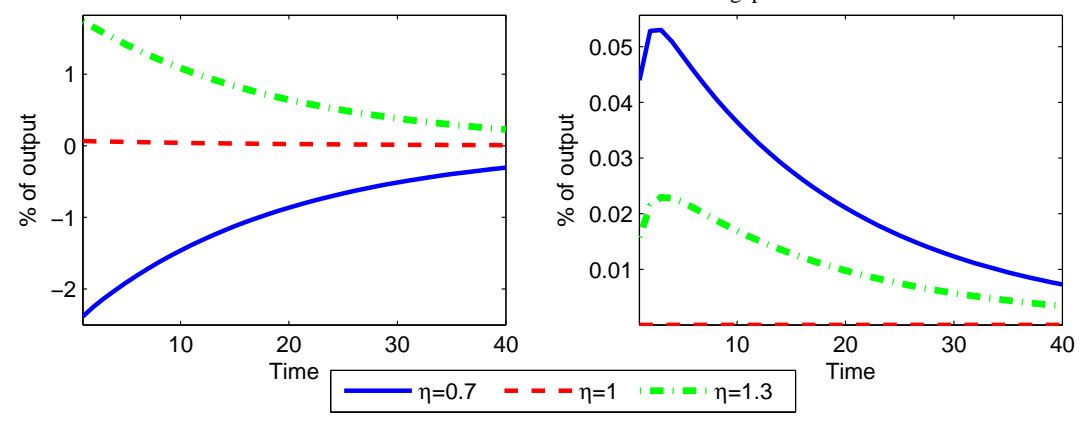

Figure 6: Response of model variables to the technology shock under optimal monetary policy with commitment out of ZLB 
Panel A: Conventional Variables

1. i (Nominal Interest Rate, in levels)
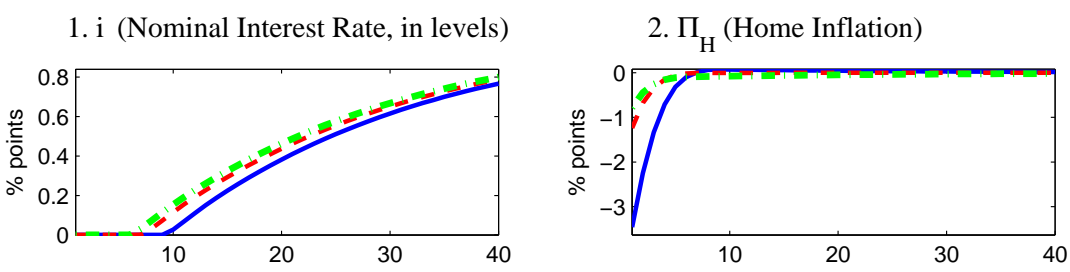

3. $\mathrm{Y}_{\text {gap }}$ (Output gap)

4. c (Consumption)
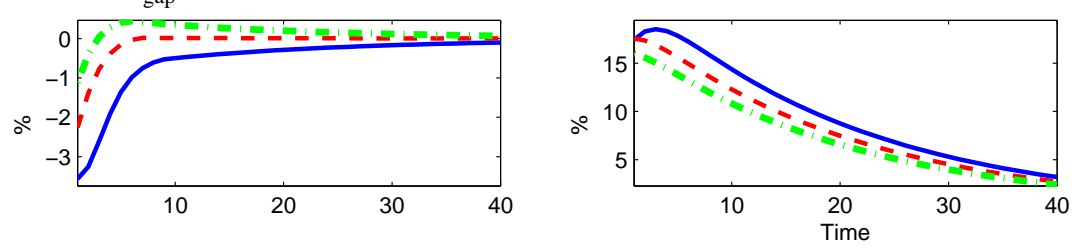

5. $\mathrm{r}_{\text {gap }}$ (Real Interest Rate Gap)

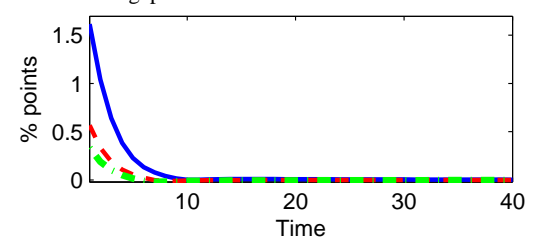

$$
\begin{aligned}
& -\eta=0.7 \\
& ---\eta=1 \\
& -\eta=1.3
\end{aligned}
$$

Panel B: Open Economy Variables
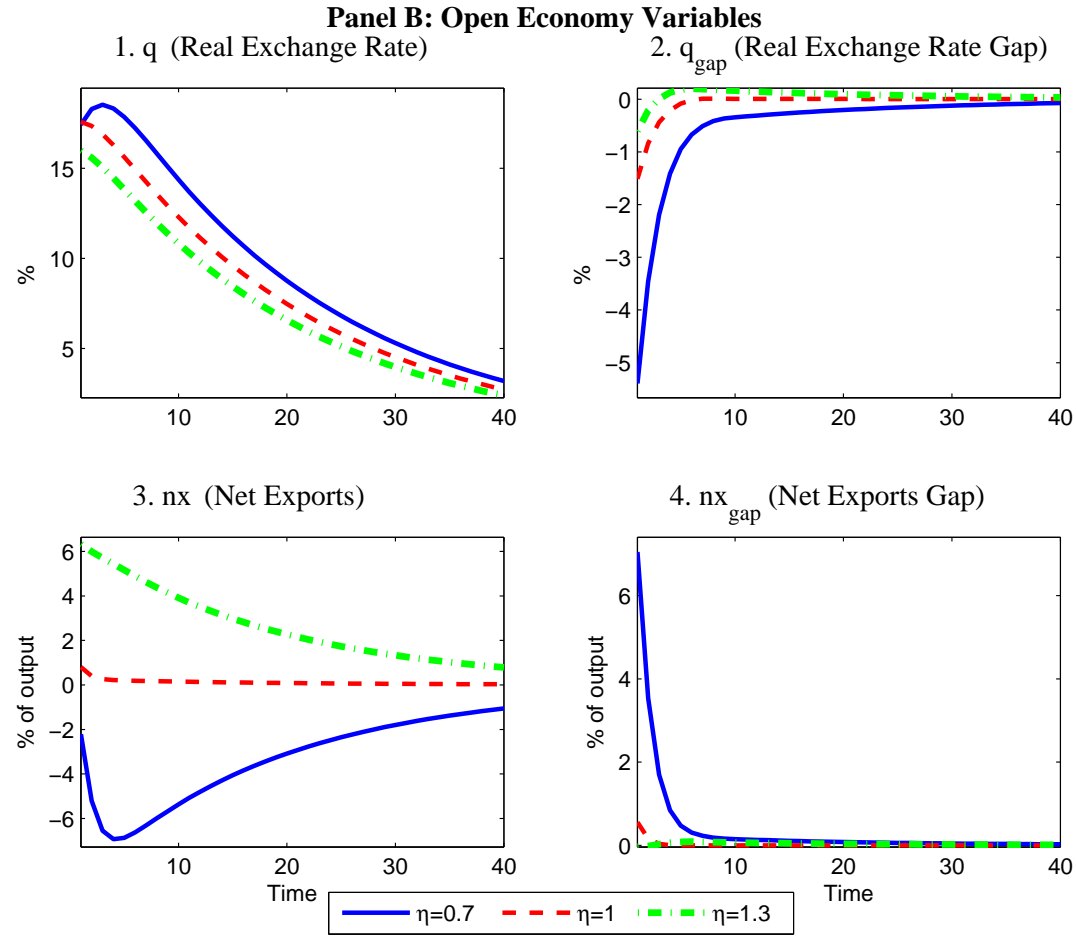

Figure 7: Response of model variables to the technology shock under optimal monetary policy without commitment at the ZLB 
Panel A: Conventional Variables

1. i (Nominal Interest Rate, in levels)

2. $\Pi_{\mathrm{H}}($ Home Inflation $)$
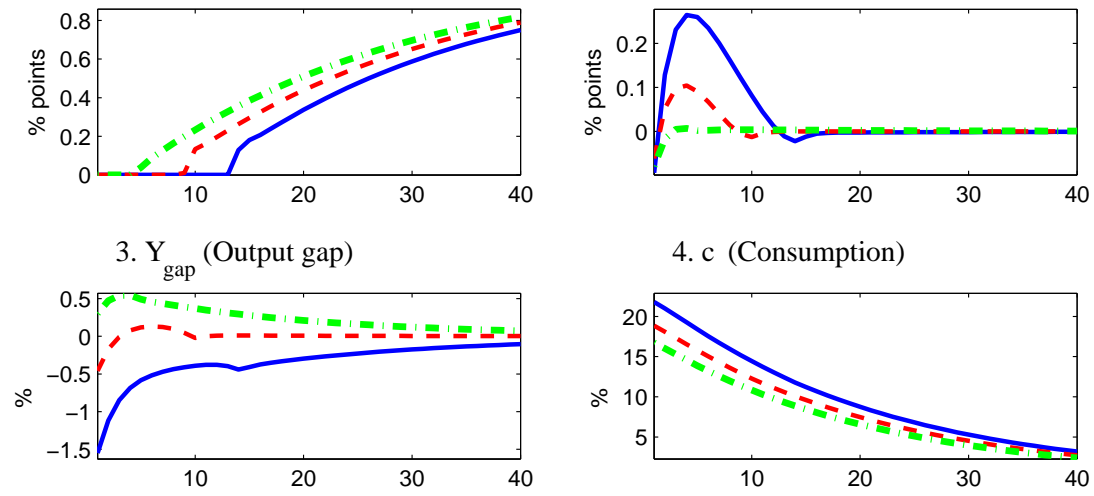

4. c (Consumption)

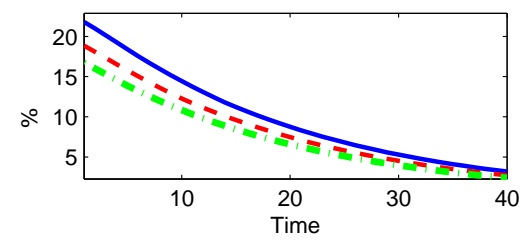

5. $r_{\text {gap }}$ (Real Interest Rate Gap)

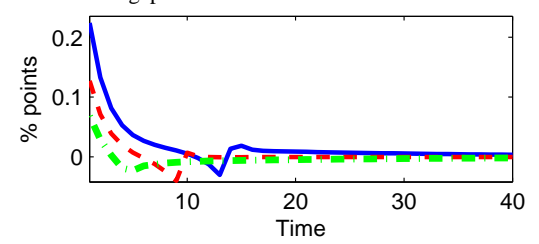

$$
\begin{aligned}
& -\eta=0.7 \\
& ---\eta=1 \\
& -\eta=1.3
\end{aligned}
$$

Panel B: Open Economy Variables
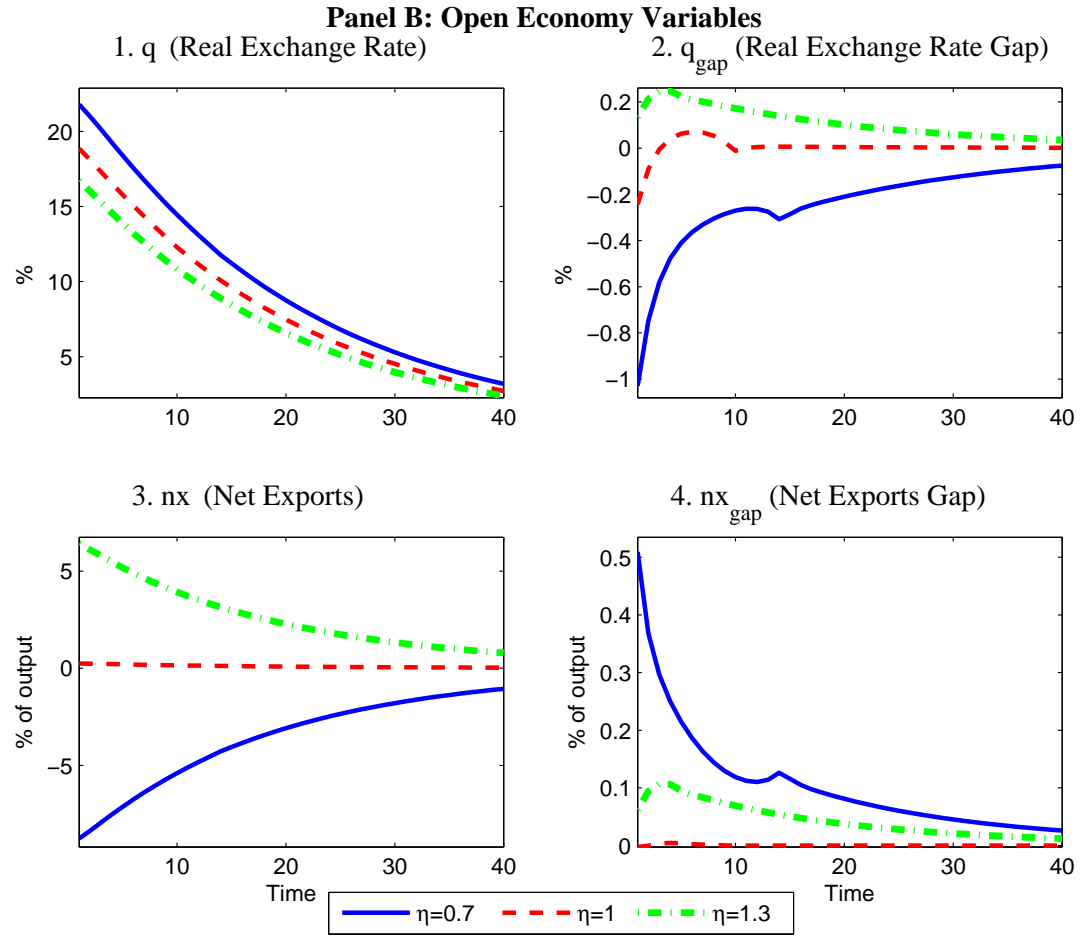

Figure 8: Response of model variables to the technology shock under optimal monetary policy with commitment at the ZLB 
Panel A: Conventional Variables

1. i (Nominal Interest Rate, in levels)
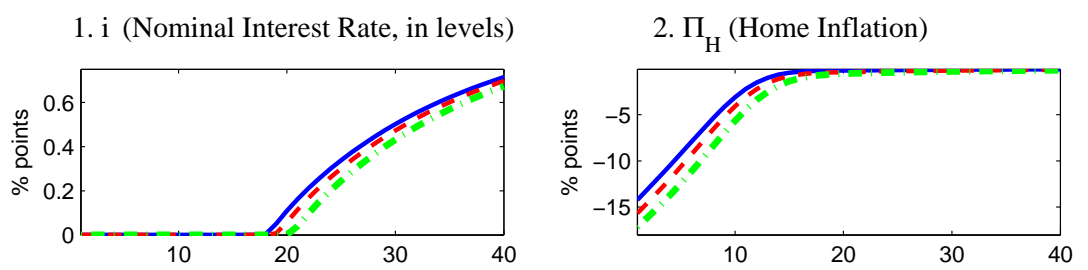

3. $\mathrm{Y}_{\text {gap }}$ (Output gap)

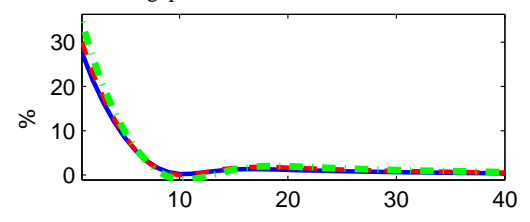

4. c (Consumption)

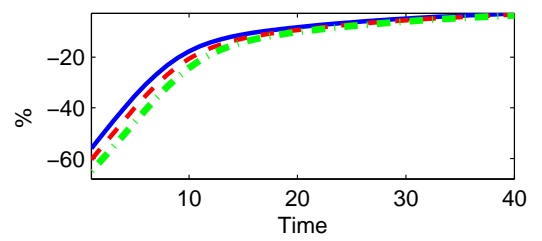

5. $\mathrm{r}_{\text {gap }}$ (Real Interest Rate Gap)
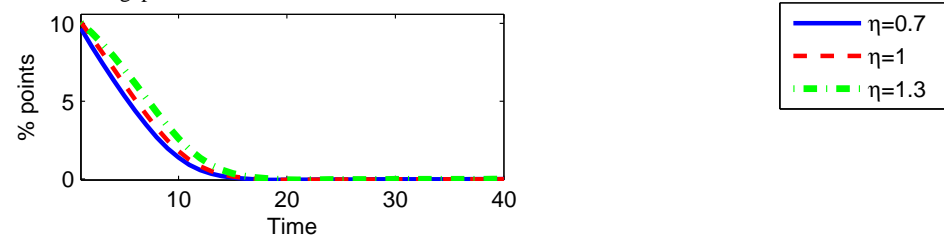

Panel B: Open Economy Variables
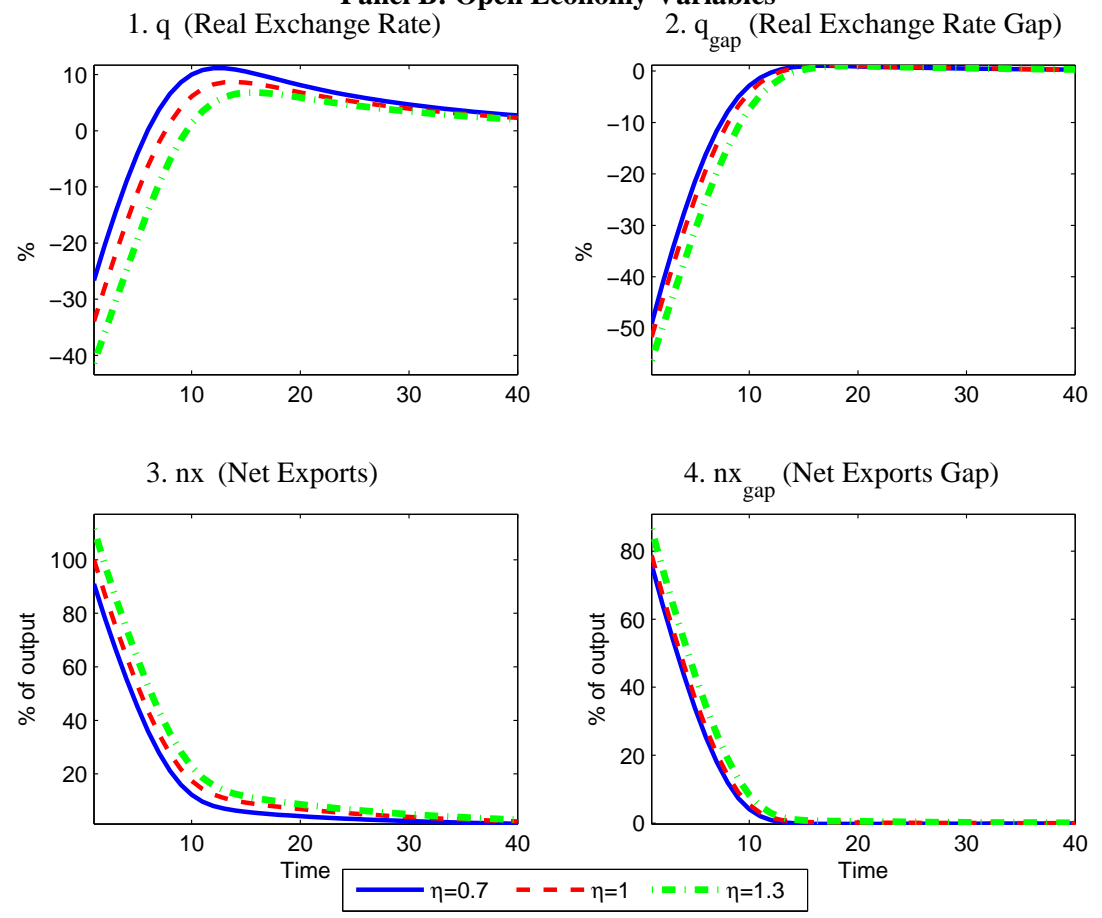

Figure 9: Response of model variables to the preference shock under optimal monetary policy without commitment at the ZLB 
Panel A: Conventional Variables

1. i (Nominal Interest Rate, in levels)

2. $\Pi_{\mathrm{H}}$ (Home Inflation)
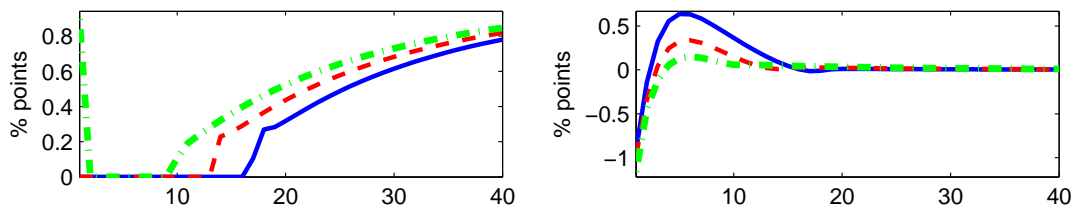

3. $Y_{\text {gap }}$ (Output gap)

4. c (Consumption)
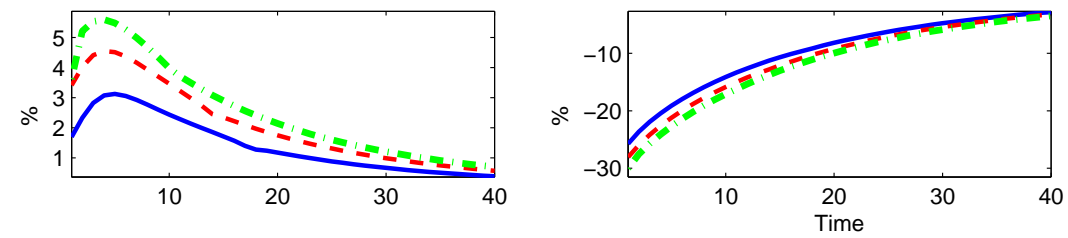

5. $r_{\text {gap }}$ (Real Interest Rate Gap)

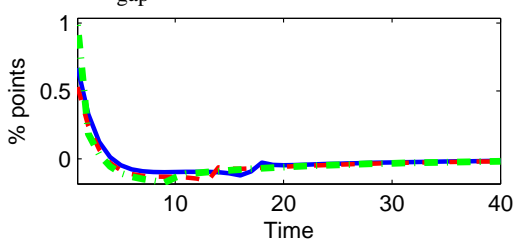

$$
\begin{aligned}
& \eta=0.7 \\
& ---\eta=1
\end{aligned}
$$$$
\eta=\eta=1.3
$$

Panel B: Open Economy Variables

1. q (Real Exchange Rate)

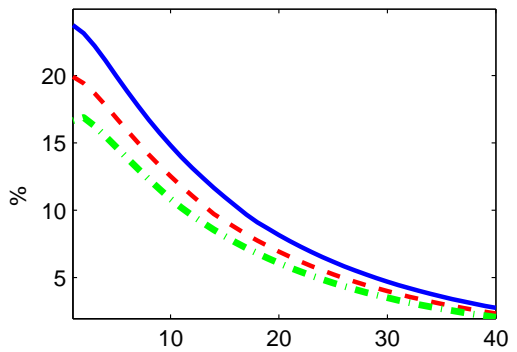

3. $\mathrm{nx}$ (Net Exports)
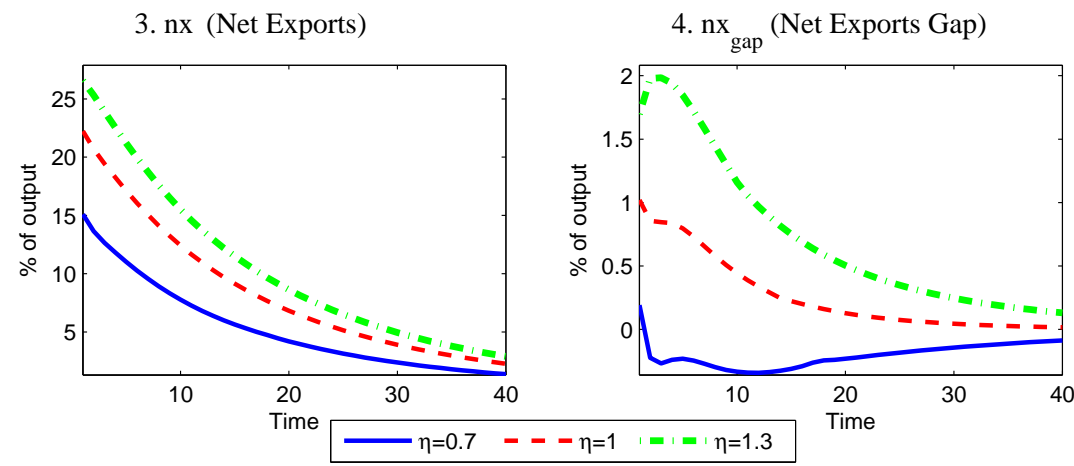

Figure 10: Response of model variables to the preference shock under optimal monetary policy with commitment at the ZLB 
Panel A: Conventional Variables
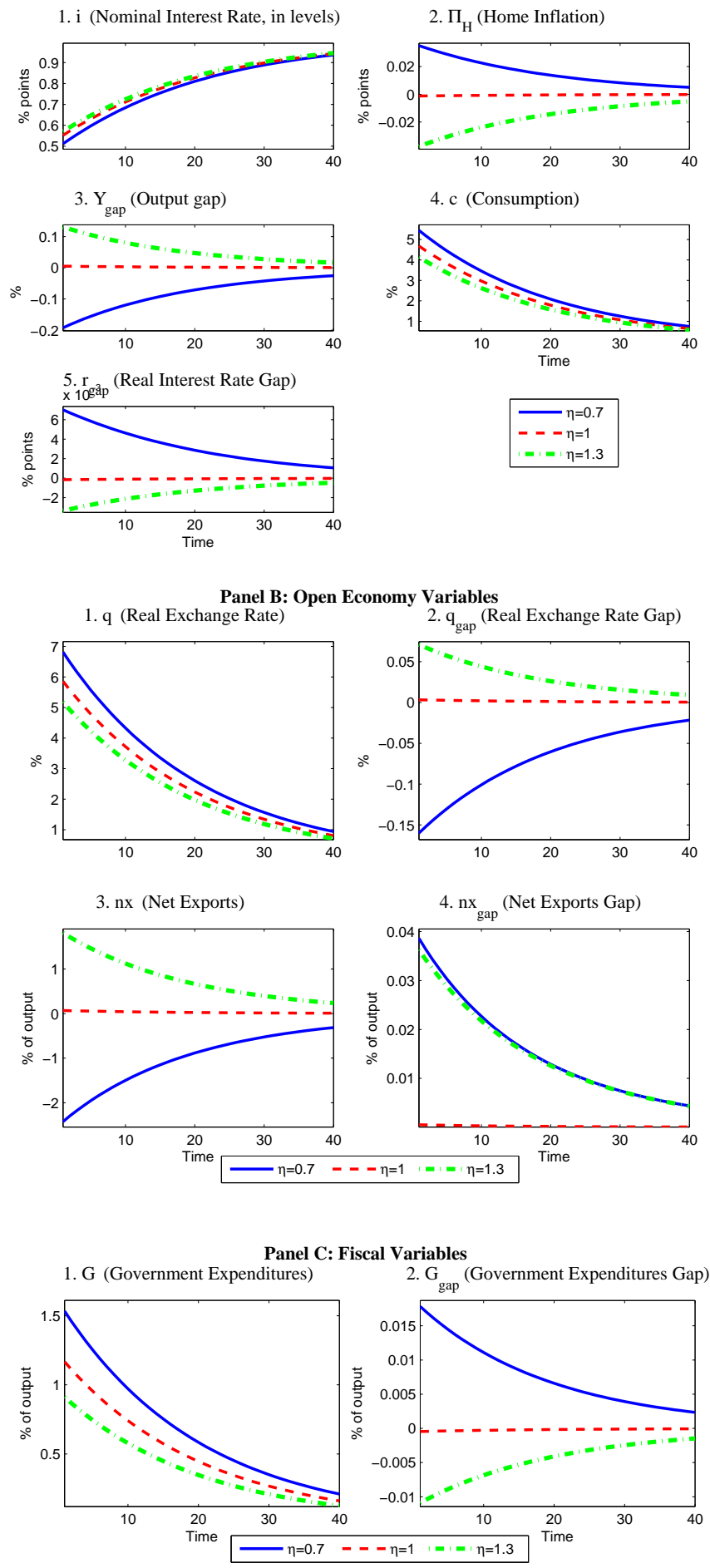

Figure 11: Response of model variables to the technology shock under optimal monetary and fiscal policy without commitment out of ZLB 
Panel A: Conventional Variables
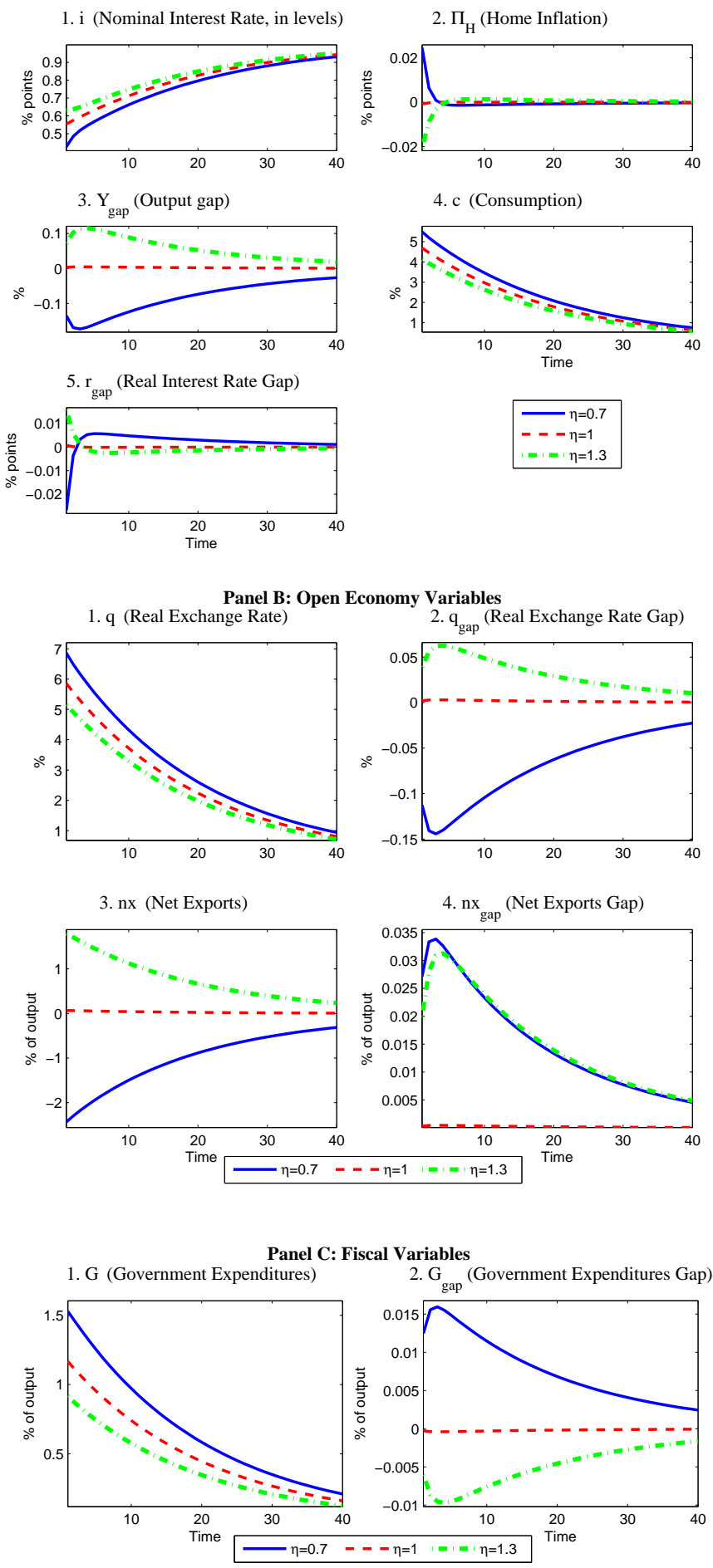

Figure 12: Response of model variables to the technology shock under optimal monetary and fiscal policy with commitment out of ZLB 
Panel A: Conventional Variables
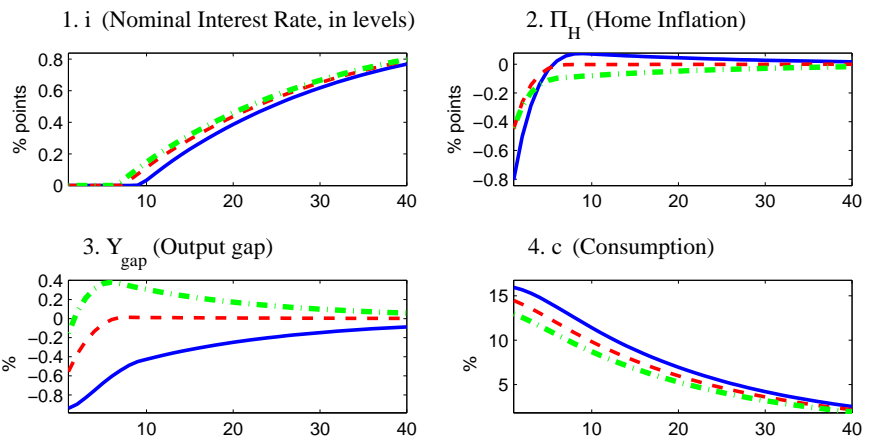

4. c (Consumption)
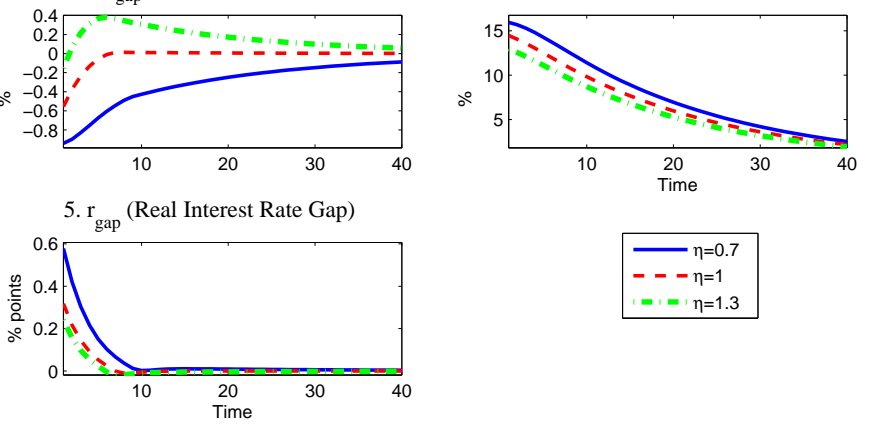

Panel B: Open Economy Variables
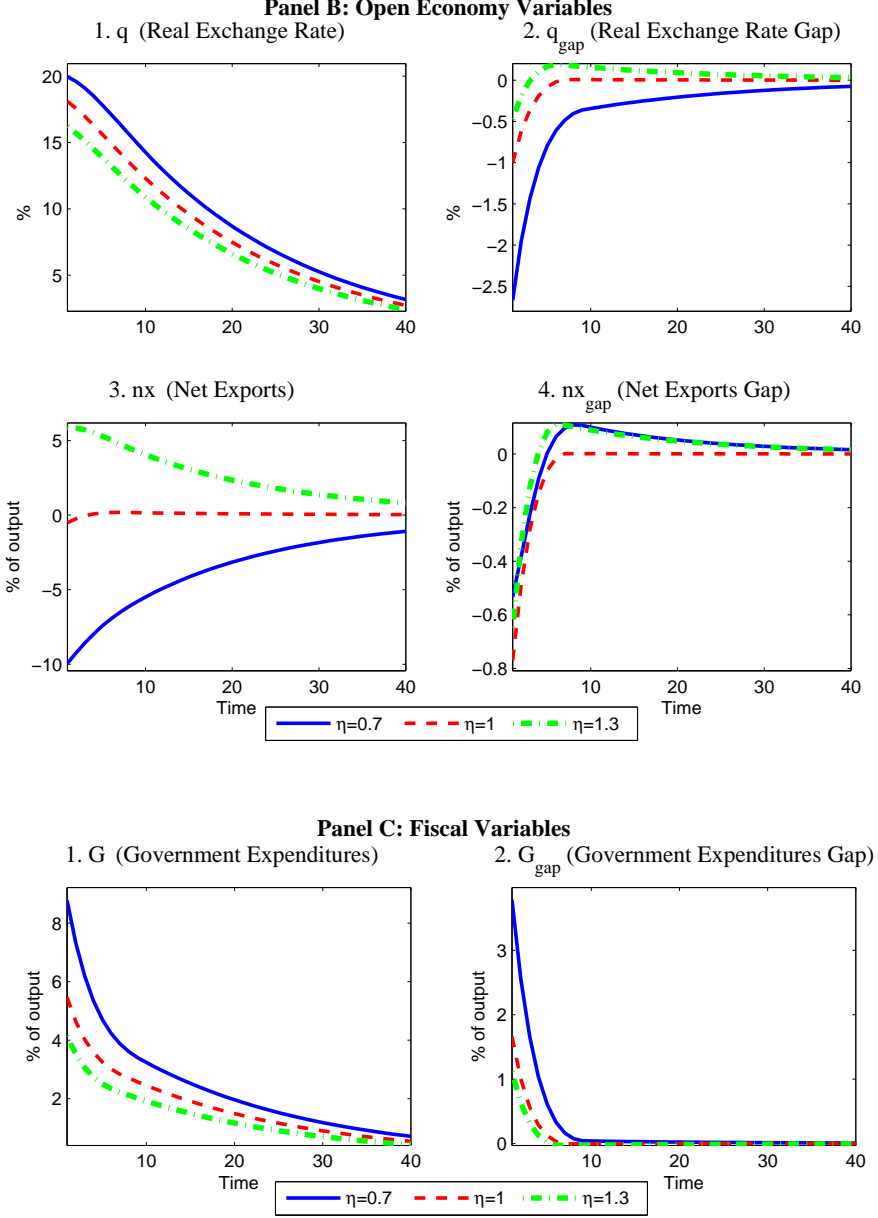

Figure 13: Response of model variables to the technology shock under optimal monetary and fiscal policy without commitment at the ZLB 
Panel A: Conventional Variables
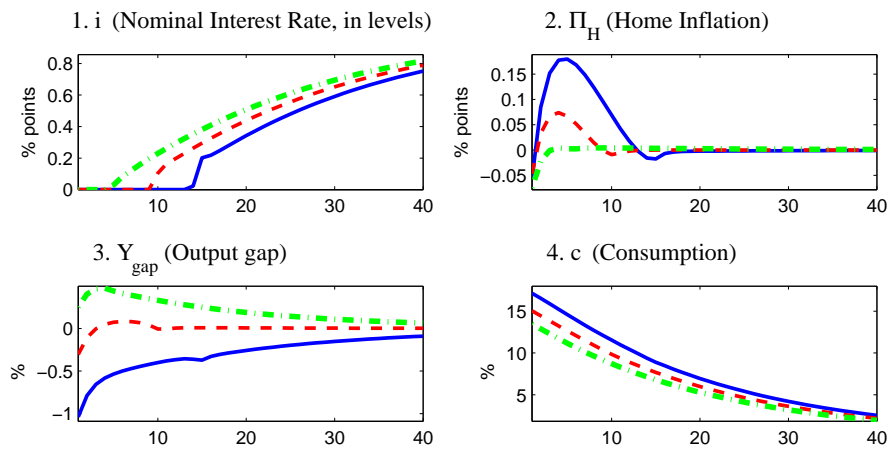

4. c (Consumption)
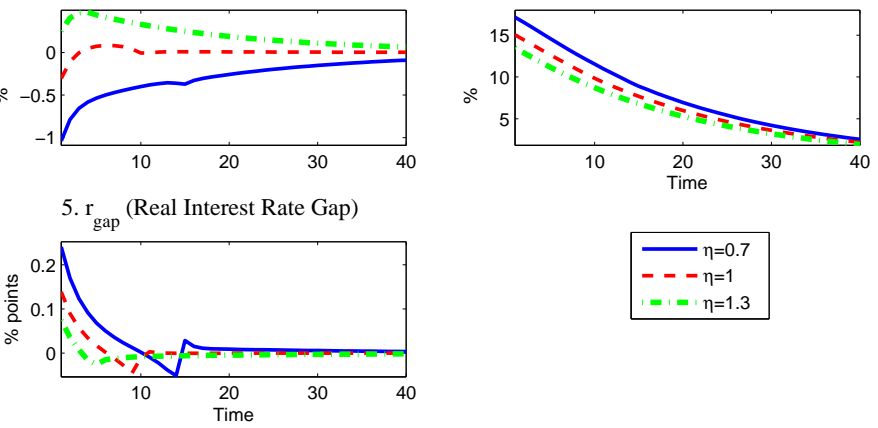

ange Rate)
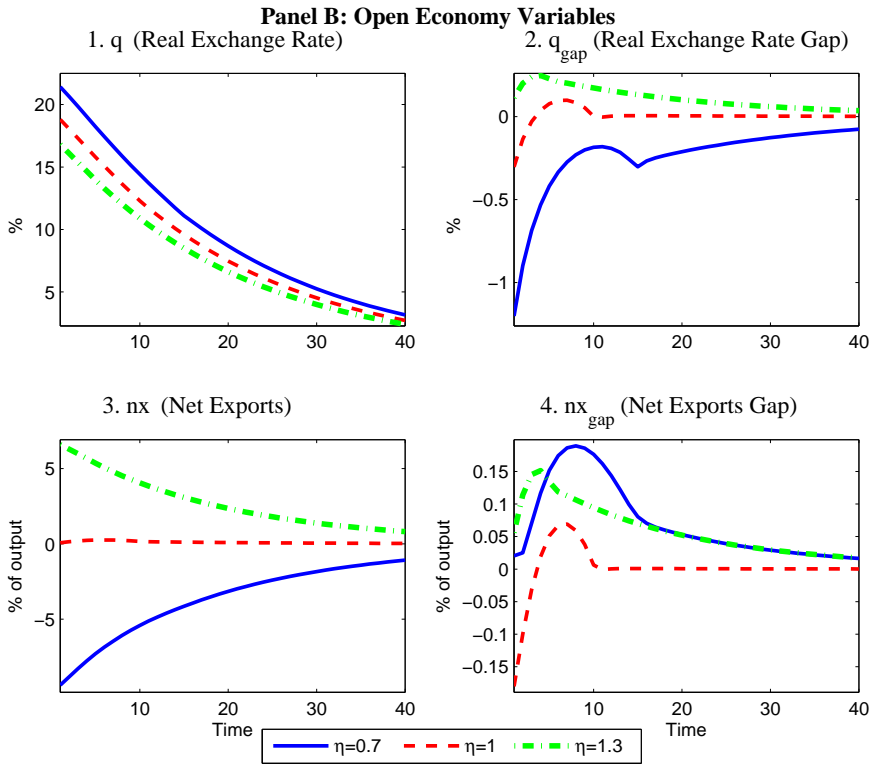

Panel C: Fiscal Variables

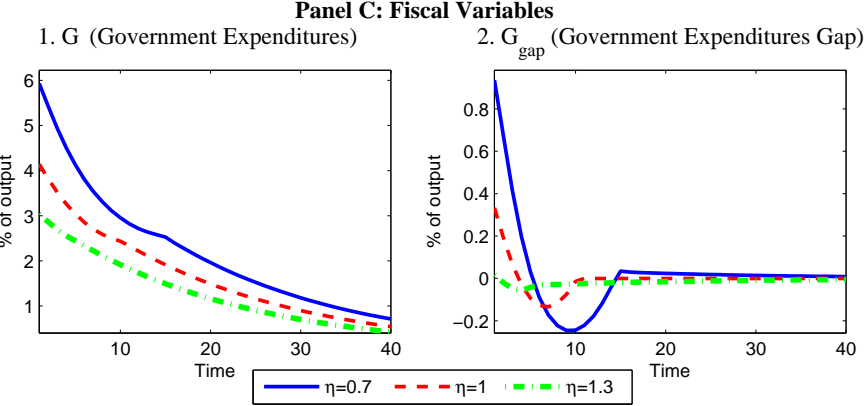

Figure 14: Response of model variables to the technology shock under optimal monetary and fiscal policy with commitment at the ZLB 

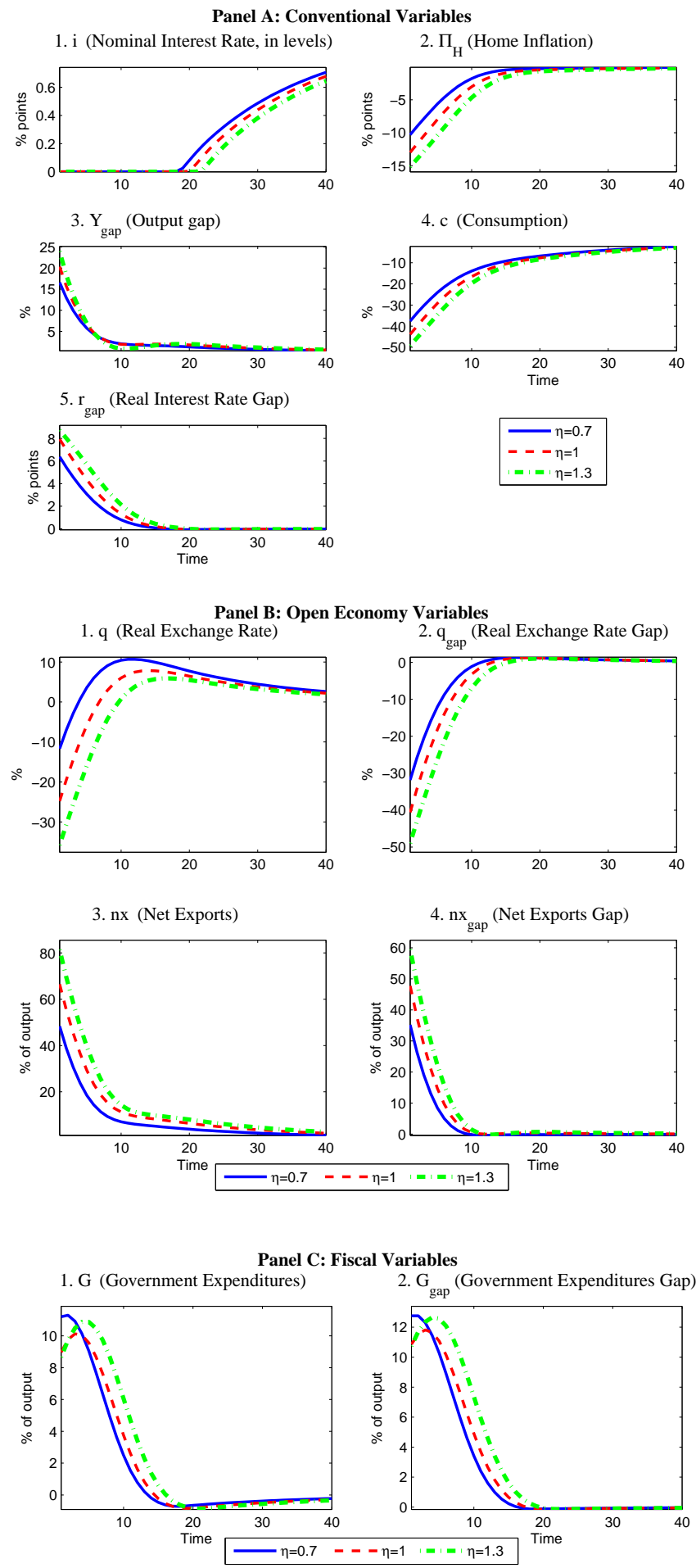

Figure 15: Response of model variables to the preference shock under optimal monetary and fiscal policy without commitment at the ZLB 
Panel A: Conventional Variables

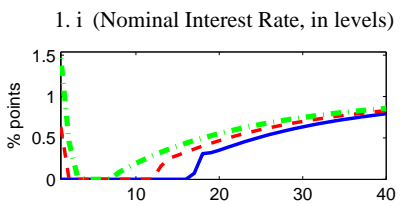

2. $\Pi_{\mathrm{H}}($ Home Inflation)
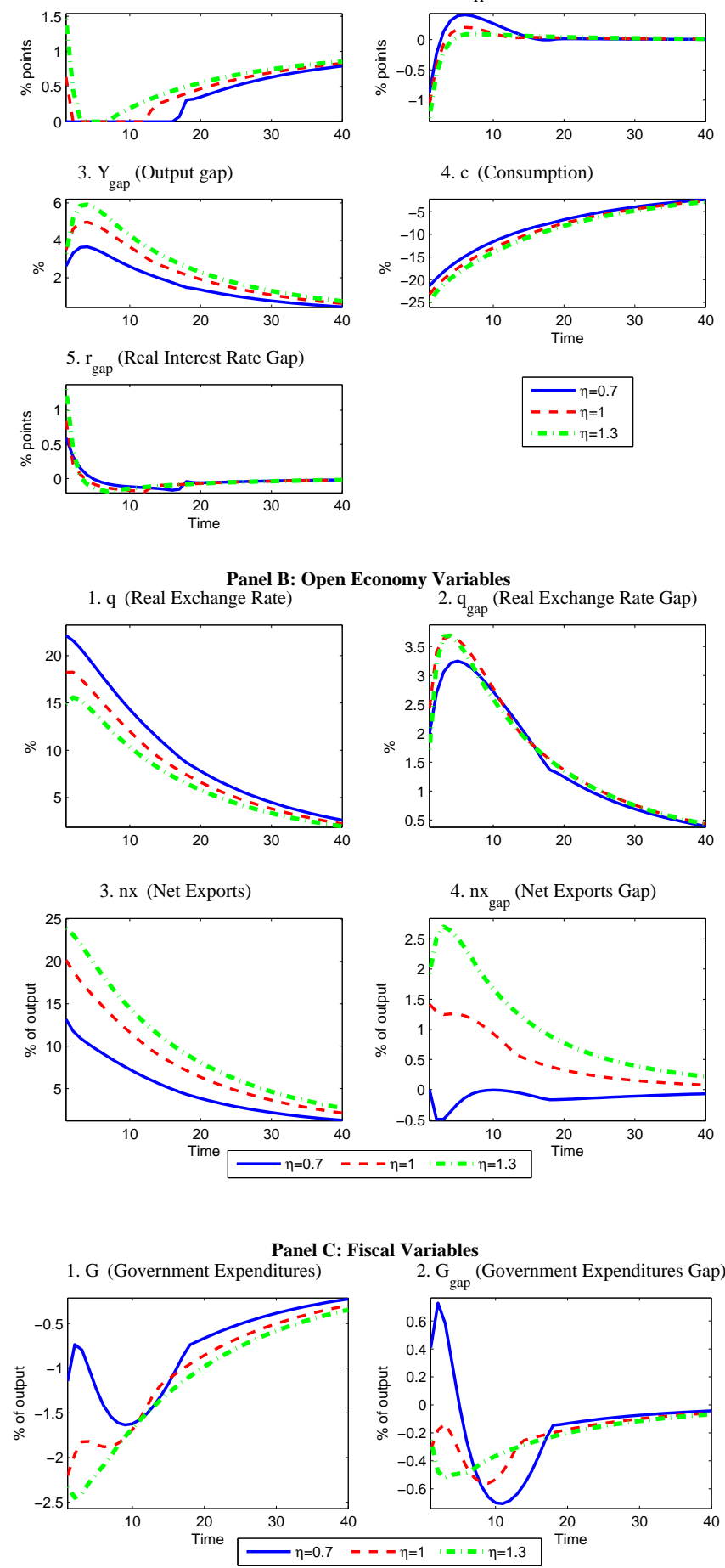

Figure 16: Response of model variables to the preference shock under optimal monetary and fiscal policy with commitment at the ZLB 


\section{Appendix to Optimal Monetary and Fiscal Policy at the Zero Lower Bound in a Small Open Economy}

\section{Figure}

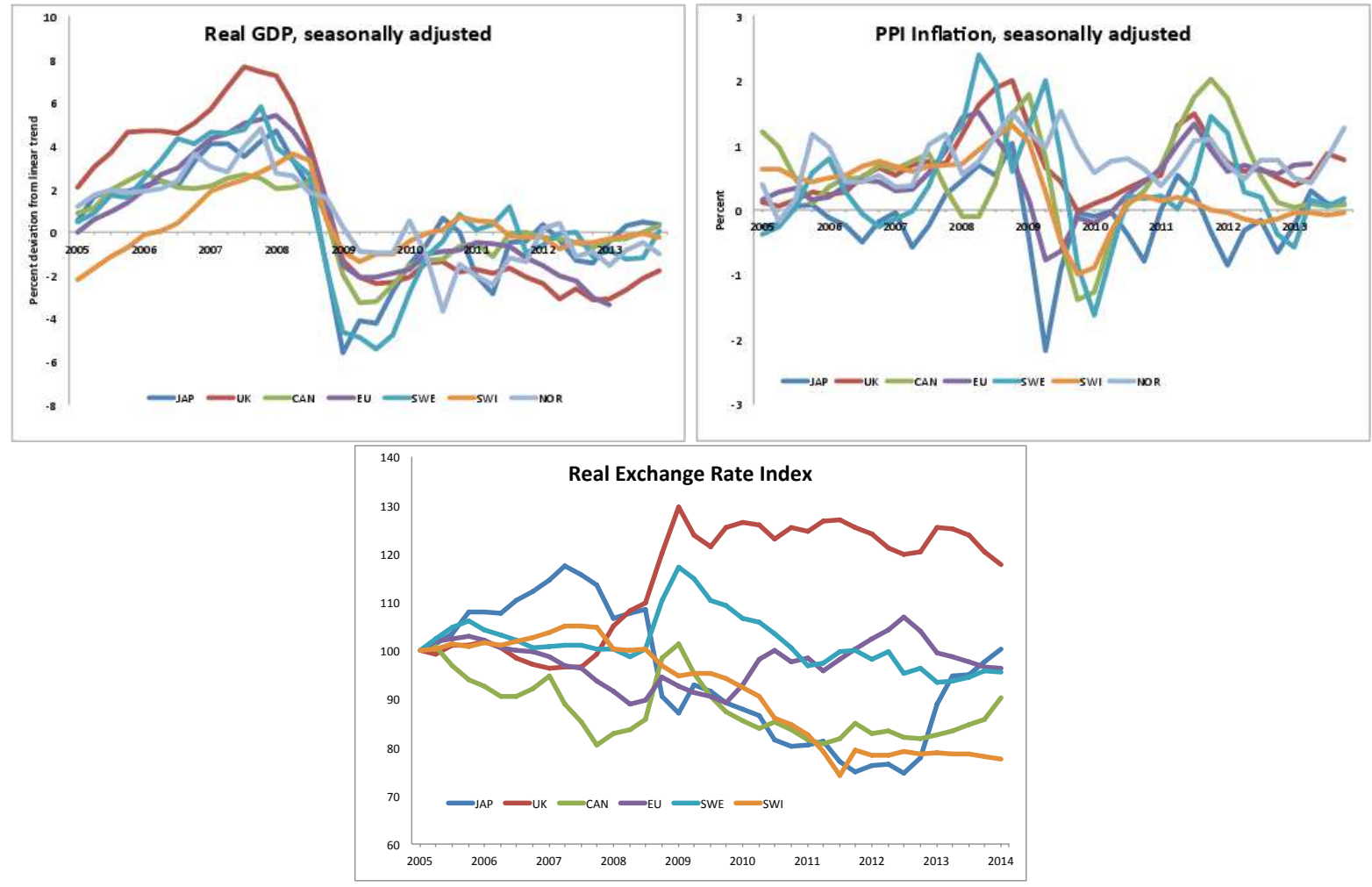

Figure 1: Output gap, inflation, and real exchange rate of small open economies 


\section{Equilibrium conditions}

\subsection{Efficient equilibrium}

Planner's problem is characterized by the following Lagrangian

$$
\begin{aligned}
L_{t} & =u\left(C_{t}, \xi_{t}\right)-\tilde{v}\left(Y_{t}\right)+g\left(G_{t}\right) \\
& +\phi_{1 t}\left(q\left(\varsigma_{t}\right)-\frac{u_{C}\left(C_{t}^{*}, \xi_{t}^{*}\right)}{u_{C}\left(C_{t}, \xi_{t}\right)}\right) \\
& +\phi_{2 t}\left(Y_{t}-(1-\alpha) r\left(\varsigma_{t}\right)^{\eta}\left(C_{t}+G_{t}\right)-\alpha \varsigma_{t}^{\eta}\left(C_{t}^{*}+G_{t}^{*}\right)\right)
\end{aligned}
$$

which leads to the following system of FOCs

$$
\begin{aligned}
\frac{\partial L_{t}}{\partial Y_{t}} & =-\tilde{v}_{Y}+\phi_{2 t} \\
\frac{\partial L_{t}}{\partial C_{t}} & =u_{C}+\phi_{1 t}\left[\frac{u_{c}^{*}}{\left(u_{C}\right)^{2}} u_{C C}\right]+\phi_{2 t}\left[-(1-\alpha) r\left(\varsigma_{t}\right)^{\eta}\right] \\
\frac{\partial L_{t}}{\partial \varsigma_{t}} & =\phi_{1 t}\left[q^{\prime}\left(\varsigma_{t}\right)\right]+\phi_{2 t}\left[-(1-\alpha) \eta r\left(\varsigma_{t}\right)^{\eta-1} r^{\prime}\left(\varsigma_{t}\right)\left(C_{t}+G_{t}\right)-\alpha \eta \varsigma_{t}^{\eta-1}\left(C_{t}^{*}+G_{t}^{*}\right)\right] \\
\frac{\partial L_{t}}{\partial G_{t}} & =g_{G}+\phi_{2 t}\left[-(1-\alpha) r\left(\varsigma_{t}\right)^{\eta}\right]
\end{aligned}
$$

This system can be expressed without Lagrange multipliers through just two conditions,

$$
\begin{gathered}
1+\tilde{v}_{Y}\left[(1-\alpha) r\left(\varsigma_{t}\right)^{\eta}\left[\eta \frac{r^{\prime}\left(\varsigma_{t}\right)}{r\left(\varsigma_{t}\right)}-\frac{\eta}{\varsigma_{t}}\right]\left(C_{t}+G_{t}\right)+Y_{t}\left(\frac{\eta}{\varsigma_{t}}\right)\right]\left[\frac{q\left(\varsigma_{t}\right)}{q^{\prime}\left(\varsigma_{t}\right)\left(u_{C}\right)^{2}} u_{C C}\right]+\frac{\tilde{v}_{Y}}{u_{C}}\left[-(1-\alpha) r\left(\varsigma_{t}\right)^{\eta}\right]=0 \\
g_{G}+\tilde{v}_{Y}\left[-(1-\alpha) r\left(\varsigma_{t}\right)^{\eta}\right]=0,
\end{gathered}
$$

which after plugging in functional forms become

$$
\begin{gathered}
0=1-\eta \frac{\lambda}{\kappa} \xi_{t}^{C} \frac{Y_{t}^{\frac{1+\phi-\kappa}{\kappa}}}{\xi_{t}^{P \frac{1+\phi}{\kappa}}}\left[Y_{t}-(1-\alpha)^{2}\left(C_{t}+G_{t}\right)\left[(1-\alpha)+\alpha \varsigma_{t}^{1-\eta}\right]^{\frac{2 \eta-1}{1-\eta}}\right] \frac{(1-\alpha)+\alpha \varsigma_{t}^{1-\eta}}{\xi_{t}^{C} C_{t}^{1-\sigma}} \frac{\sigma}{(1-\alpha)} \\
-\frac{\lambda}{\kappa} \frac{Y_{t}^{\frac{1+\phi-\kappa}{\kappa}}}{\xi_{t}^{P^{P \frac{1+\phi}{\kappa}}}} C_{t}^{\sigma}(1-\alpha)\left[(1-\alpha)+\alpha \varsigma_{t}^{1-\eta}\right]^{\frac{\eta}{1-\eta}} \\
0=\xi_{t}^{C} \lambda_{G} G_{t}^{-\sigma^{\prime}}-(1-\alpha) \frac{\lambda}{\kappa} \xi_{t}^{C} \frac{Y_{t}^{\frac{1+\phi-\kappa}{\kappa}}}{\xi_{t}^{P \frac{1+\phi}{\kappa}}}\left[(1-\alpha)+\alpha \varsigma_{t}^{1-\eta}\right]^{\frac{\eta}{1-\eta}} .
\end{gathered}
$$

Thus, solution to the social planner's problem is described by these conditions along with two constraints.

\section{Steady state}

We will denote variables without a time-subscript as steady-state values of the variables. We focus on symmetric steady-state where

$$
\begin{gathered}
C=C^{*} \\
G=G^{*} \\
Y=C+G \\
q(\varsigma)=\varsigma=1 .
\end{gathered}
$$


Steady-state is characterized by set of FOCs and constraints without time subscripts. After simplifying we get

$$
\begin{gathered}
1+\tilde{v}_{Y}\left[\frac{1-(1-\alpha)^{2}}{(1-\alpha)}\right] \eta\left[\frac{(C+G) u_{C C}}{\left(u_{C}\right)^{2}}\right]+\frac{\tilde{v}_{Y}}{u_{C}}[-(1-\alpha)]=0 \\
g_{G}+\tilde{v}_{Y}[-(1-\alpha)]=0 .
\end{gathered}
$$

This two equations together with $Y=C+G$ gives us solution for the steady-state.

Moreover, in what follows we adopt several normalizations in the steady state. That is we set $Y=C+G=1$ and we target some value of the ratio of government expenditures to GDP

$\theta_{G} \equiv \frac{G}{Y}$ (and accordingly $1-\theta_{G} \equiv \theta_{C}$ ). We do this by choosing appropriate values of labor supply parameter $\lambda$ and utility parameter $\lambda_{G}$. We give more details below in the section about commitment equilibrium.

\subsection{Private sector equilibrium (PSE)}

Private sector equilibrium conditions after dropping expectation signs and plugging in functional forms become

$$
\begin{gathered}
1+i_{t}=\frac{\xi_{t}^{C} C_{t}^{-\sigma}}{\beta \xi_{t+1}^{C} C_{t+1}^{-\sigma}} \frac{\left[(1-\alpha)+\alpha \varsigma_{t+1}^{1-\eta}\right]^{\frac{1}{1-\eta}}}{\left[(1-\alpha)+\alpha \varsigma_{t}^{1-\eta}\right]^{\frac{1}{1-\eta}}} \Pi_{H, t+1} \\
0=\varepsilon Y_{t}\left[(1+s) \frac{\varepsilon-1}{\varepsilon} \xi_{t}^{C} C_{t}^{-\sigma}-\frac{\lambda}{\kappa} \xi_{t}^{C} \frac{Y_{t}^{\frac{1+\phi-\kappa}{\kappa}}}{\xi_{t}^{P \frac{1+\phi}{\kappa}}}\left[(1-\alpha)+\alpha \varsigma_{t}^{1-\eta}\right]^{\frac{1}{1-\eta}}\right]+\xi_{t}^{C} C_{t}^{-\sigma} 2 d_{1}\left(\Pi_{H, t}-1\right) \Pi_{H, t} \\
-\beta\left[(1-\alpha)+\alpha \varsigma_{t}^{1-\eta}\right]^{\frac{1}{1-\eta}} \xi_{t+1}^{C} C_{t+1}^{-\sigma} 2 d_{1}\left(\Pi_{H, t+1}-1\right) \frac{\Pi_{H, t+1}}{\left[(1-\alpha)+\alpha \varsigma_{t+1}^{1-\eta}\right]^{\frac{1}{1-\eta}}} \\
Y_{t}=(1-\alpha)\left[(1-\alpha)+\alpha \varsigma_{t}^{1-\eta}\right]^{\frac{\eta}{1-\eta}}\left(C_{t}+G_{t}\right)+\alpha \varsigma_{t}^{\eta}\left(C_{t}^{*}+G_{t}^{*}\right)+d_{1}\left(\Pi_{H, t}-1\right)^{2} \\
\frac{\varsigma_{t}}{\left[(1-\alpha)+\alpha \varsigma_{t}^{1-\eta}\right]^{\frac{1}{1-\eta}}}=\frac{\xi_{t}^{* C} C_{t}^{*-\sigma}}{\xi_{t}^{C} C_{t}^{-\sigma}} \\
i_{t} \geq 0 \\
\frac{\Pi_{t}}{\Pi_{H, t}}=\frac{\left[(1-\alpha)+\alpha \varsigma_{t}^{1-\eta}\right]^{\frac{1}{1-\eta}}}{\left[(1-\alpha)+\alpha \varsigma_{t-1}^{1-\eta}\right]^{\frac{1}{1-\eta}}}
\end{gathered}
$$




\subsection{Commitment (Ramsey) equilibrium}

Let's formulate the Lagrangian

$$
\begin{aligned}
L_{0} & =E_{0} \sum_{t=0}^{\infty} u\left(C_{t}, \xi_{t}\right)-\tilde{v}\left(Y_{t}\right)+g\left(G_{t}, \xi_{t}\right) \\
& +\phi_{2 t}\left(\beta f_{t}^{e}-\frac{u_{C}\left(C_{t}, \xi_{t}\right)}{1+i_{t}}\right) \\
& +\phi_{3 t}\left(\varepsilon Y_{t}\left[\frac{\varepsilon-1}{\varepsilon}(1+s) u_{C}\left(C_{t}, \xi_{t}\right)-\tilde{v}_{y}\left(Y_{t}, \xi_{t}\right) r\left(\varsigma_{t}\right)\right]+u_{C}\left(C_{t}, \xi_{t}\right) d^{\prime}\left(\Pi_{H, t}\right) \Pi_{H, t}-\beta r\left(\varsigma_{t}\right) S_{t}^{e}\right) \\
& +\phi_{4 t}\left(\frac{\Pi_{t}}{\Pi_{H, t}}-\frac{r\left(\varsigma_{t}\right)}{r\left(\varsigma_{t-1}\right)}\right) \\
& +\phi_{5 t}\left(q\left(\varsigma_{t}\right)-\frac{u_{C}\left(C_{t}^{*}, \xi_{t}^{*}\right)}{u_{C}\left(C_{t}, \xi_{t}\right)}\right) \\
& +\phi_{6 t}\left(Y_{t}-(1-\alpha) r\left(\varsigma_{t}\right)^{\eta}\left(C_{t}+G_{t}\right)-\alpha \varsigma_{t}^{\eta}\left(C_{t}^{*}+G_{t}^{*}\right)-d\left(\Pi_{H, t}\right)\right) \\
& +\psi_{1 t}\left(f_{t}^{e}-u_{C}\left(C_{t+1}, \xi_{t+1}\right) \Pi_{t+1}^{-1}\right) \\
& +\psi_{2 t}\left(S_{t}^{e}-u_{C}\left(C_{t+1}, \xi_{t+1}\right) d^{\prime}\left(\Pi_{H, t+1}\right) \frac{\Pi_{H, t+1}}{r\left(\varsigma_{t+1}\right)}\right) \\
& +\gamma_{1 t}\left(i_{t}-0\right)
\end{aligned}
$$

and take derivatives to get

$$
\begin{aligned}
\frac{\partial L_{s}}{\partial \Pi_{t}} & =\phi_{4 t} \Pi_{H, t}^{-1}+\beta^{-1} \psi_{1 t-1} u_{C} \Pi_{t}^{-2} \\
\frac{\partial L_{s}}{\partial Y_{t}} & =-\tilde{v}_{Y}+\phi_{3 t}\left[\varepsilon\left(\frac{\varepsilon-1}{\varepsilon}(1+s) u_{C}-\tilde{v}_{y} r\left(\varsigma_{t}\right)\right)-\varepsilon Y_{t} \tilde{v}_{y y} r\left(\varsigma_{t}\right)\right]+\phi_{6 t} \\
\frac{\partial L_{s}}{\partial i_{t}} & =\phi_{2 t}\left[u_{C}\left(1+i_{t}\right)^{-2}\right]+\gamma_{1 t} \\
\frac{\partial L_{s}}{\partial C_{t}} & =u_{C}+\phi_{2 t}\left[-u_{C C}\left(1+i_{t}\right)^{-1}\right]+\phi_{3 t}\left[\varepsilon Y_{t} \frac{\varepsilon-1}{\varepsilon}(1+s) u_{C C}+u_{C C} d^{\prime} \Pi_{H, t}\right]+\phi_{5 t}\left[u_{C^{*}} u_{C}^{-2} u_{C C}\right] \\
& +\phi_{6 t}\left[-(1-\alpha) r\left(\varsigma_{t}\right)^{\eta}\right]+\beta^{-1} \psi_{1 t-1}\left(-u_{C C} \Pi_{t}^{-1}\right)+\beta^{-1} \psi_{2 t-1}\left[-u_{C C} d^{\prime}\left(\Pi_{H, t}\right) \frac{\Pi_{H, t}}{r\left(\varsigma_{t}\right)}\right] \\
\frac{\partial L_{s}}{\partial G_{t}} & =g_{G}+\phi_{6 t}\left[-(1-\alpha) r\left(\varsigma_{t}\right)^{\eta}\right] \\
\frac{\partial L_{s}}{\partial \Pi_{H, t}} & =\phi_{3 t}\left[u_{C} d^{\prime \prime} \Pi_{H, t}+u_{C} d^{\prime}\right]+\phi_{4 t}\left(-\Pi_{t} \Pi_{H, t}^{-2}\right)+\phi_{6 t}\left[-d^{\prime}\right]-\beta^{-1} \psi_{2 t-1} u_{C} d^{\prime} \frac{1}{r\left(\varsigma_{t}\right)}-\beta^{-1} \psi_{2 t-1} u_{C} \frac{\Pi_{H, t}}{r\left(\varsigma_{t}\right)} d^{\prime \prime} \\
\frac{\partial L_{s}}{\partial \varsigma_{t}} & =\phi_{3 t}\left[-\varepsilon Y_{t} \tilde{v}_{y} r^{\prime}\left(\varsigma_{t}\right)-\beta S_{t}^{e} r^{\prime}\left(\varsigma_{t}\right)\right]+\phi_{4 t}\left[-\frac{r^{\prime}\left(\varsigma_{t}\right)}{r\left(\varsigma_{t-1}\right)}\right]+\beta E_{t} \phi_{4 t+1} r^{\prime}\left(\varsigma_{t}\right)\left[\frac{r\left(\varsigma_{t+1}\right)}{r\left(\varsigma_{t}\right)^{2}}\right]+\phi_{5 t}\left[q^{\prime}\left(\varsigma_{t}\right)\right] \\
& +\phi_{6 t}\left[-(1-\alpha) \eta r\left(\varsigma_{t}\right)^{\eta-1} r^{\prime}\left(\varsigma_{t}\right)\left(C_{t}+G_{t}\right)-\alpha \eta \varsigma_{t}^{\eta-1}\left(C_{t}^{*}+G_{t}^{*}\right)\right] \\
& +\beta^{-1} \psi_{2 t-1}\left[u_{C} d^{\prime} \frac{\Pi_{H, t}}{r\left(\varsigma_{t}\right)^{2}}\right] r^{\prime}\left(\varsigma_{t}\right) \\
\frac{\partial L_{s}}{\partial f_{t}^{e}} & =\beta \phi_{2 t}+\psi_{1 t} \\
\frac{\partial L_{s}}{\partial S_{t}^{e}} & =\phi_{3 t}\left[-\beta r\left(\varsigma_{t}\right)\right]+\psi_{2 t} .
\end{aligned}
$$


Plugging in functional forms and simplifying leads to the following system of equations

$$
\begin{aligned}
& 0=-\frac{\lambda}{\kappa} \xi_{t}^{C} \frac{Y_{t}^{\frac{1+\phi-\kappa}{\kappa}}}{\xi_{t}^{P \frac{1+\phi}{\kappa}}}+\phi_{3 t} \varepsilon\left[(1+s) \frac{\varepsilon-1}{\varepsilon} \xi_{t}^{C} C_{t}^{-\sigma}-\frac{\lambda}{\kappa} \frac{1+\phi}{\kappa} \xi_{t}^{C} \frac{Y_{t}^{\frac{1+\phi-\kappa}{\kappa}}}{\xi_{t}^{P \frac{1+\phi}{\kappa}}}\left[(1-\alpha)+\alpha \varsigma_{t}^{1-\eta}\right]^{\frac{1}{1-\eta}}\right]+\phi_{6 t} \\
& 0= \xi_{t}^{C} C_{t}^{-\sigma}-\phi_{3 t} \sigma \xi_{t}^{C} C_{t}^{-1-\sigma}\left[\varepsilon Y_{t}(1+s) \frac{\varepsilon-1}{\varepsilon}+2 d_{1}\left(\Pi_{H, t}-1\right) \Pi_{H, t}\right]-\sigma C_{t}^{\sigma-1} C_{t}^{*-\sigma} \xi_{t}^{* C}\left(\xi_{t}^{C}\right)^{-1} \phi_{5 t} \\
&+\phi_{6 t}\left[-(1-\alpha)\left[(1-\alpha)+\alpha \varsigma_{t}^{1-\eta}\right]^{\frac{\eta}{1-\eta}}\right]+\phi_{3 t-1} \sigma \xi_{t}^{C} C_{t}^{-1-\sigma} 2 d_{1}\left(\Pi_{H, t}-1\right) \Pi_{H, t} \frac{\left[(1-\alpha)+\alpha \varsigma_{t-1}^{1-\eta}\right]^{\frac{1}{1-\eta}}}{\left[(1-\alpha)+\alpha \varsigma_{t}^{1-\eta}\right]^{\frac{1}{1-\eta}}} \\
& 0= \xi_{t}^{C} \lambda_{G} G_{t}^{-\sigma^{\prime}}-(1-\alpha) \phi_{6 t}\left[(1-\alpha)+\alpha \varsigma_{t}^{1-\eta}\right]^{\frac{\eta}{1-\eta}} \\
& 0= \phi_{3 t} \xi_{t}^{C} C_{t}^{-\sigma}\left(2 \Pi_{H, t}-1\right)-\phi_{6 t}\left(\Pi_{H, t}-1\right)-\phi_{3 t-1} \xi_{t}^{C} C_{t}^{-\sigma}\left(2 \Pi_{H, t}-1\right) \frac{\left[(1-\alpha)+\alpha \varsigma_{t-1}^{1-\eta}\right]^{\frac{1}{1-\eta}}}{\left[(1-\alpha)+\alpha \varsigma_{t}^{1-\eta}\right]^{\frac{1}{1-\eta}}} \\
& 0-\phi_{3 t} \alpha \varsigma_{t}^{-\eta}\left[(1-\alpha)+\alpha \varsigma_{t}^{1-\eta}\right]^{\frac{\eta}{1-\eta}}\left[\varepsilon \frac{\lambda}{\kappa} \xi_{t}^{C} \frac{Y_{t}^{\frac{1+\phi}{\kappa}}}{\xi_{t}^{P \frac{1+\phi}{\kappa}}}+\beta \xi_{t+1}^{C} C_{t+1}^{-\sigma} \frac{2 d_{1}\left(\Pi_{H, t+1}-1\right) \Pi_{H, t+1}}{\left[(1-\alpha)+\alpha \varsigma_{t+1}^{1-\eta}\right]^{\frac{1}{1-\eta}}}\right] \\
&+\phi_{5 t}(1-\alpha)\left[(1-\alpha)+\alpha \varsigma_{t}^{1-\eta}\right]^{\frac{\eta-2}{1-\eta}}-\phi_{6 t} \alpha \eta\left[(1-\alpha)\left(C_{t}+G_{t}\right) \varsigma_{t}^{-\eta}\left[(1-\alpha)+\alpha \varsigma_{t}^{1-\eta}\right]^{\frac{2 \eta-1}{1-\eta}}+\varsigma_{t}^{\eta-1}\left(C_{t}^{*}+G_{t}^{*}\right)\right] \\
&+\phi_{3 t-1} \xi_{t}^{C} C_{t}^{-\sigma} 2 d_{1}\left(\Pi_{H, t}-1\right) \Pi_{H, t} \frac{\alpha \varsigma_{t}^{-\eta}}{(1-\alpha)+\alpha \varsigma_{t}^{1-\eta}} \frac{\left[(1-\alpha)+\alpha \varsigma_{t-1}^{1-\eta}\right]^{\frac{1}{1-\eta}}}{\left[(1-\alpha)+\alpha \varsigma_{t}^{1-\eta}\right]^{\frac{1}{1-\eta}}} \\
& \gamma_{1 t} \geq 0, i_{t} \geq 0, \gamma_{1 t} i_{t}=0 .
\end{aligned}
$$

Solution to the commitment problem is the solution to the system of these conditions along with PSE conditions.

\section{Steady state}

After simplifying the system of FOCs and constraints, it becomes

$$
\begin{gathered}
1+i=\frac{1}{\beta \Pi_{H}^{-1}} \\
\varepsilon Y\left[\frac{\varepsilon-1}{\varepsilon}(1+s) u_{C}-\tilde{v}_{y} r(\varsigma)\right]+u_{C} d^{\prime}\left(\Pi_{H}\right) \Pi_{H}=\beta r(\varsigma)\left[u_{C} d^{\prime}\left(\Pi_{H}\right) \frac{\Pi_{H}}{r(\varsigma)}\right] \\
Y=(1-\alpha) r(\varsigma)^{\eta}(C+G)+\alpha \varsigma^{\eta}\left(C^{*}+G^{*}\right)+d\left(\Pi_{H}\right) \\
q(\varsigma)=\frac{u_{C}^{*}}{u_{C}}=\frac{\varsigma}{r(\varsigma)} \\
r(\varsigma)=\left[(1-\alpha)+\alpha \varsigma^{1-\eta}\right]^{\frac{1}{1-\eta}} \\
0=-\tilde{v}_{Y}+\phi_{3}\left[\varepsilon\left(\frac{\varepsilon-1}{\varepsilon}(1+s) u_{C}-\tilde{v}_{y} r(\varsigma)\right)-\varepsilon Y \tilde{v}_{y y} r(\varsigma)\right]+\phi_{6} \\
0=u_{C}+\phi_{3}\left[\varepsilon Y \frac{\varepsilon-1}{\varepsilon}(1+s) u_{C C}\right]+\phi_{5}\left[u_{C^{*}} u_{C}^{-2} u_{C C}\right]+\phi_{6}\left[-(1-\alpha) r(\varsigma)^{\eta}\right] \\
0=g_{G}+\phi_{6}\left[-(1-\alpha) r(\varsigma)^{\eta}\right] \\
0=\phi_{6}\left[-d^{\prime}\right] \\
0=\phi_{3}\left[-\varepsilon Y \tilde{v}_{y} r^{\prime}(\varsigma)-\beta u_{C} d^{\prime} \frac{\Pi_{H}}{r(\varsigma)} r^{\prime}(\varsigma)\right]+\phi_{5}\left[q^{\prime}(\varsigma)\right]+\phi_{6}\left[-(1-\alpha) \eta r(\varsigma)^{\eta-1} r^{\prime}(\varsigma)(C+G)-\alpha \eta \varsigma^{\eta-1}\left(C^{*}+G^{*}\right)\right] \\
+\phi_{3}\left[u_{C} d^{\prime} \frac{\Pi_{H}}{r(\varsigma)}\right] r^{\prime}(\varsigma) .
\end{gathered}
$$


Now we will find such value of production subsidy $(1+s)$ so that this steady state coincides with the efficient one. So we plug in some steady state relationships like $\Pi_{H}=1$ or $\varsigma=1$, and ultimately we get

$$
\begin{gathered}
0=g_{G}+\tilde{v}_{Y}[-(1-\alpha)] \\
\frac{\varepsilon-1}{\varepsilon}(1+s) u_{C} \eta \alpha \frac{(2-\alpha)}{[1-\alpha]}(C+G)=\frac{\frac{\varepsilon-1}{\varepsilon}(1+s)(1-\alpha)-1}{u_{C}^{-2} u_{C C}}
\end{gathered}
$$

from where we arrive at

$$
\begin{gathered}
g_{G}=(1-\alpha) \tilde{v}_{Y}=\frac{\varepsilon-1}{\varepsilon}(1+s) u_{C}(1-\alpha) \\
(1+s)=\frac{\varepsilon}{\varepsilon-1}\left[-\eta \alpha \frac{(2-\alpha)}{[1-\alpha]}(C+G) \frac{u_{C C}}{u_{C}}+(1-\alpha)\right]^{-1}
\end{gathered}
$$

where the second equation basically defines the subsidy as it can be rewritten as

$$
1+s=\frac{\varepsilon}{\varepsilon-1} \times \frac{\frac{1-\alpha}{\sigma} \theta_{C}}{(2-\alpha) \eta \alpha+\frac{(1-\alpha)^{2}}{\sigma} \theta_{C}}
$$

after we plug in steaty state values $Y=C+G=1$ and $C=\theta_{C}$.

Now we need to show that at this value of production subsidy conditions of the efficient steady state are satisfied. Combining the last two equations yields

$$
\left[-\eta \alpha \frac{(2-\alpha)}{[1-\alpha]}(C+G) \frac{u_{C C}}{u_{C}}+(1-\alpha)\right]=\frac{u_{C}(1-\alpha)}{g_{G}}
$$

which is exactly the same expression as we get by combining the last two expressions in efficient equilibrium section section.

This proved that with appropriate value of production subsidy efficient steady state is achieved under commitment. Now let's see how our normalizations can be achieved in this environment.

One of the optimality conditions in the steady state is

$$
(1+s) \frac{\varepsilon-1}{\varepsilon} u_{C}=\tilde{v}_{y}
$$

which under our functional form transforms to

$$
(1+s) \frac{\varepsilon-1}{\varepsilon} C^{-\sigma}=\frac{\lambda}{\kappa} Y^{\frac{1+\phi-\kappa}{\kappa}}
$$

so we set $\lambda=\kappa(1+s) \frac{\varepsilon-1}{\varepsilon} C^{-\sigma}$ in order to achieve $Y=1$.

Also in steady state the following condition should be satisfied

$$
\left[-\eta \alpha \frac{(2-\alpha)}{[1-\alpha]}(C+G) \frac{u_{C C}}{u_{C}}+(1-\alpha)\right]=\frac{u_{C}(1-\alpha)}{g_{G}}
$$

which becomes

$$
\sigma \eta \alpha \frac{(2-\alpha)}{[1-\alpha]}+\left(\sigma \eta \alpha \frac{(2-\alpha)}{[1-\alpha]}+1-\alpha\right) \frac{1-\theta_{G}}{\theta_{G}}=\frac{\left(1-\theta_{G}\right)^{1-\sigma}}{\theta_{G}^{1-\sigma^{\prime}}} \frac{(1-\alpha)}{\lambda_{G}}
$$

so after we choose value of $\theta_{G}$ we set $\lambda_{G}$ to the value implied by this relationship. 


\subsection{Discretion (Markov perfect) equilibrium}

The policy problem can be written as

$$
J\left(\varsigma_{t-1}, \xi_{t}, C_{t}^{*}, G_{t}^{*}, \xi_{t}^{*}\right)=\max \left[U\left(C_{t}, \xi_{t}\right)-\tilde{v}\left(Y_{t}\right)+g\left(G_{t}, \xi_{t}\right)+\beta E_{t} J\left(\varsigma_{t}, \xi_{t+1}, C_{t+1}^{*}, G_{t+1}^{*}, \xi_{t+1}^{*}\right)\right]
$$

subject to

$$
\begin{gathered}
1+i_{t}=\frac{u_{C}\left(C_{t}, \xi_{t}\right)}{\beta f_{t}^{e}} \\
i_{t} \geq 0 \\
\varepsilon Y_{t}\left[\frac{\varepsilon-1}{\varepsilon}(1+s) u_{C}\left(C_{t}, \xi_{t}\right)-\tilde{v}_{y}\left(Y_{t}, \xi_{t}\right) r\left(\varsigma_{t}\right)\right]+u_{C}\left(C_{t}, \xi_{t}\right) d^{\prime}\left(\Pi_{H, t}\right) \Pi_{H, t}=\beta r\left(\varsigma_{t}\right) S_{t}^{e} \\
Y_{t}=(1-\alpha) r\left(\varsigma_{t}\right)^{\eta}\left(C_{t}+G_{t}\right)+\alpha \varsigma_{t}^{\eta}\left(C_{t}^{*}+G_{t}^{*}\right)+d\left(\Pi_{H, t}\right) \\
\frac{\Pi_{t}}{\Pi_{H, t}}=\frac{r\left(\varsigma_{t}\right)}{r\left(\varsigma_{t-1}\right)} \\
q\left(\varsigma_{t}\right)=\frac{u_{C}\left(C_{t}^{*}, \xi_{t}^{*}\right)}{u_{C}\left(C_{t}, \xi_{t}\right)} \\
f_{t}^{e}=E_{t}\left[u_{C}\left(C_{t+1}, \xi_{t+1}\right) \Pi_{t+1}^{-1}\right]=\bar{f}^{e}\left(\varsigma_{t}, \xi_{t}, C_{t}^{*}, G_{t}^{*}, \xi_{t}^{*}\right) \\
S_{t}^{e}=E_{t}\left[u_{C}\left(C_{t+1}, \xi_{t+1}\right) d^{\prime}\left(\Pi_{H, t+1}\right) \frac{\Pi_{H, t+1}}{r\left(\varsigma_{t+1}\right)}\right]=\bar{S}^{e}\left(\varsigma_{t}, \xi_{t}, C_{t}^{*}, G_{t}^{*}, \xi_{t}^{*}\right) .
\end{gathered}
$$

From here on we will omit foreign shocks $\left(C_{t}^{*}, G_{t}^{*}, \xi_{t}^{*}\right)$ in the state vector to keep notation simple.

Formulate the Lagrangian

$$
\begin{aligned}
L_{t} & =u\left(C_{t}, \xi_{t}\right)-\tilde{v}\left(Y_{t}\right)+g\left(G_{t}, \xi_{t}\right)+\beta E_{t} J\left(\varsigma_{t}, \xi_{t+1}\right) \\
& +\phi_{2 t}\left(\beta f_{t}^{e}-\frac{u_{C}\left(C_{t}, \xi_{t}\right)}{1+i_{t}}\right) \\
& +\phi_{3 t}\left(\varepsilon Y_{t}\left[\frac{\varepsilon-1}{\varepsilon}(1+s) u_{C}\left(C_{t}, \xi_{t}\right)-\tilde{v}_{y}\left(Y_{t}, \xi_{t}\right) r\left(\varsigma_{t}\right)\right]+u_{C}\left(C_{t}, \xi_{t}\right) d^{\prime}\left(\Pi_{H, t}\right) \Pi_{H, t}-\beta r\left(\varsigma_{t}\right) S_{t}^{e}\right) \\
& +\phi_{4 t}\left(\frac{\Pi_{t}}{\Pi_{H, t}}-\frac{r\left(\varsigma_{t}\right)}{r\left(\varsigma_{t-1}\right)}\right) \\
& +\phi_{5 t}\left(q\left(\varsigma_{t}\right)-\frac{u_{C}\left(C_{t}^{*}, \xi_{t}^{*}\right)}{u_{C}\left(C_{t}, \xi_{t}\right)}\right) \\
& +\phi_{6 t}\left(Y_{t}-(1-\alpha) r\left(\varsigma_{t}\right)^{\eta}\left(C_{t}+G_{t}\right)-\alpha \varsigma_{t}^{\eta}\left(C_{t}^{*}+G_{t}^{*}\right)-d\left(\Pi_{H, t}\right)\right) \\
& +\psi_{1 t}\left(f_{t}^{e}-\bar{f}^{e}\left(b_{t}, \varsigma_{t}, \xi_{t}\right)\right) \\
& +\psi_{2 t}\left(S_{t}^{e}-\bar{S}^{e}\left(b_{t}, \varsigma_{t}, \xi_{t}\right)\right) \\
& +\gamma_{1 t}\left(i_{t}-0\right)
\end{aligned}
$$


FOCs (where all the derivatives are to be equated to zero) with substituted envelope condition are

$$
\begin{aligned}
\frac{\partial L_{s}}{\partial \Pi_{t}} & =\phi_{4 t}\left[\Pi_{H, t}^{-1}\right] \\
\frac{\partial L_{s}}{\partial Y_{t}} & =-\tilde{v}_{Y}+\phi_{3 t}\left[\varepsilon\left(\frac{\varepsilon-1}{\varepsilon}(1+s) u_{C}-\tilde{v}_{y} r\left(\varsigma_{t}\right)\right)-\varepsilon Y_{t} \tilde{v}_{y y} r\left(\varsigma_{t}\right)\right]+\phi_{6 t} \\
\frac{\partial L_{s}}{\partial i_{t}} & =\phi_{2 t}\left[u_{C}\left(1+i_{t}\right)^{-2}\right]+\gamma_{1 t} \\
\frac{\partial L_{s}}{\partial C_{t}} & =u_{C}+\phi_{2 t}\left[-u_{C C}\left(1+i_{t}\right)^{-1}\right]+\phi_{3 t}\left[\varepsilon Y_{t} \frac{\varepsilon-1}{\varepsilon}(1+s) u_{C C}+u_{C C} d^{\prime} \Pi_{H, t}\right]+\phi_{5 t}\left[u_{C^{*}} u_{C}^{-2} u_{C C}\right]+\phi_{6 t}\left[-(1-\alpha) r\left(\varsigma_{t}\right)^{\eta}\right] \\
\frac{\partial L_{s}}{\partial G_{t}} & =g_{G}+\phi_{6 t}\left[-(1-\alpha) r\left(\varsigma_{t}\right)^{\eta}\right] \\
\frac{\partial L_{s}}{\partial \Pi_{H, t}} & =\phi_{3 t}\left[u_{C} d^{\prime \prime} \Pi_{H, t}+u_{C} d^{\prime}\right]+\phi_{4 t}\left(-\Pi_{t} \Pi_{H, t}^{-2}\right)+\phi_{6 t}\left[-d^{\prime}\right] \\
\frac{\partial L_{s}}{\partial \varsigma_{t}} & =\beta E_{t}\left[\phi_{4 t+1}\left(\frac{r\left(\varsigma_{t+1}\right)}{\left[r\left(\varsigma_{t}\right)\right]^{2}} r^{\prime}\left(\varsigma_{t}\right)\right)\right]+\phi_{3 t}\left[-\varepsilon Y_{t} \tilde{v}_{y} r^{\prime}\left(\varsigma_{t}\right)-\beta S_{t}^{e} r^{\prime}\left(\varsigma_{t}\right)\right]+\phi_{4 t}\left[-\frac{r^{\prime}\left(\varsigma_{t}\right)}{r\left(\varsigma_{t-1}\right)}\right]+\phi_{5 t}\left[q^{\prime}\left(\varsigma_{t}\right)\right] \\
& +\phi_{6 t}\left[-(1-\alpha) \eta r\left(\varsigma_{t}\right)^{\eta-1} r^{\prime}\left(\varsigma_{t}\right)\left(C_{t}+G_{t}\right)-\alpha \eta \varsigma_{t}^{\eta-1}\left(C_{t}^{*}+G_{t}^{*}\right)\right] \\
& +\psi_{1 t}\left[-\bar{f}_{\varsigma}^{e}\right]+\psi_{2 t}\left[-\bar{S}_{\varsigma}^{e}\right] \\
\frac{\partial L_{s}}{\partial f_{t}^{e}} & =\beta \phi_{2 t}+\psi_{1 t} \\
\frac{\partial L_{s}}{\partial S_{t}^{e}} & =\phi_{3 t}\left[-\beta r\left(\varsigma_{t}\right)\right]+\psi_{2 t} .
\end{aligned}
$$

Note that from the first condition it follows that $\phi_{4 t}=0$, and then all the terms with $\varsigma_{t-1}$ drop out from the policymaker's problem (in constraints it appears only in the definition of $\Pi_{t}$ ). Therefore there is no state variable in this problem, and thus $\bar{S}_{\varsigma}^{e}=\bar{f}_{\varsigma}^{e}=0$.

Plugging in functional forms and simplifying leads to the following system of equations

$$
\begin{aligned}
& 0=-\frac{\lambda}{\kappa} \xi_{t}^{C} \frac{Y_{t}^{\frac{1+\phi-\kappa}{\kappa}}}{\xi_{t}^{P \frac{1+\phi}{\kappa}}}+\phi_{3 t} \varepsilon\left[(1+s) \frac{\varepsilon-1}{\varepsilon} \xi_{t}^{C} C_{t}^{-\sigma}-\frac{\lambda}{\kappa} \frac{1+\phi}{\kappa} \xi_{t}^{C} \frac{Y_{t}^{\frac{1+\phi-\kappa}{\kappa}}}{\xi_{t}^{P \frac{1+\phi}{\kappa}}}\left[(1-\alpha)+\alpha \varsigma_{t}^{1-\eta}\right]^{\frac{1}{1-\eta}}\right]+\phi_{6 t} \\
& 0= \xi_{t}^{C} C_{t}^{-\sigma}-\phi_{3 t} \sigma \xi_{t}^{C} C_{t}^{-1-\sigma}\left[\varepsilon Y_{t}(1+s) \frac{\varepsilon-1}{\varepsilon}+2 d_{1}\left(\Pi_{H, t}-1\right) \Pi_{H, t}\right]-\sigma C_{t}^{\sigma-1} C_{t}^{*-\sigma} \xi_{t}^{* C}\left(\xi_{t}^{C}\right)^{-1} \phi_{5 t} \\
&+\phi_{6 t}\left[-(1-\alpha)\left[(1-\alpha)+\alpha \varsigma_{t}^{1-\eta}\right]^{\frac{\eta}{1-\eta}}\right]-\sigma C_{t}^{-1} \gamma_{1 t} \\
& 0= \xi_{t}^{C} \lambda_{G} G_{t}^{-\sigma^{\prime}}-(1-\alpha) \phi_{6 t}\left[(1-\alpha)+\alpha \varsigma_{t}^{1-\eta}\right]^{\frac{\eta}{1-\eta}} \\
& 0= \phi_{3 t} \xi_{t}^{C} C_{t}^{-\sigma} 2 d_{1}\left(2 \Pi_{H, t}-1\right)-\phi_{6 t} 2 d_{1}\left(\Pi_{H, t}-1\right) \\
& 0-\phi_{3 t} \alpha \varsigma_{t}^{-\eta}\left[(1-\alpha)+\alpha \varsigma_{t}^{1-\eta}\right]^{\frac{\eta}{1-\eta}}\left[\varepsilon \frac{\lambda}{\kappa} \xi_{t}^{C} \frac{Y_{t} \frac{1+\phi}{\kappa}}{\xi_{t}^{P \frac{1+\phi}{\kappa}}}+\beta \xi_{t+1}^{C} C_{t+1}^{-\sigma} \frac{2 d_{1}\left(\Pi_{H, t+1}-1\right) \Pi_{H, t+1}}{\left[(1-\alpha)+\alpha \varsigma_{t+1}^{1-\eta}\right]^{\frac{1}{1-\eta}}}\right] \\
&+\phi_{5 t}(1-\alpha)\left[(1-\alpha)+\alpha \varsigma_{t}^{1-\eta}\right]^{\frac{\eta-2}{1-\eta}}-\phi_{6 t} \alpha \eta\left[(1-\alpha)\left(C_{t}+G_{t}\right) \varsigma_{t}^{-\eta}\left[(1-\alpha)+\alpha \varsigma_{t}^{1-\eta}\right]^{\frac{2 \eta-1}{1-\eta}}+\varsigma_{t}^{\eta-1}\left(C_{t}^{*}+G_{t}^{*}\right)\right] \\
& \gamma_{1 t} \geq 0, i_{t} \geq 0, \gamma_{1 t} i_{t}=0 .
\end{aligned}
$$

Solution to the discretion problem is the solution to the system of these conditions along with PSE conditions. 


\section{Steady state}

After simplifying the system above and substituting some of the efficient steady state relationships we get

$$
\begin{gathered}
1+i=\frac{1}{\beta} \\
{\left[\frac{\varepsilon-1}{\varepsilon}(1+s) u_{C}-\tilde{v}_{y}\right]=0} \\
Y=(1-\alpha)(C+G)+\alpha\left(C^{*}+G^{*}\right) \\
q(\varsigma)=\frac{u_{C}^{*}}{u_{C}} \\
0=-\tilde{v}_{Y}+\phi_{6} \\
0=u_{C}+\phi_{5}\left[u_{C^{*}} u_{C}^{-2} u_{C C}\right]+\phi_{6}[-(1-\alpha)] \\
0=g_{G}+\phi_{6}[-(1-\alpha)] \\
0=\phi_{5}\left[q^{\prime}(\varsigma)\right] \\
+\phi_{6}\left[-(1-\alpha) \eta r^{\prime}(\varsigma)(C+G)-\alpha \eta\left(C^{*}+G^{*}\right)\right] .
\end{gathered}
$$

This is the exact same set of equations as in the commitment steady-state. Therefore the value of production subsidy in Markov perfect equilibrium will be the same as in the commitment equilibrium.

\section{Proofs of Propositions}

\subsection{Proposition 1}

The derivation of the production subsidy for commitment equilibrium that makes the steadystate coincide with the efficient one is given in the section with commitment equilibrium. Section with discretion equilibrium shows that the same steady state subsidy applies to Markov perfect equilibrium.

\subsection{Proposition 2}

Problem of social planner can be represented as

$$
\begin{gathered}
U_{t}=u\left(C_{t}, \xi_{t}\right)-\tilde{v}\left(Y_{t}\right) \rightarrow \max _{C_{t}, Y_{t}, \varsigma_{t}} \\
C_{t}^{*} q\left(\varsigma_{t}\right)^{\frac{1}{\sigma}}=C_{t} \\
Y_{t}=(1-\alpha) r\left(\varsigma_{t}\right)^{\eta} C_{t}^{*} q\left(\varsigma_{t}\right)^{\frac{1}{\sigma}}+\alpha \varsigma_{t}^{\eta} C_{t}^{*} .
\end{gathered}
$$

Let's substitute consumption and output from constraints into objective function and take FOC to get

$$
0=u_{c}\left(C_{t}\left(\varsigma_{t}\right), \xi_{t}\right) \frac{d C_{t}}{d \varsigma_{t}}-\tilde{v}_{Y}\left(Y_{t}\left(\varsigma_{t}\right)\right) \frac{d Y_{t}}{d \varsigma_{t}}
$$


which after taking derivatives of two constraints becomes

$$
\begin{aligned}
\frac{u_{c}\left(C_{t}\left(\varsigma_{t}\right), \xi_{t}\right)}{\tilde{v}_{Y}\left(Y_{t}\left(\varsigma_{t}\right)\right)} & =\frac{\frac{d Y_{t}}{d \varsigma_{t}}}{\frac{d C_{t}}{d \varsigma_{t}}}=\frac{(1-\alpha) \eta r\left(\varsigma_{t}\right)^{\eta-1} r^{\prime}\left(\varsigma_{t}\right) q\left(\varsigma_{t}\right)^{\frac{1}{\sigma}}+(1-\alpha) r\left(\varsigma_{t}\right)^{\eta} \frac{1}{\sigma} q\left(\varsigma_{t}\right)^{\frac{1}{\sigma}-1} q^{\prime}\left(\varsigma_{t}\right)+\alpha \eta \varsigma_{t}^{\eta-1}}{\frac{1}{\sigma} q\left(\varsigma_{t}\right)^{\frac{1}{\sigma}-1} q^{\prime}\left(\varsigma_{t}\right)} \\
& =\frac{(1-\alpha) q\left(\varsigma_{t}\right)^{1-\eta+\frac{1}{\sigma}} r^{\prime}\left(\varsigma_{t}\right)\left(\eta-\frac{1}{\sigma}\right)+\frac{(1-\alpha)}{\sigma} q\left(\varsigma_{t}\right)^{\frac{1}{\sigma}-\eta}+\alpha \eta}{r\left(\varsigma_{t}\right)^{\eta-\frac{1}{\sigma} \frac{(1-\alpha)}{\sigma}} \varsigma_{t}^{\eta-\frac{1}{\sigma}} r\left(\varsigma_{t}\right)}
\end{aligned}
$$

where we used

$$
\begin{gathered}
q(\varsigma)=\frac{\varsigma}{r(\varsigma)} \\
r(\varsigma)=\left[(1-\alpha)+\alpha \varsigma^{1-\eta}\right]^{\frac{1}{1-\eta}} .
\end{gathered}
$$

At the first best there is zero inflation, and thus both commitment and discretion coincide with the flexible price equilibrium. This equilibrium (out of ZLB) with production subsidy is characterized by three conditions

$$
\begin{gathered}
\frac{\varepsilon-1}{\varepsilon}(1+s) u_{C}\left(C_{t}, \xi_{t}\right)=\tilde{v}_{y}\left(Y_{t}, \xi_{t}\right) r\left(\varsigma_{t}\right) \\
Y_{t}=(1-\alpha) r\left(\varsigma_{t}\right)^{\eta} C_{t}+\alpha \varsigma_{t}^{\eta} C_{t}^{*} \\
q\left(\varsigma_{t}\right)=\frac{u_{C}\left(C_{t}^{*}, \xi_{t}^{*}\right)}{u_{C}\left(C_{t}, \xi_{t}\right)}
\end{gathered}
$$

where the second and third are the same as in the social planner's problem. Therefore, for two outcomes to coincide, the first condition should coincide with the optimality condition, that is we need

$$
\frac{u_{c}\left(C_{t}\left(\varsigma_{t}\right), \xi_{t}\right)}{\tilde{v}_{Y}\left(Y_{t}\left(\varsigma_{t}\right)\right)}=\frac{r\left(\varsigma_{t}\right)}{\frac{\varepsilon-1}{\varepsilon}(1+s)}=\frac{\frac{d Y_{t}}{d \varsigma_{t}}}{\frac{d C_{t}}{d \varsigma_{t}}}=\frac{u_{c}\left(C_{t}\left(\varsigma_{t}\right), \xi_{t}\right)}{\tilde{v}_{Y}\left(Y_{t}\left(\varsigma_{t}\right)\right)} .
$$

When $\sigma \eta=1$ this condition becomes

$$
\frac{\varepsilon-1}{\varepsilon}(1+s)=\frac{1}{1-\alpha}
$$

which is satisfied since this is the value of production subsidy under $\theta_{C}=1$ and $\sigma \eta=1$.

\subsection{Proposition 3}

FOCs of the social planner's problem are

$$
\begin{gathered}
0=1-\eta \frac{\lambda}{\kappa} \xi_{t}^{C} \frac{Y_{t}^{\frac{1+\phi-\kappa}{\kappa}}}{\xi_{t}^{P \frac{1+\phi}{\kappa}}}\left[Y_{t}-(1-\alpha)^{2}\left(C_{t}+G_{t}\right)\left[(1-\alpha)+\alpha \varsigma_{t}^{1-\eta}\right]^{\frac{2 \eta-1}{1-\eta}}\right] \frac{(1-\alpha)+\alpha \varsigma_{t}^{1-\eta}}{\xi_{t}^{C} C_{t}^{1-\sigma}} \frac{\sigma}{(1-\alpha)} \\
-\frac{\lambda}{\kappa} \frac{Y_{t}^{\frac{1+\phi-\kappa}{\kappa}}}{\xi_{t}^{P \frac{1+\phi}{\kappa}}} C_{t}^{\sigma}(1-\alpha)\left[(1-\alpha)+\alpha \varsigma_{t}^{1-\eta}\right]^{\frac{\eta}{1-\eta}} \\
0=\xi_{t}^{C} \lambda_{G} G_{t}^{-\sigma^{\prime}}-(1-\alpha) \frac{\lambda}{\kappa} \xi_{t}^{C} \frac{Y_{t}^{\frac{1+\phi-\kappa}{\kappa}}}{\xi_{t}^{P \frac{1+\phi}{\kappa}}}\left[(1-\alpha)+\alpha \varsigma_{t}^{1-\eta}\right]^{\frac{\eta}{1-\eta}}
\end{gathered}
$$

along with two constraints

$$
\begin{gathered}
C_{t}^{*} q\left(\varsigma_{t}\right)^{\frac{1}{\sigma}}=C_{t} \\
Y_{t}=(1-\alpha) r\left(\varsigma_{t}\right)^{\eta}\left(C_{t}+G_{t}\right)+\alpha \varsigma_{t}^{\eta}\left(C_{t}^{*}+G_{t}^{*}\right)+d\left(\Pi_{H, t}\right) .
\end{gathered}
$$


Under $\sigma=\eta=1$ FOCs become

$$
\begin{gathered}
1-\frac{\lambda}{\kappa} \frac{Y_{t}^{\frac{1+\phi-\kappa}{\kappa}}}{\xi_{t}^{P \frac{1+\phi}{\kappa}}}\left[Y_{t}-(1-\alpha)^{2}\left(C_{t}+G_{t}\right) \varsigma_{t}^{\alpha}\right] \frac{1}{(1-\alpha)}-\frac{\lambda}{\kappa} \frac{Y_{t}^{\frac{1+\phi-\kappa}{\kappa}}}{\xi_{t}^{P \frac{1+\phi}{\kappa}}} C_{t}(1-\alpha) \varsigma_{t}^{\alpha}=0 \\
\lambda_{G} G_{t}^{-1}-(1-\alpha) \frac{\lambda}{\kappa} \frac{Y_{t}^{\frac{1+\phi-\kappa}{\kappa}}}{\xi_{t}^{P \frac{1+\phi}{\kappa}}} \varsigma_{t}^{\alpha}=0
\end{gathered}
$$

where

$$
\begin{gathered}
\frac{\lambda}{\kappa}=s \frac{\varepsilon-1}{\varepsilon} \theta_{C}^{-\sigma}=\frac{(1-\alpha)}{(2-\alpha) \alpha+(1-\alpha)^{2} \theta_{C}} \\
\lambda_{G}=\frac{\lambda}{\kappa}(1-\alpha) \theta_{G} .
\end{gathered}
$$

Now let's combine these FOCs to get

$$
1-\frac{\lambda}{\kappa} \frac{Y_{t}^{\frac{1+\phi}{\kappa}}}{\xi_{t}^{P \frac{1+\phi}{\kappa}}} \frac{1}{(1-\alpha)}+\lambda_{G}=0
$$

and so $Y_{t}=\xi_{t}^{P}$. Then from the market clearing and risk sharing conditions it follows that $\varsigma_{t}=\xi_{t}^{P}$.

Next, it's straightforward to verify that FOCs under discretion and PSE conditions are satisfied when we plug in the efficient solution. Finally, as policymaker under discretion delivers first best in this case, so does the policymaker under commitment. 